\title{
RECOVERY OF VALUABLE CHLOROSILANE INTERMEDIATES BY A NOVEL WASTE CONVERSION PROCESS
}

Technical Report for Phase IIIA (Final) and Phase IIIB (Progress)

\author{
By \\ Kurt E. Anderson
}

October 1998

Work Performed Under Contract No. DE-FC04-94AL99566

For

U.S. Department of Energy

Office of Industrial Technologies

Washington, $\mathrm{DC}$

\section{MASTER}

DISTARUTION OF THS DOCUMENT IS UAMTIED

By

Dow Corning Corporation

Midland, Michigan 


\section{DISCLAIMER}

This report was prepared as an account of work sponsored by an agency of the United States Government. Neither the United States Govemment nor any agency thereof, nor any of their employees, makes any warranty, express or implied, or assumes any legal liability or responsibility for the accuracy, completeness, or usefulness of any information. apparatus. product. or process disclosed. or represents that its use would not infringe privately owned rights. Reference herein to any specific commercial product, process, or service by trade name. trademark, manufacturer, or otherwise does not necessarily constitute or imply its endorsement. recommendation. or favoring by the United States Government or any agency thereor. The views and opinions of authors expressed herein do not necessarily state or reflect those of the United States Government or any agency thereof.

This report has been reproduced directly from the best available copy.

The Office of Scientific and Technical Information (OSTI) provides electronic access to the Department of Energy's scientific and technical information holdings through the DOE Information Bridge.

DOE and contractor employees can search and download records of worldwide energy research and full text of DOE-sponsored or acquired research results at https://apollo.osti.gov/dds. Registration and password are required. Contact OSTI at 423-576-8401 or E-mail informationbridge@adonis.osti.gov for new accounts.

Public access to bibliographic records and full text of DOE-sponsored research reports is available electronically through the U.S. Government Printing Office at http://www.2ccess.gpo.gov.su_docs/. No registration or password is required.

Available to DOE and DOE contractors in paper from OSTI, P.O. Box 62, Oak Ridge, TN 37831 : prices available from (423) 576-8401.

Printed copy and microfiche of DOE-sponsored research reports are available from the Department of Commerce, National Technical Information Service (NTIS), 5285 Port Royal Road, Springfield, VA 22161; (1-800-553-NTIS). Detailed ordering information is available at http://www.ntis.gov/ordering.htm 


\section{DISCLAIMER}

Portions of this document may be illegible in electronic image products. Images are produced from the best available original document. 
DOE/AL/99566-1

(DE98

Distribution Category UC-1414

\section{RECOVERY OF VALUABLE CHLOROSILANE INTERMEDIATES BY A NOVEL WASTE CONVERSION PROCESS}

Technical Report

Phase IIIA (Final) and Phase IIIB (Progress)

by

Kurt E. Anderson

October 1998

Work Performed Under Contract No. DE-FC04-94AL99566

Prepared for

U.S. Department of Energy

Office of Industrial Technologies

Washington, DC 20585

Prepared by

Dow Corning Corporation

P.O. Box 994

Midland, Michigan 48686-0994 


\begin{abstract}
From July 1994 through May 1998, direct process residue (DPR) hydrogenolysis has been studied in the laboratory, at a small Pilot Plant, and finally at a larger Pilot Plant within Dow Corning's Carrollton, Kentucky plant. The system reacts filtered DPR with monomer at high temperature and pressure. The process demonstrates DPR conversion up to $86 \%$. The reaction product contains high concentrations of valuable monomers such as dimethyldichlorosilane and methyldichlorosilane. A larger DPR hydrogenolysis reactor based on these results is being designed for operation in Europe at Dow Coming's Barry, Wales site.
\end{abstract}

\title{
PREFACE
}

The objective of this Dow corning Corporation and DOE cost-shared project is to develop a novel waste conversion process for the recovery of valuable chlorosilane intermediates. The project started with Phase IIIA, Engineering development - Intermediate Scale, which consists of testing with two systems, termed the Pilot Plant and Pilot Plant 1I, both a t Carroliton, KY. All of Phase IIIA is described in this report. Phase IIIB, Engineering Development - Full Scale, is the development of the commercial system at Barry, Wales. The first year of that development is described in this report. Finally, Phase IV, Demonstration Full Scale, which will not start until the development is completed., will complete the project.

\section{ACKNOWLEDGMENTS}

Brian Volintine is the Program Manager for the DOW Office of Industrial Technologies. Ken Lucien is the Technical Manager for the DOW Albuquerque Operations Office. Frank Childs, the Project Technical Monitor, is on the staff of Scientech, Inc. (Idaho Falls, Idaho). Steve Freeburne is Manager of the Silicon Methyl Intermediates department for Dow Corning Corporation. Ben Franklin is a Contracts Specialist in the Federal Business and Contract Development Department of Dow Corning Corporation. Darrell Whiteley and J. Ashley Brinson were past Principal Investigators.

Work supported by the U.S. Department of Energy, Assistam Secretary for Energy Efficiency and Renewable Energy, Office of Industrial Technologies, under DOE Albuquerque Operations Office Cooperative Agreement DE-FC04-94AL99566. 


\section{TABLE OF CONTENTS}

\section{INTRODUCTION}

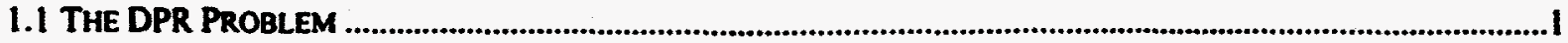

1.2 PAST EFFORTS

1.2.I Literature Prior to 1990

1.2.2 Prior Dow Corning Efforts with DPR Hydrogenolysis.................................................................2

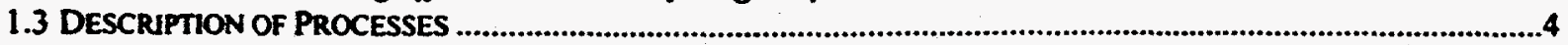

1.3.1 Pilot Plant.

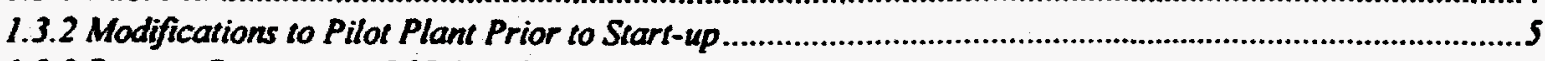

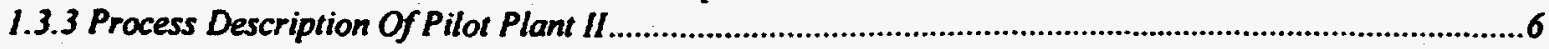

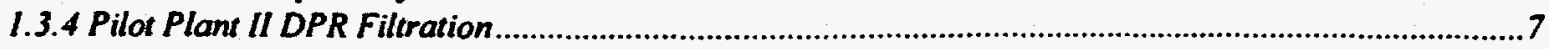

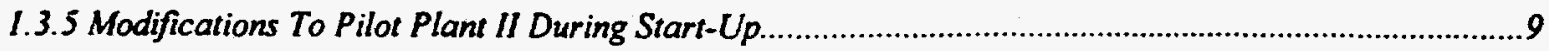

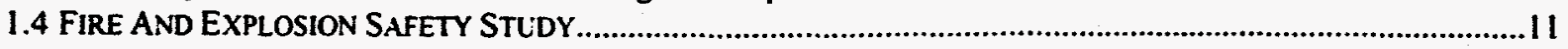

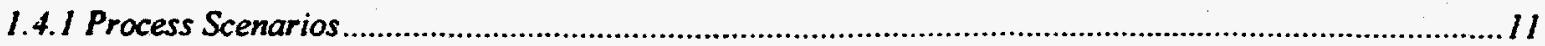

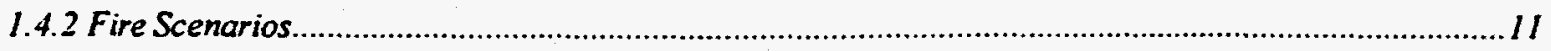

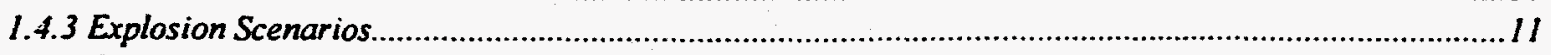

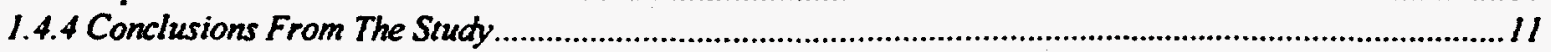

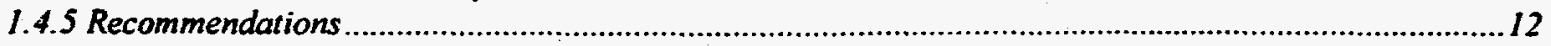

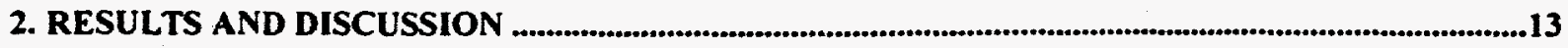

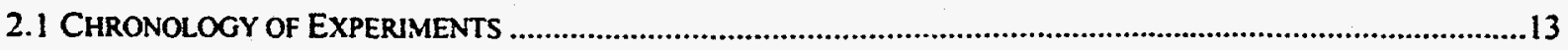

2.1.1 1995 Experiments - Pilot Plant

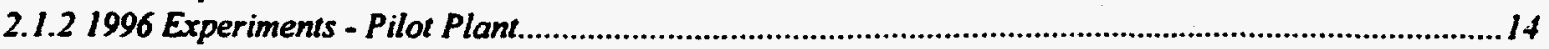

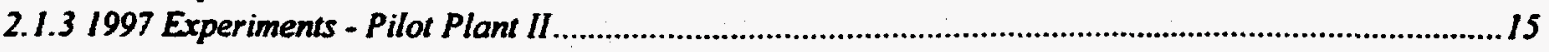

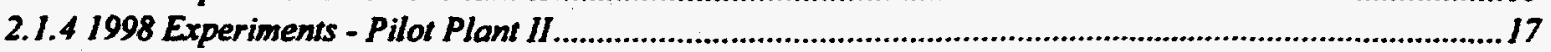

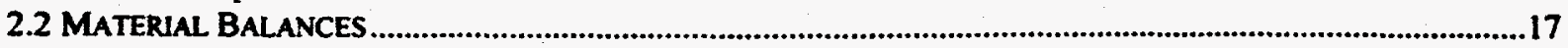

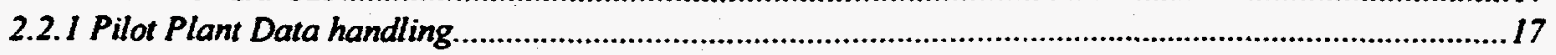

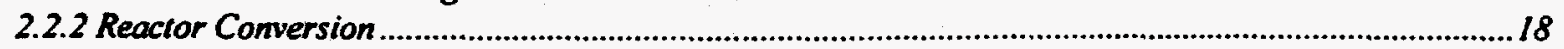

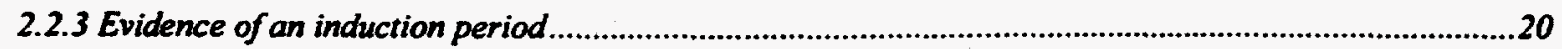

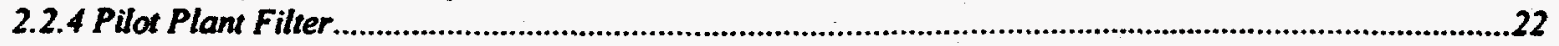

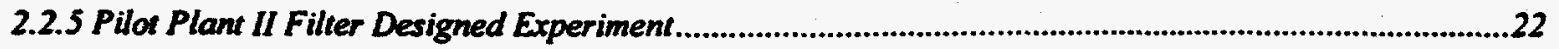

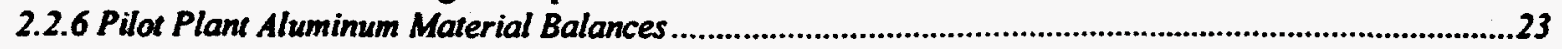

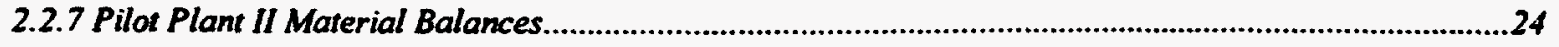

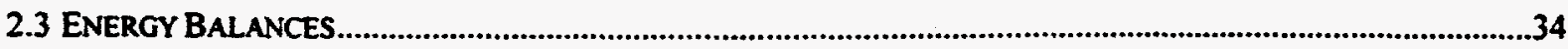

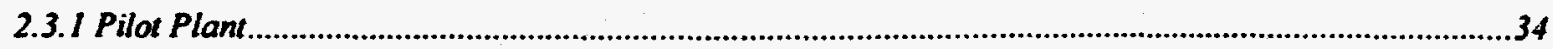

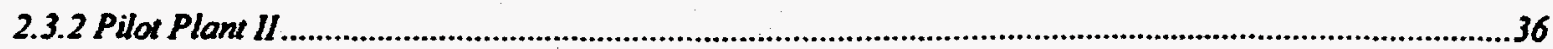

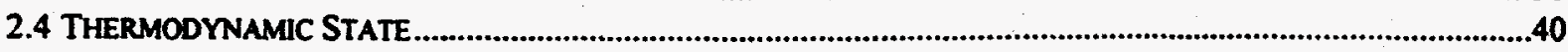

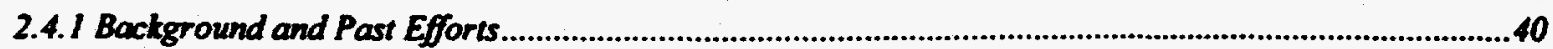

2.4.2 Description and Principals of Operation of Ronan Nuclear Density Meter..........................................40

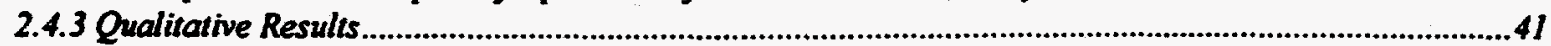

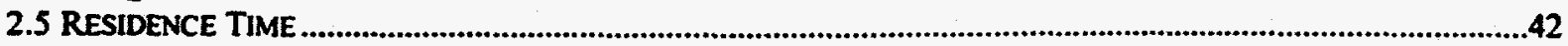

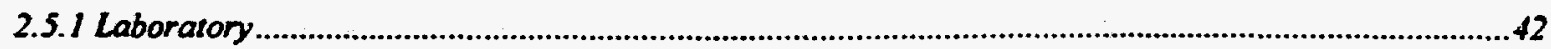

2.5.2 Pilot Plant

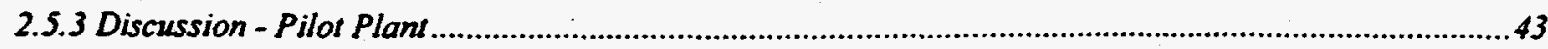

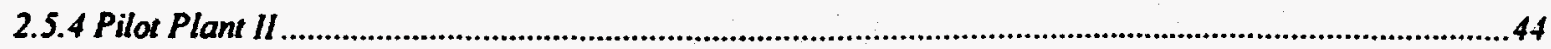

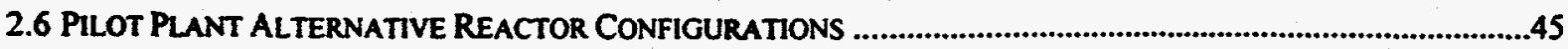

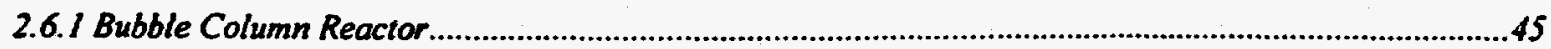

2.6.2 Alternative Hydrogen Spargers in the Bubble Column Configuration :.................................................46

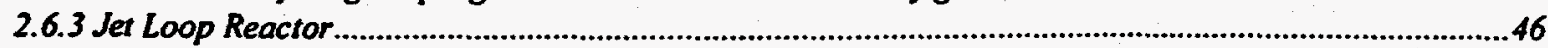

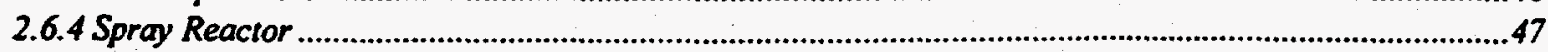

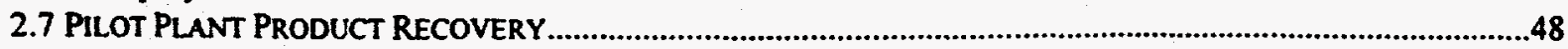

2.7.1 Background 


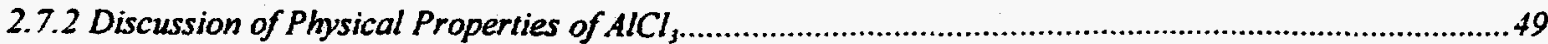

2.7.3 Solubility of $\mathrm{AlCl}_{3}$ in Chlorosilanes at the Pilot Plant

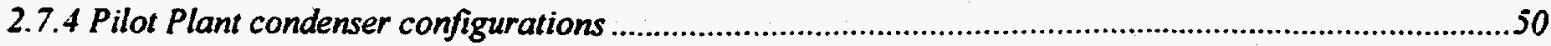

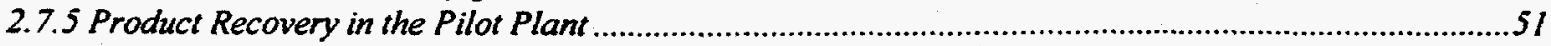

2.7.6 Non-AlCl ${ }_{3}$ Solids Formation in Piping Downstream of Reactor .....................................................5I

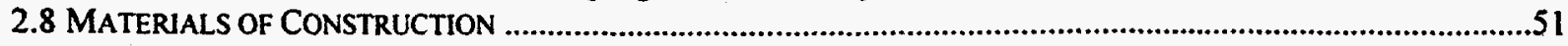

2.8.1 Background

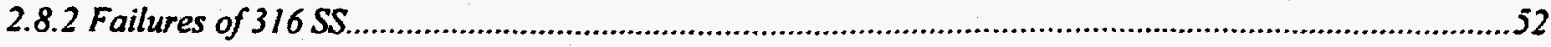

2.8.3 Discussion of Chloride Stress Corrosion Cracking ...........................................................................53

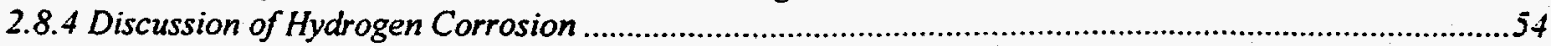

2.8.5 Open Literature on Materials of Construction for Chlorosilane Hydrogenation...................................5

2.8.6 Corrosion Coupon Study Results from the Pilot Plant ..................................................................55

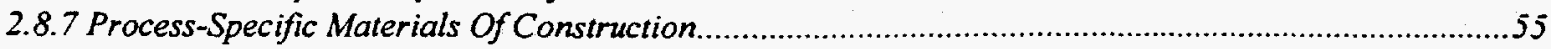

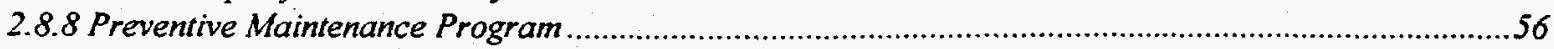

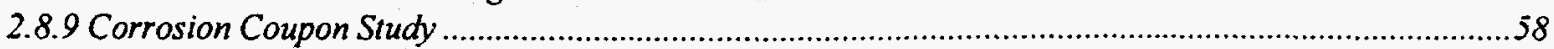

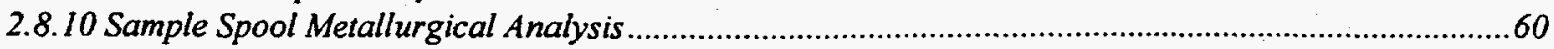

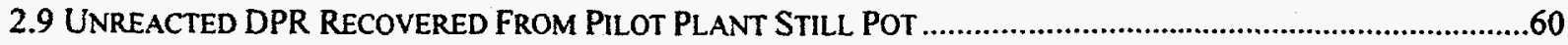

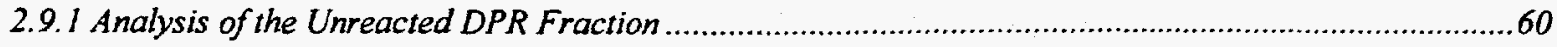

2.9.2 Further Reaction of Still Pot Bottoms in the Laboratory Reactor ...................................................60

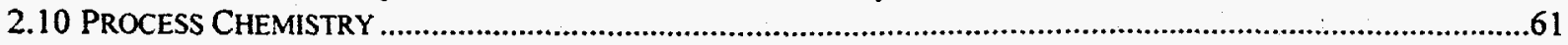

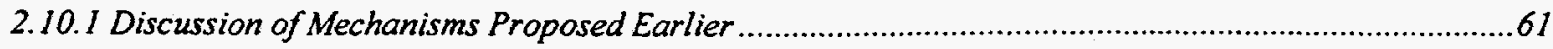

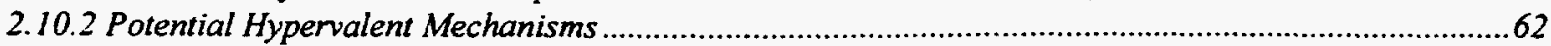

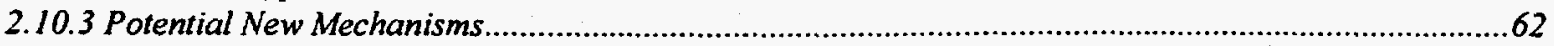

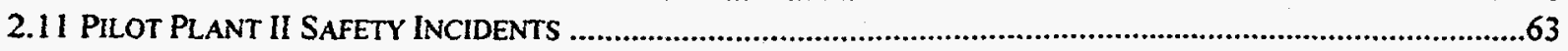

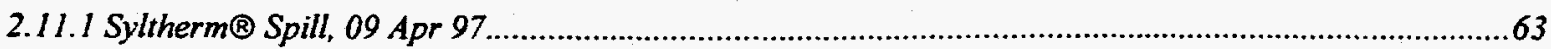

2.11.2 Trimethylchlorosilane Skin Exposure, 14 Apr 97 ......................................................................63

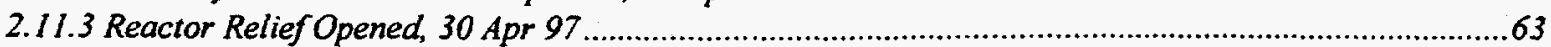

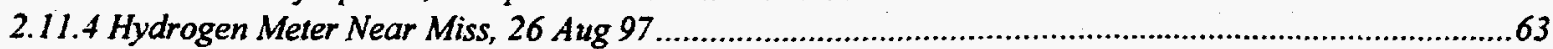

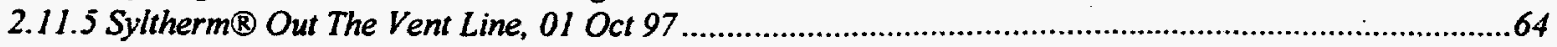

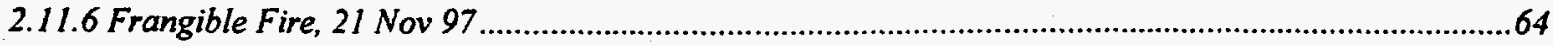

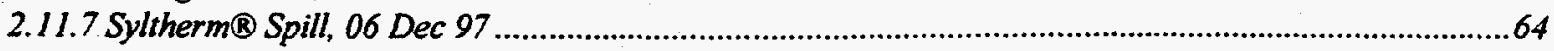

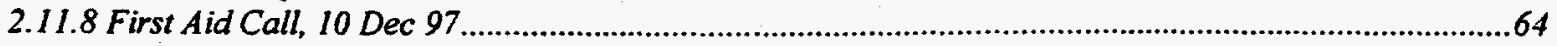

2.12 PILOT PLANT II EMERGENCY SHUTDOWN SYSTEMS AND PROCESS INTERLOCKS ......................................65

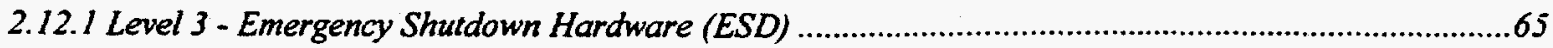

2.12.2 Level 2 - Emergency Shutdown Software (ESS) ...............................................................................66

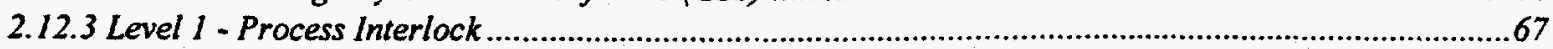

2.13 PILOT PLANT II AUTOSPEC, SIMULATOR VERIFICATION, AND DCS PROGRAMMING.....................................70

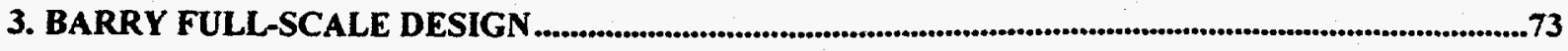

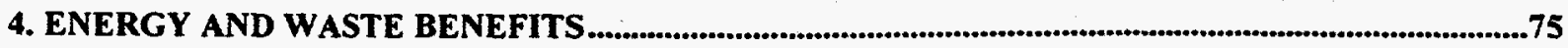

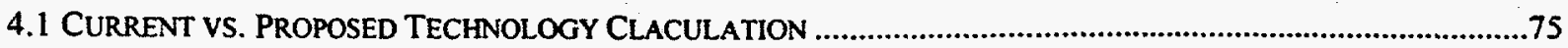

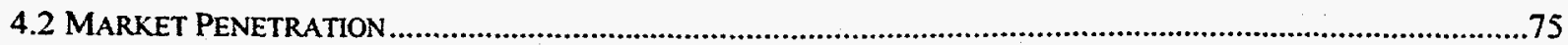

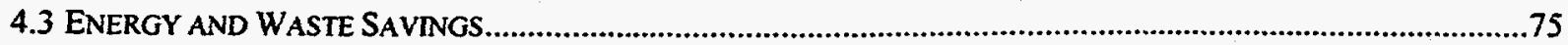

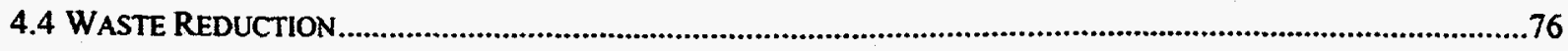

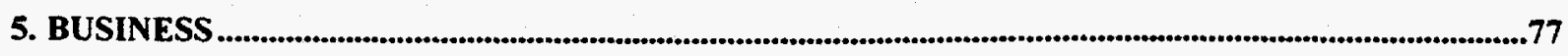

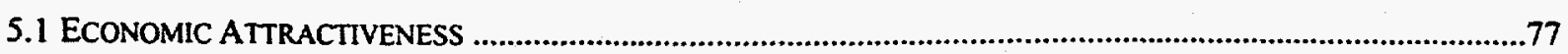

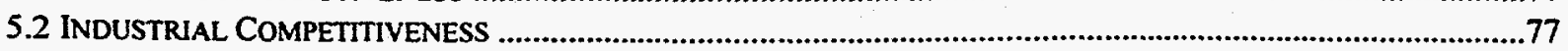

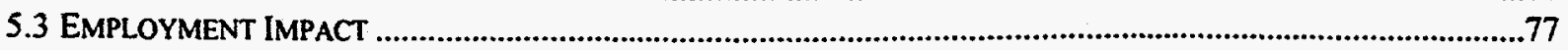

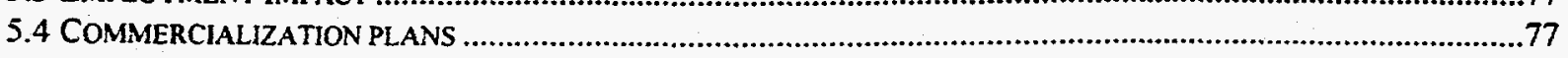

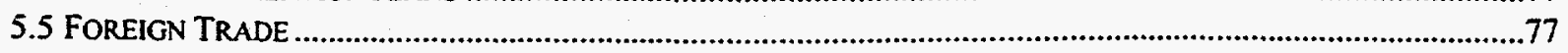

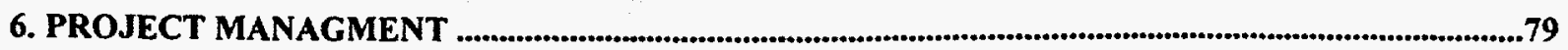




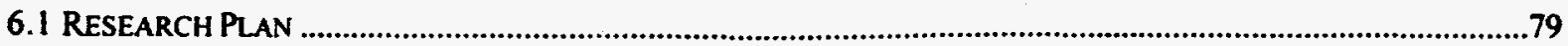

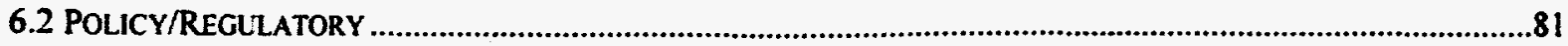

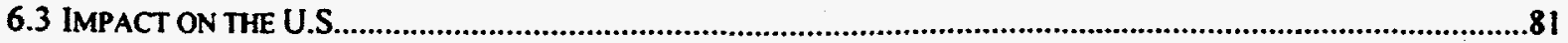

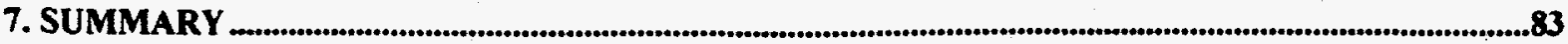

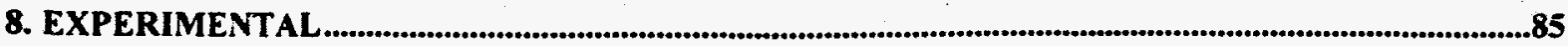

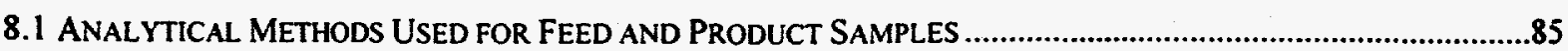

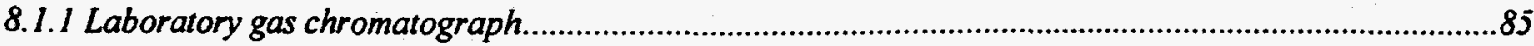

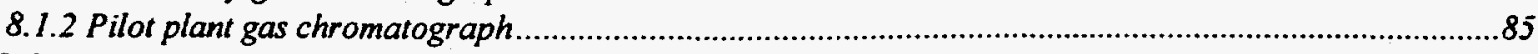

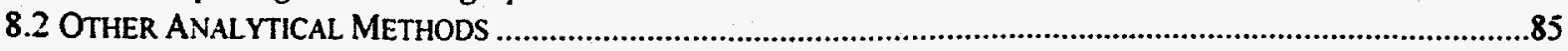

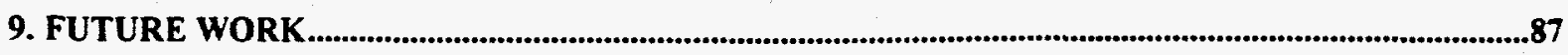

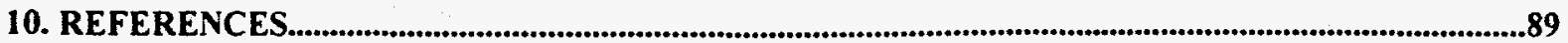




\section{Index of Figures}

FIGURE 1: TYPICAL FILTRATION CYCLE

FIGURE 2: PROCESS SCHEMATIC FOR PILOT PLANTS.

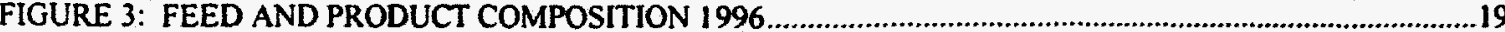

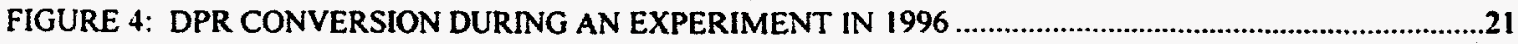

FIGURE 5: PRODUCT COMPOSITION DURING AN EXPERIMENT IN 1996 ................................................21

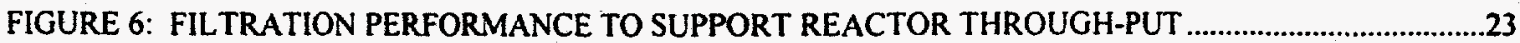

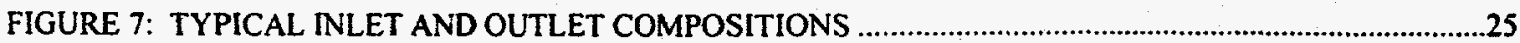

FIGURE 8: REACTION INITIATION, 08 OCT 97

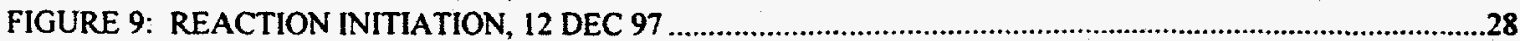

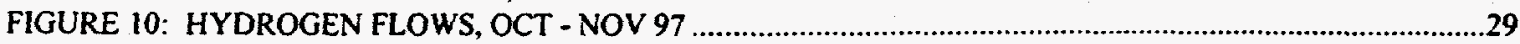

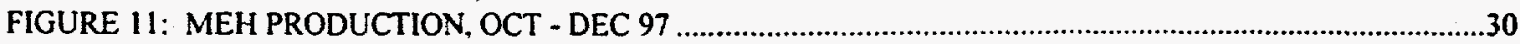

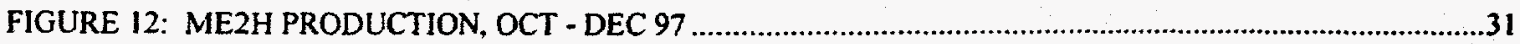

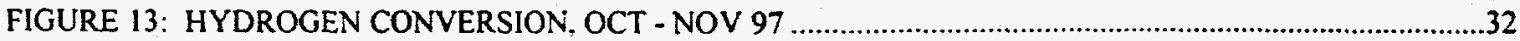

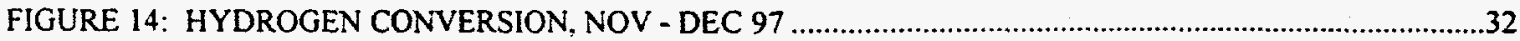

FIGURE 15: NET VAPOR PRODUCT COMPOSITION FOR VARIOUS FEEDS ……….......................................34

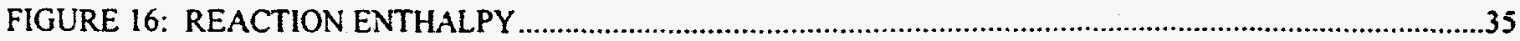

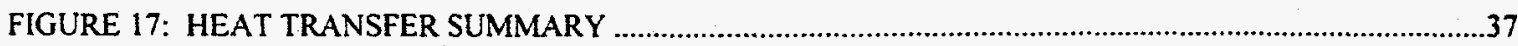

FIGURE 18: REACTOR AMBIENT HEAT LOSSES DURING LEAK TESTING ……............................................

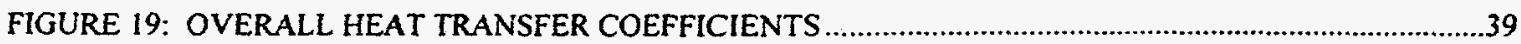

FIGURE 20: THE RONAN NUCLEAR DENSITY METER ON PILOT PLANT REACTOR

FIGURE 21: TREND DISPLAY FROM THE NUCLEAR DENSITY METER IN PROFILE MODE .........................41

FIGURE 22: A LIQUID LEVEL DETECTED BY THE NUCLEAR DENSITY METER

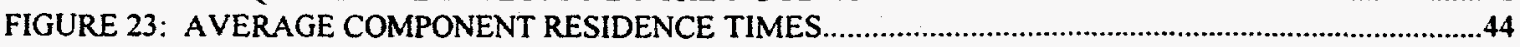

FIGURE 24: BUBBLE COLUMN REACTOR CONFIGURATION ……............................................................45

FIGURE 25: JET LOOP REACTOR CONFIGURATION ….....................................................................47

FIGURE 26: SPRAY REACTOR CONFIGURATION ……..........................................................................48

FIGURE 27: SCHEMATIC DIAGRAM OF REACTOR COUPON RACK

FIGURE 28: PROPOSED DISILANE REACTION SEQUENCE

FIGURE 29: PROPOSED SILMETHYLENE REACTION SEQUENCE

\section{Index of Tables}

TABLE 1: PRODUCT PROPERTY MEASUREMENT FOR SAFETY STUDY .....................................................

TABLE 2: SUMMARY OF 1995 CAMPAIGNS …………..........................................................................14

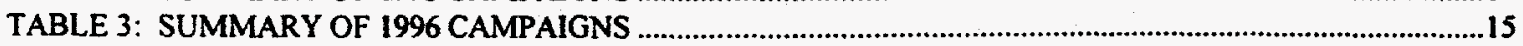

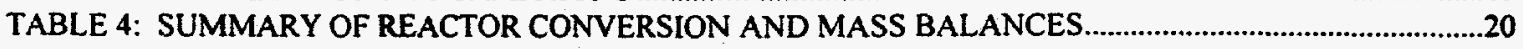

TABLE 5: ENERGY BALANCE INFORMATION (ALL UNITLESS) .............................................................38

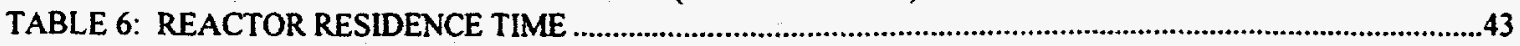

TABLE 7: SOLUBILITY OF ALUMINUM CHLORIDE IN CHLOROSILANES

TABLE 8: CORROSION RATES OF METALS TESTED IN THE REACTOR ........................................................55

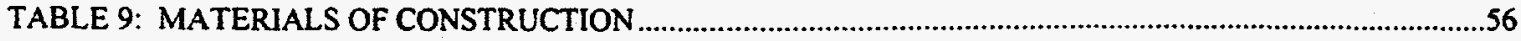

TABLE 10: CORROSION COUPON STUDY

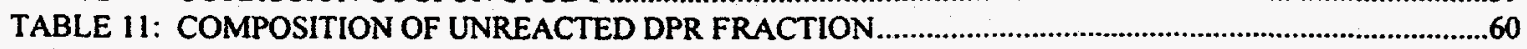

TABLE 12: CONVERSION RATES FOR SECOND PASS HYDROGENOLYSIS ……...............................................61

TABLE 13: LEVEL 3 EMERGENCY SHUTDOWN SYSTEM (ESD) ……............................................................65

TABLE 14: LEVEL 2 EMERGENCY SHUTDOWN SYSTEM (ESS) ……........................................................66

TABLE 15: REACTOR SYSTEM PROCESS NTTERLOCKS …………………………................................67

TABLE 16: HYDROGEN AND DPR COLUMN PROCESS INTERLOCKS ……….............................................68

TABLE 17: CHLOROSILANE FEED PROCESS INTERLOCKS .....................................................................69

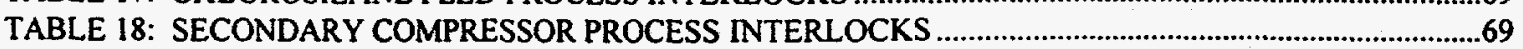

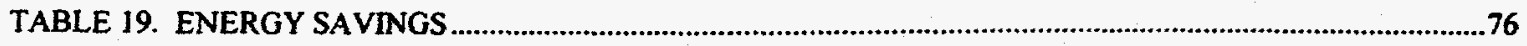

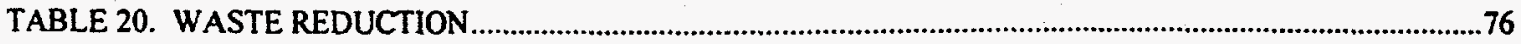

TABLE 21. INDUSTRIAL PARTICIPATION

TABLE 22. MILESTONES

TABLE 23. BUDGET ( IN THOUSANDS) 


\section{INTRODUCTION}

\subsection{The DPR Problem}

Dow Coming produces dimethyldichlorosilane $\left(\mathrm{Me}_{2} \mathrm{SiCl}_{2}\right)$ by the reaction of methyl chloride and silicon metal in a system known as the "direct process". Although $\mathrm{Me}_{2} \mathrm{SiCl}_{2}$ is the main desired product, several other chlorosilane monomers and oligomers are produced in side reactions. The byproduct monomers include methyltrichlorosilane $\left(\mathrm{MeSiCl}_{3}\right)$, trimethylchlorosilane $\left(\mathrm{Me}_{3} \mathrm{SiCl}\right)$, methyldichlorosilane ( $\mathrm{MeHSiCl}_{2}$ ) and lesser amounts of other monomers. The oligomers include a high boiling mixture of disilanes, silmethylenes, and polysilalkylenes known as "direct process residue" or DPR.

One objective of the operation of the direct process fluidized bed reactor (FBR) is to maximize selectivity of the reaction towards $\mathrm{Me}_{2} \mathrm{SiCl}_{2}$ and away from other monomers. Selectivity can be improved by manipulating the operating parameters of the FBR, but it is impossible to suppress formation of non- $\mathrm{Me}_{2} \mathrm{SiCl}_{2}$ monomers completely. Although there are downstream commercial markets for the other major monomer byproducts, $\mathrm{MeSiCl}_{3}$ has relatively few uses. Currently, most $\mathrm{MeSiCl}_{3}$ is used to produce fumed silica. Future demand for $\mathrm{Me}_{2} \mathrm{SiCl}_{2}$ is expected to produce an oversupply of $\mathrm{MeSiCl}_{3}$. It is believed the unneeded $\mathrm{MeSiCl}_{3}$ will become a waste stream requiring off site incineration.

Direct process residue is also a waste stream. Suppression of DPR is another key objective of FBR operation, but DPR cannot be completely suppressed.

In Barry, DPR is separated from the desirable monomers, then quenched with water and lime slurry to form solid gels. The gels are landfilled on site.

In Carrollton, DPR is separated from the monomers, then further processed.

Methylchlorodisilanes (MCDS) are distilled from the silmethylenes and other higher boiling species. MCDS is shipped to the Midland thermal cracker process where the material is reacted at high temperature with hydrogen chloride to form monomers. The cracker product contains a relatively high fraction of low-value monomers. The cracker process also has a history of poor maintenance reliability, a high frequency of safety incidents and a number of failures due to corrosion. The cracker cannot process silmethylenes and higher boiling chlorosilanes. Cracker product is shipped back from Midland to Carroltton for distillation in the main process train. In Carrollton, the bottoms of the MCDS column, are quenched with water and lime slurry, then landfilled as in Barry.

A process which recycles DPR internally and produces a high value product offers significant economical advantages over the existing cracker process and the various recycle programs. The benefits include environmental (reduced landfill, reduced quenching costs), raw material conservation (recovered chloride and silicon), and valuable monomer production.

\subsection{Past Efforts}

\subsubsection{Literature Prior to 1990}

In 1952, Wagner demonstrated hydrogenation of $\mathrm{Si}_{2} \mathrm{Cl}_{6}, \mathrm{HSi}_{2} \mathrm{Cl}_{5}$, and $\mathrm{Si}_{3} \mathrm{Cl}_{8}$ at $300-400{ }^{\circ} \mathrm{C}$ and 500-1,000 psig with no catalyst. [1]

In 1972, Atwell and coworkers hydrogenated organohalide disilanes at 750-5,200 psig and 25-250 ${ }^{\circ} \mathrm{C}$ with transition metal catalysts such as $5 \%$ Pd on carbon. [2] 
In 1977, Caias and coworkers hydrogenated organohalide disilanes at low temperatures and low pressures using a tertiary amide base and nickel catalyst. [3]

In 1978 , Neale hydrogenated methylchloropolysilanes at $25-350^{\circ} \mathrm{C}$ and $500-1,000$ psig using copper catalysts. [4]

In 1983, Ritzer and coworkers redistributed alkyl rich disilanes with $\mathrm{MeSiCl}_{3}$ to yield $\mathrm{Me}_{2} \mathrm{SiCl}_{2}$ and chlorine rich disilanes at low pressure. The chlorine rich disilanes were claimed to be easier to cleave in subsequent processing. [5]

\subsubsection{Prior Dow Corning Efforts with DPR Hydrogenolysis}

In 1990, Johnson and Hammers characterized the composition and production rate of DPR produced in Carrollton during a twelve month period. Elutable chlorosilanes, solids content, and metals content were analyzed. [6]

In 1991, Johnson and coworkers performed feasibility studies of the reaction of DPR with four different gases: $\mathrm{H}_{2}, \mathrm{HCl}, \mathrm{MeCl}$, and $\mathrm{Cl}_{2}$ [7]. Average DPR conversion rates were similar for all the gases $(36 \%-42 \%)$, but highest for $\mathrm{H}_{2}(42 \%)$. Most reactions were catalyzed, but no given catalyst performed better than any other during the hydrogenation trials. Reaction with $\mathrm{H}_{2}$ yielded the most desirable product distribution with higher levels of $\mathrm{Me}_{2} \mathrm{SiCl}_{2}$ and lower levels of $\mathrm{HSiCl}_{3}$ and $\mathrm{SiCl}_{4}$. The work with various cracking gases was patented $[8,9,10,11]$.

In 1996, Jarvis, Grosse and Tecklenburg [12] characterized methyl DPR high-boilers using Gas Chromatography/Mass Spectrometry (GC/MS) and desorption chemical ionization mass spectrometry. At that time, it was known that disilanes reacted readily and silmethylenes to a lesser extent. However, little was known about the effect of hydrogenolysis on DPR highboilers. This was largely because the composition of the highboiling fraction of DPR was unknown. The report details the composition of the highboilers through the use of various mass spectrometry techniques such as chemical ionization, electron impact ionization and desorption chemical ionization. It was found that DPR highboilers contain materials having backbones with the following structures: SiCSi, SiCCSi, SiCCCSi, SiSiSi, SiCSiSi, SiCSiCSi, SiCSiCSiSi and SiCSiCSiCSi.

In 1996, Knutson [13] characterized the hazards of methyl DPR solids (i.e., filter solids). This documentation was requested by the Safety Audit Team for the Pilot Plant II project. Testing was done on Methyl DPR solids to determine hazards. Four tests were conducted.

1. Self heating

2. Hydrolyzable chloride

3. Flammability of solids - burning rate

4. Dangerous when wet

The results of these tests were:

1. The solids exothermed

2. Hydrolyzable chloride was present

3. These solids are classified as a Division 4.1, Packing Group III substance.

4. These solids are not classified as a Division 4.3 (dangerous when wet substance). No measurable gas evolution was observed.

In 1996, Knutson documented the filtration of methyl DPR [14]. Filtration of methyl direct process residue (DPR) was achieved in the DPR hydrogenolysis Pilot Plant. The objective was to determine if solids could be removed from this liquid stream to a level of $<0.5 \mathrm{wt} \%$, or essentially "solids free" from visual inspection. Filter cartridge life was studied and different operational 
techniques were tested. Plugging of the elements and diminished filter performance were not observed during this period. Data such as solids loading and slurry flow rate per filter area were used for scale-up in the design of a DPR filter for the next phase (Commercial Plant) of the project.

In a 1996 Technical Conference Poster session, Jarvis, Crum and Gohndrone presented the reaction of DPR with organohalides to form higher value organohalosilane monomers. Organochlorides attempted included allyl chloride, 1,3-dichloropropane, 1-chlorooctane, cyclohexylchloride, cyclopentylchloride, and chlorobenzene. All of these reactions formed some useful chlorosilane products, but usually only a very small amount. The exception was allyl chloride which when reacted 1,1-dichlorotetramethyldisilane quantitatively formed $\mathrm{Me}_{3} \mathrm{SiCl}$ and $\mathrm{PrMeSiCl}$. GC/MS showed that the $\mathrm{Pr}$ - ligand was isomerized to form a variety of products. The isomerization of this ligand is an indication of the reason why allyl chloride worked so well. Having the chlorine next to the double bond allowed the formation of some reactive intermediate, perhaps a cation or radical, that was accessible to the other organochlorides. Organochlorides other than allyl chloride instead underwent dehydrochlorination and/or decomposition. It was shown that dehydrochlorination could be followed by hydrosilylation using a platinum catalyst and trichlorosilane to form useful products. Attempts to use silylene trapping agents to determine the mechanism of disilane reaction were unsuccessful due to decomposition of the trapping agent. Jarvis was awarded two patents $[57,58]$.

In 1997, Brinson and Pfanstiel reported the Hydrogenolysis of Direct Process Residue in the Pilot Plant $[15,56]$. In 1995 and 1996, a DPR hydrogenolysis Pilot Plant was operated. The reaction product contained high concentrations of valuable monomers such as $\mathrm{MeHSiCl}_{2}$ and $\mathrm{Me}_{2} \mathrm{SiCl}_{2}$.

Early in 1998, Crum finalized an effort with a contract testing facility to determine the flammability limits, autoignition temperature, minimum ignition energy and explosion severity for the reactor mixture, including hydrogen gas. The product mixture exhibited the properties shown below in Table 1 .

Table 1: Product Property Measurement For Safety Study

\begin{tabular}{|l|l|}
\hline Measurement & Value \\
\hline Lower Flammability Limit & $3.98-5.02 \%$ \\
\hline Upper Flammability Limit & $23.6-24.8 \%$ \\
\hline Autoignition Temperature & $537-540^{\circ} \mathrm{C}$ \\
\hline Minimum Ignition Energy & $<0.12 \mathrm{milliJoules}$ \\
\hline Maximum Explosion Pressure & $7.1 \mathrm{barg}$ \\
\hline Maximum Explosion Pressure Rise Rate & $424 \mathrm{bar} / \mathrm{s}$ \\
\hline $\begin{array}{l}\text { Equivalent Maximum Explosion Pressure Rise Rate In A One } \mathrm{m}^{3} \\
\text { Vessel }\end{array}$ & $115 \mathrm{bar} \mathrm{m} / \mathrm{s}$ \\
\hline
\end{tabular}




\subsection{Description of Processes}

\subsubsection{Pilot Plant}

\subsubsection{Process Description}

The Pilot Plant consisted of feed tanks, a DPR filter, preheaters, a reactor, a product condenser, distillation column, a product storage tank, and hot oil system.

Chlorosilane monomer was transferred to a Monomer Tank from a plant header originating in the tank farm. Monomer was used as a DPR co-feed, to flush the DPR filter with liquid, and to flush the reactor for cleaning. DPR from a FBR was transferred to the DPR Tank. The DPR pump operated continuously to recycle material in a loop from the bottom of the DPR Tank to the top to keep silicon solids suspended.

To remove silicon solids, DPR was pumped to the filter from the DPR Tank. Filtrate was routed back to the DPR Tank or over to the Filtrate Tank. The filter was cleaned in place with nitrogen and monomer. Solids were flushed into a transfer line back to the FBR system. When a sufficient amount of filtrate was collected, it was diluted with monomer in the Filtrate Tank to prepare the reactor feed mixture.

The feed pump pressurized the mixed chlorosilane feed to reactor pressure. The pump was a positive displacement model with an eccentric gear, piston, diaphragm, and double check valve design. Chlorosilane feed was heated with oil in a double pipe exchanger constructed of tube fittings. DPR entered the reactor on the bottom or the top depending on valve arrangements. Typically, DPR was fed to the bottom of the reactor.

Hydrogen was supplied from an existing liquid hydrogen tank maintained by a third-party. Liquid hydrogen was vaporized in an air-warmed finned pipe exchanger at low pressures. Hydrogen gas from the vaporizer was compressed above reactor pressure with a two stage reciprocating piston machine and stored in a tube trailer. From the tube trailer, $\mathrm{H}_{2}$ was regulated to supply pressure. A control valve in the Pilot Plant further regulated flow and pressure. Hydrogen was preheated to with oil in a preheater, a double pipe exchanger also constructed of tube fittings. $\mathrm{H}_{2}$ entered the reactor on the bottom or the top depending on valve arrangements. Typically, $\mathrm{H}_{2}$ was fed to the bottom of the reactor.

After several hours of operation, a liquid level formed in the bottom $-25 \%$ of the vessel. $\mathrm{H}_{2}$ was fed through spargers and bubbled up through this reacting liquid. Pressure was controlled in the vapor region above the liquid. When pressure rose in the reactor, the reactor vent valve opened to lower the pressure. Temperature inside the reactor was monitored at three different vertical heights and three different axial points at each height. Temperature was controlled by adjusting the power input to the entire oil system at the heater. The liquid level in the reactor was monitored by means of a nuclear density meter, but the level was not controlled.

Typically, product was withdrawn overhead from the reactor. (After start-up, different reactor feed and product configurations were tested.) Plugging made it impossible to operate water cooled condensers as originally designed. Product recovery via liquid contacting condensation proved to be most successful.

In the original scheme, reactor effluent was condensed at high pressure in a shell and tube condenser using service water to cool the stream. Liquid product and $\mathrm{H}_{2}$ flowed down into a gas/liquid disengagement vessel. Unreacted $\mathrm{H}_{2}$ flowed out the top of the disengagement vessel, and liquid was discharged from the bottom. The reactor and the disengagement tank operated at the same pressure in this scheme. Reactor pressure was controlled at the $\mathrm{H}_{2}$ vent from the disengagement tank. Hydrogen was throttled down from high pressure to low pressure. Unreacted hydrogen (plus any uncondensed chlorosilanes or blanketing nitrogen from the low pressure storage tanks) was vented to the FBR's DPR column. Liquid product from the 
disengagement tank was throttled from high pressure to low pressure through an automatic valve into a low pressure storage tank.

In later product recovery schemes, the shell and tube condenser was replaced with double pipe condensers. The most successful scheme proved to be product recovery in the still pot of a distillation column. In this scheme, reactor vapor was throttled down to low pressure immediately on exiting the reactor. The low pressure line to the reboiler was heat traced to prevent $\mathrm{AlCl}_{3}$ condensation. At the reboiler, the stream entered the vessel below the liquid level. This scheme proved to be successful and all experiments in 1996 utilized this mode of product recovery.

In the distillation column, desirable monomers were separated from unreacted DPR. In the final product recovery mode, the column and overhead accumulator were used to separate unreacted $\mathrm{H}_{2}$ from the product. The column contained structured packing. Overhead vapor from the distillation column was condensed with service water and flowed into an accumulator. The reflux rate was controlled to maintain lower temperature in the column. Liquid product was pumped to a product storage tank. The reboiler was operated at temperatures above atmospheric, but below the reactor temperature. Bottoms were pumped out of the still pot as needed to maintain a liquid level of approximately $50 \%$. Bottoms were also pumped to the product storage tank.

The hot oil system used Syltherm $\otimes 800$ silicone heat transfer fluid. Oil from the expansion tank was pumped to the emergency cooler and an electric resistance heater. A pair of automatic bypass valves diverted flow to the heater or cooler depending on the needs. Typically $10 \%$ of flow was routed through the cooler to keep the cooler tubes warm and to avoid thermal shock in case of an emergency. Power input to the heater was adjusted by means of a silicon controlled rectifier (SCR). A temperature controller for the oil loop automatically controlled power. To adjust reactor temperature, the setpoint to the oil loop was changed.

\subsubsection{Safety Procedures for Pressure Testing and Leak Testing}

Detailed efforts were made to test all equipment and tubing prior to pressurizing the Pilot Plant with hydrogen and chlorosilanes. First, low pressure pneumatic tests were completed at plant air header pressure. Next, all lines were hydrostatically tested at high pressure. The hydrogen header was tested with water. The line proved to be difficult to dry after testing. The remainder of the Pilot Plant high pressure equipment was tested with DC 200 fluid(B.

After hydrostatic testing, the high pressure system was leak tested with helium at operating pressure, ambient temperature. Fittings were soap tested. Flanges were taped and pin holed. The entire system was tested with a Matheson(3) model 8065 Leak Hunter gun capable of detecting helium leaks in the range of $10^{-5}-10^{-4} \mathrm{cc} / \mathrm{sec}$.

Finally, the system was leak tested at operating pressure and temperature with helium. Pressure was held for 8 to 16 hours and monitored on the reactor pressure transmitter to verify no leaks occurred.

A similar pressure testing procedure was applied each time the reactor was disassembled for maintenance. All new tubing installed or modified was subjected to a $150 \%$ design pressure hydrostatic test or $110 \%$ pneumatic test.

\subsubsection{Modifications to Pilot Plant Prior to Start-up}

\subsubsection{Electric Heater Upgrade and Cooler Bypass}

During commissioning of the hot oil system, it was found that the system temperature could not be raised to design specifications with the original electric heater. The maximum temperature achieved was approximately $150^{\circ} \mathrm{C}$ lower than needed. Heat losses were much higher than originally estimated. A new heater element was installed to overcome this problem. Also, pipes 
and bypass valves were installed to shunt approximately $90 \%$ of the hot oil flow away from the emergency cooler.

\subsubsection{Fittings Seal Welded}

During hydrostatic leak tests, a number of problems were discovered with NPT threaded connections. Screwed half-coupling fittings were originally specified to connect tubing to the reactor and high pressure filter. Other screwed fittings were used in the hot oil system. These had originally been sealed with a paste rated for high temperature and high pressure. Many fittings leaked during hydrostatic testing. After numerous failed attempts to identify a new sealing paste or tape, all screwed fittings in the high temperature, high pressure system were disassembled, cleaned, and seal welded to eliminate any potential for leakage. Low temperature screwed fittings were successfully sealed with Teflon paste or tape and did not require seal welding.

\subsubsection{Intermediate product cooler}

During equipment inspections a design error was discovered in the temperature rating of a vapor product cooler. The unit was incorrectly designed for a temperature rating of $140^{\circ} \mathrm{C}$ lower than the design specification. An inquiry was made with the manufacturer to increase the temperature rating, but the change would have required addition of a thermal expansion joint on the shell. To avoid a probable start-up delay of several weeks, an intermediate coiled and finned air cooler was installed between the reactor and the vapor product cooler. The unit operated as designed, cooling the product well below the maximum temperature of the vapor product cooler.

\subsubsection{Process Description Of Pilot Plant II}

A second Pilot Plant - "Pilot Plant II" - was constructed to overcome the problems encountered in the first unit.

DPR from the adjoining FBR's reboiler or from the site's DPR tank is transferred to the dirty DPR tank. A DPR pump operates continuously to recycle material in a loop from the bottom of the dirty DPR tank through a service water cooler and back to the tank to keep silicon solids suspended and precipitate some $\mathrm{AlCl}_{3}$ out of solution. Methyldichlorosilanes (MCDS) are transferred to the feed tanks as a substitute for DPR, and used to back-flush the DPR filter.

To remove silicon solids, DPR is pumped to the filter from the dirty DPR tank. Filtrate is routed to a mix tank. The filter is cleaned in place with nitrogen and MCDS. Solids are discharged into the site's DPR tank. After every batch of filtrate is collected, monomer is added to prepare the reactor feed mixture to be transferred to the feed tank. Chlorosilane monomer is transferred to the mix tank from a plant header originating in the tank farm.

The positive displacement feed pump pressurizes the mixed chlorosilane feed to reactor pressure. Chlorosilane feed is heated with Syltherm 8 in a finned-tube preheater. Chlorosilanes enter the reactor on the bottom or the top depending on valve arrangements. Typically, chlorosilanes are fed to the bottom of the reactor to help prevent plugging of the bottom nozzles and pipework by reaction by-products that are solid.

Hydrogen is supplied from a new liquid hydrogen tank maintained by a third-party. Hydrogen liquid from the tank is compressed beyond reactor pressure with a reciprocating piston pump. The high-pressure liquid hydrogen is then vaporized in an ambient air vaporizer and stored in a tube bank. From the tube bank, $\mathrm{H}_{2}$ is regulated to supply pressure. A control valve in Pilot Plant II controls flow to regulate flow at reactor pressure. Hydrogen is preheated with Syltherm $\otimes 800$ in a shell and tube preheater. $\mathrm{H}_{2}$ enters the reactor on the bottom or the top depending on valve arrangements. Typically, $\mathrm{H}_{2}$ is fed to the bottom of the reactor.

Several hours into the start-up operation, a liquid level forms in the bottom one-third of the reactor vessel. $\mathrm{H}_{2}$ feed bubbles up through this reacting liquid. Pressure is controlled in the vapor region 
above the liquid. When pressure rises in the reactor, the reactor overheads pressure control valve opens to lower the pressure. Temperature inside the reactor is monitored at three different vertical heights. Temperature is controlled indirectly by adjusting the power input to the entire oil system at the heater. The liquid level in the reactor is monitored by means of weigh cells and a nuclear density meter, but the level is not controlled directly.

Reactor pressure is controlled at the overheads pressure control valve from the reactor. Overhead product is throttled down from reactor pressure to DPR Column pressure. Unreacted hydrogen and vapor chlorosilanes are continuously vented to the adjoining FBR's DPR column. Liquid product from the reactor is throttled from reactor pressure to DPR Column pressure through a level-control valve, and flows into the adjoining FBR's DPR column.

Typically, product is continuously withdrawn overhead from the reactor. Intermittent blowdown of liquid from the bottom of the reactor is necessary to purge the vessel of unreacted high-boilers and polymer/solid that is being formed. During blowdown, chlorosilane feeds are directed to the top of the reactor.

Commercial Plant product recovery occurs via the adjoining FBR's DPR column, where monomers from Pilot Plant II join effluent from the FBR overhead. Any unreacted high-boilers or polymer that are formed in the reactor exit out the bottom of the DPR column with the rest of adjoining FBR's DPR.

The hot oil system uses Syltherm $\otimes 800$ silicone heat transfer fluid. Oil from the expansion tank is pumped to the electric heater. A pair of automatic valves then divert flow to an emergency air fan cooler or directly to the preheaters and reactor. Typically $-10 \%$ of flow is routed through the cooler to keep the cooler tubes warm and to avoid thermal shock during an emergency that calls for full cooling. Power input to the heater is adjusted by means of a silicon controlled rectifier (SCR). A temperature controller for the oil loop automatically controls powver. To adjust reactor temperature, the setpoint to the oil loop is changed.

\subsubsection{Pilot Plant II DPR Filtration}

\subsubsection{Operation}

Processing DPR in a filter is defined by six distinct operations. A typical filtration cycle is also shown in Figure 1 below.

1. Idle is the normal resting state for the filter unit. Here, automatic valve positions are verified, and the filter waits for the slurry feed tank to have a sufficient quantity of DPR for processing, and for the mix tank to have sufficient storage volume to allow filtration. During this operation DPR is pumped in a continuous fashion through a service water cooler and back to the feed tank.

2. During the Filtration operation, an automatic valve opens allowing flow into the filter housing. Constant flow filtration is the idealized model for this unit. Filtrate flow is controlled by the use of a recycle back-pressure control valve. However, at the beginning of the filtration operation, filtrate flow is greater than setpoint. Thus, even with the backpressure control valve completely open, filtrate flow exceeds setpoint. As the cake builds on the filter elements, filtrate flow decreases such that the setpoint is approached. In response, the back pressure control valve begins to close, forcing slurry through the growing filter cake. Pressure-drop increases as filter cake builds, until a predetermined maximum pressure-drop is achieved. At this point, the filtration operation is completed by opening the recycle control valve and closing the filter feed valve.

3. During the Drain operation, the filter housing is drained of clear liquid in preparation for displacing the filter cake. First, an automatic nitrogen valve is opened. This forces clean liquid out of the filter housing. Outlet flow measured by an orifice-plate flow meter rises sharply, steadies out, then drops sharply. This indicates that all liquid has been displaced 
from the housing and nitrogen gas is blowing through the meter. This completes the operation. At this point, the mix tank is allowed to proceed to Monomer Addition.

4. During the Monomer Addition operation, a fixed weight of monomer is added to the mix tank according to a operator-defined ratio of filtered DPR to monomer. Based on the mix tank weight prior to monomer addition, and the weight of filtrate collected in the mix tank during Filtration and Drain, a mix tank target weight is calculated. By means of an automatic valve, monomer is added. This operation cannot be conducted during Filtration or Drain; it may proceed concurrently with Idle, Blowdown or Rinse.

5. Blowdown includes pressurizing the filter housing with $N_{2}$ and dumping the filter cake to a receiver below. The purpose of this operation is to drive the filter cake off the filter elements so that another filtration cycle can be initiated. First, the $\mathrm{N}_{2}$ backpulse valve is opened. When the $\mathrm{N}_{2}$ surge tank pressure (equivalent to the filter housing pressure) comes within $15 \%$ of the normal $\mathrm{N}_{2}$ header pressure, the $\mathrm{N}_{2}$ backpulse valve is closed. The filter dump valve is then opened for 5 seconds. Based on operator input menu, the pressurization/dump steps are repeated as necessary.

6. Rinse involves bringing clean liquid through the filter from the clean-side to dirty-side to help rinse solids down to the receiver below. The purpose of the liquid rinse is to aid the inprocess cleaning of the filter elements. At the operator's discretion, rinse is requested to immediately follow Blowdown. It is requested if observations over time lead the operator to believe that the Blowdown alone is not sufficiently discharging all of the cake from the elements. An automatic valve is simply opened for a prescribed length of time, allowing liquid to flush through the housing and elements during this operation.

Material from the mix tank rinses the filters. This results in a small loss of reactable feeds, since the mix tank material is feed for the reactor.

Figure 1: Typical Filtration Cycle

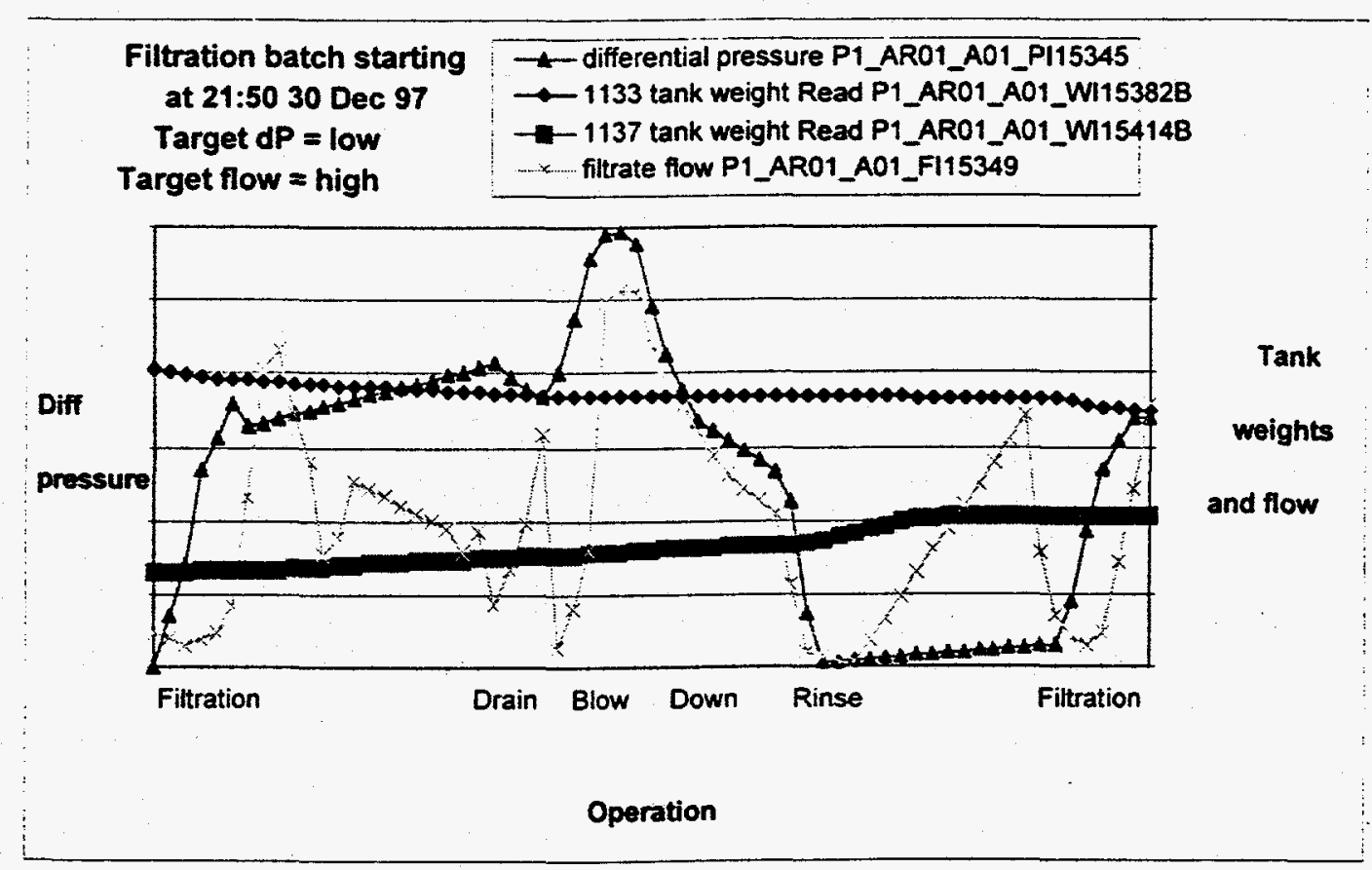




\subsubsection{Modifications To Pilot Plant II During Start-Up}

\subsubsection{Stainless Steel Flanges On Carbon Steel Valves (Q1 97)}

Stainless steel is prone to Chloride Stress Corrosion Cracking (CSCC). In a chlorosilane processing area, this attack is typically the result of small releases that occur during planned maintenance activities. This gradual attack can eventually result in failed fittings and piping. In fact, such failures did occur in the pilot Plant unit. Therefore when it was discovered during the construction phase of the project that the carbon steel manual valves had been delivered with stainless steel flanges, it was decided to ship the valves back to the manufacturer to be re-built. Inspection of the Dow Corning data sheets showed that we had in fact specified carbon steel flanges in the original purchase order.

\subsubsection{Gasketing (Q2 97)}

Slip-on flanges were used in the fabrication of the high-pressure piping in Pilot Plant II. In the smaller sizes (1.5" and less), the inside diameter of the spiral-wound gaskets is less than the inside diameter of the slip-on flange bore. The resulting mismatch results in a distortion of the unsupported gasket windings. The use of slip-on flanges was contrary to ASME B16.20, which called for weld neck flanges. A change in gaskets from spiral wound to solid alloy steel was instituted. These solid alloy gaskets are sturdy and contain no spiral windings that might be subject to unraveling. This situation and potential solutions were entered as an Opportunity for Improvement (OPI) for the Valve Tech Team.

\subsubsection{Electric Heater (Q2 97 - Q1 98)}

Three distinct failures of the electric heater were experienced during start-up. First, the unit was delivered with only five of six resistance temperature detectors (RTDs) operational. Shortly thereafter, another RTD failed. A convenient opportunity during valve rework arose allowing the heater to be sent back to the vendor for repair.

Upon start-up of the reactor system, the heater repeatedly suffered blown fuses, resulting in operation of only two, and sometimes one, of the three heating banks. The unit was removed and repaired at the vendor's facility after a visit and inspection from the local Sales Engineer. This caused a one-week shutdown, and possibly led to subsequent, longer shutdowns due to the operational problems it caused.

Finally, the heater failed completely. This resulted in a total replacement of the heater with a new unit. The also resulted in a one month shutdown toward the end of the start-up period.

The cause of the failure was identified as poor brazing of nut and bolt connectors in the control head. This allowed the electrical connections to loosen, resulting in arcing and failure.

\subsubsection{Syltherm Catch Tank (Q2 97)}

During the commissioning activities of any Syltherm $\otimes$ system, cyclics and water are driven off from the hot oil loop during the first warm-up of the system. Known "boiling-points" of these cyclics are approximately 121,149 and $177^{\circ} \mathrm{C}[16]$. It was known that low-boiling fractions would be boiled off during commissioning of the hot oil system for Pilot Plant II. Pre-start-up design and construction reviews did not reveal the desire on the part of the manufacturing team for a catch tank. Catch tanks are small vessels, sometimes simply large-diameter pipe, that are used to catch condensing vents from hot oil expansion tanks during commissioning. As commissioning was about to commence, the need for a catch tank was identified, and it was installed. 


\subsubsection{Valves (Q2 - Q3 97)}

During initial pressure and leaking testing of the system, excessive leak-through was detected in the high-pressure manual valves. Additionally, subsequent flushing with Dow Corning 200 fluid $\circledast$ and trimethylchlorosilane $\left(\mathrm{Me}_{3} \mathrm{SiCl}\right)$ revealed stem leaks and body flange leaks. Because of these defects and concerns of safety, every manual valve and automatic valve supplied by the primary vendor was removed from the process and returned. Pitting and flaking of the boronized surface on the Hastelloy ${ }^{\circledR}$ C-276 valves was discovered to be the root cause of the leak through problems. The following rework was completed to rectify these problems.

1. In carbon steel valves, metal seats were replaced with soft seats to alleviate leak through.

2. In carbon steel valves, handle extensions were eliminated for ease of operation. These handle extensions were originally installed to allow for thick insulation. All carbon steel valves in Pilot Plant II are uninsulated (they operate at ambient temperatures), and therefore the handle extensions were unnecessary.

3. In carbon steel valves, the packing was replaced to eliminate stem leaks.

4. In carbon steel valves, ball and seat materials were upgraded to higher quality stainless steel. Valve internals operate in an anhydrous environment, and therefore there was no concern for chloride stress corrosion cracking.

5. Valves were assembled with lock-washers on body bolts and bonnet bolts to prevent the nuts from loosening. Loose nuts had previously led to body leaks.

6. In Hastelloy $\circledast \mathrm{C}-276$ valves, the stems were replaced to prevent stem leaks. The original low-molybdenum stems were more prone to chloride corrosion pitting from aqueous $\mathrm{HCl}$ attack than the replacement stems.

7. For Hastelloy@ C-276 valves, new balls and seats were fabricated. They were then boronized at a third-party shop different than the original set, to combat the leak through caused by pitting and flaking.

8. Finally, all valves were hydrostatically and pneumatically tested under the observation of Dow Corning personnel at the fabricators's shop in Houston, Texas, to ensure quality control.

In all, the valve re-work resulted in a four month delay in the start-up effort. 
Figure 2: Process schematic for Pilot Plants

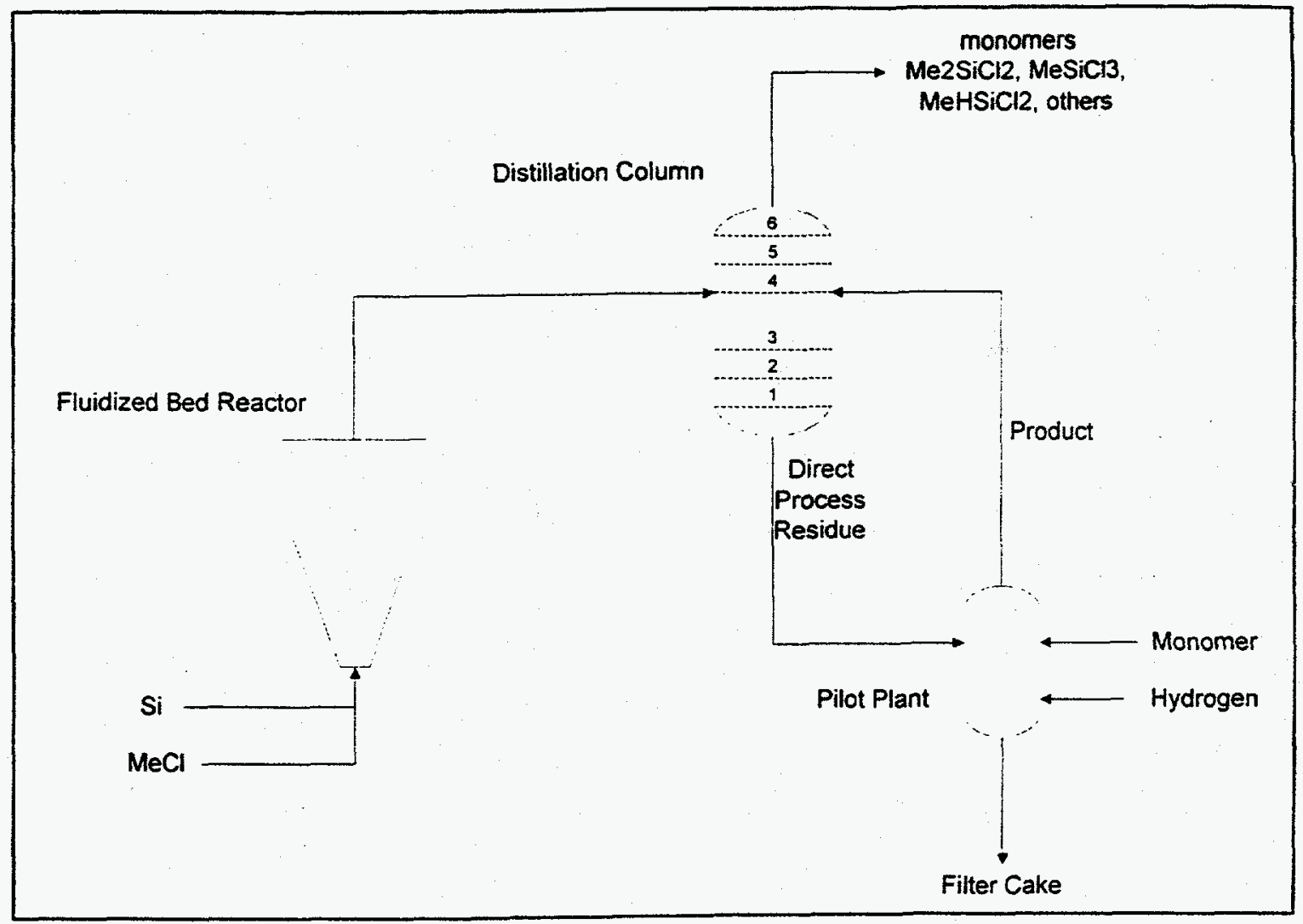

\subsection{Fire And Explosion Safety Study}

A Fire and Explosion Safety Study was conducted by an outside consultant, specifically for Pilot Plant II [17]. The following scenarios were studied.

\subsubsection{Process Scenarios}

1. Start-up: Reactor full of high-pressure hydrogen and monomers

2. Shut-down: Reactor $40 \%$ full of high-boiling liquid and hydrogen

\subsubsection{Fire Scenarios}
1. Pool fire
2. Flash fire
3. Jet fire
4. Fireball

\subsubsection{Explosion Scenarios}

1. Pressure vessel burst

2. Boiling liquid expanding vapor explosion (BLEVE)

3. Unconfined vapor cloud explosion (UVCE)

\subsubsection{Conclusions From The Study}

1. No life threatening or building destruction hazards result from the main fire and explosion scenarios. 
2. The greatest risk is a flash- or jet-fire that ignites clothing.

\subsubsection{Recommendations}

1. Allow access to the reactor platform only to persons wearing non-combustible clothing, for protection against a possible jet-fire.

2. Provide vacuum relief, using nitrogen, for the Mix Tank, to ensure that air could not be pumped into the reactor.

3. Ensure that the air inlet to the Control Building air-conditioning system can be closed promptly, in response to any alarm from a flammable or toxic vapor detector.

4. Determine the average boiling point for the material which remains liquid at the normal operating temperature and pressure, so that the BLEVE hazards can be determined more accurately.

All actions in response to these recommendations have been completed.

The recommendation concerning fire resistant clothing had by far the greatest impact. It required that the start-up team implement the following items. These should be considered by anyone who contemplates adhering to such a dress code.

1. Signs were posted in the tower prohibiting access above the ground floor without fire resistant clothing.

2. Uniforms were purchased for infrequent visitors and tradesmen. These are kept in a locked cabinet, and a sign-out roster is maintained by the spare operator.

3. A new uniform vendor was contracted to provide the fire resistant uniforms.

4. Fire resistant clothing is rendered ineffective if fibers from other clothing become impregnated in it during the laundering process. Therefore, these uniforms must be segregated from other soiled clothing and laundered separately. 


\section{RESULTS AND DISCUSSION}

\subsection{Chronology of Experiments}

\subsubsection{Experiments - Pilot Plant}

In March 1995, piping changes were completed to modify the heater system. Formal start-up approval was obtained from plant management and safety personnel.

In April, the first attempts were made to start the Pilot Plant process. Several problems were experienced with the mechanical seal on the DPR filter feed pump. The pump was designed for severe duty because of the high concentration of abrasive solids in the stream. Numerous modifications were made to overcome the seal problem. The first major experimental milestone was reached late in April when DPR was successfully filtered at the Pilot Plant.

In May, the first reactor experiment was conducted. Several problems were experienced with the in-line GC analyzer. Complete mass balances and extensive product analysis were not obtained, but hydrogenated chlorosilane monomers were detected in the product samples indicating successful conversion of DPR to valuable chlorosilanes. The nuclear density meter was started. Reaction phase monitoring was determined to be feasible with the density instrument. DPR filtration continued successfully.

In June 1995, three experimental runs were completed. In the June 5 campaign, pipework in the bottom of the reactor plugged. Modifications were made to the design, and the unit was restarted. The hot oil pump failed during the June 12 campaign. Cooling water flow to the bearings was lost due to a plug in the water rotameter. The June 21 campaign ended when an extremely high pressure drop was discovered across the reactor product condenser. The condenser and downstream piping were found to be plugged with aluminum chloride $\left(\mathrm{AlCl}_{3}\right)$. Experimental results from all three runs were similar. Disilane conversion was approximately $100 \%$. Silmethylene conversion ranged from $19-30 \%$. High boiler conversion was $8-15 \%$. Total DPR conversion ranged from $56-75 \%$. These encouraging results indicated that the original design targets were within reach.

In July 1995, two vertical double pipe condensers were installed to overcome the $\mathrm{AlCl}_{3}$ plugging problem. The modification was made so that one condenser could be cleaned in place while the other was operating. An experimental campaign began July 19. Results were comparable to the previous experiments. More $\mathrm{AlCl}_{3}$ plugging was experienced which caused shutdowns. A fitting failure caused a minor leak in a high pressure line. The fitting was forwarded to metallurgists who confirmed that the fitting had undergone chloride stress corrosion cracking. Other nearby tubing was inspected, and certain fittings were replaced. The reactor was pressure tested and deemed to be safe for restarting. Cleaning the condensers plugged by $\mathrm{AlCl}_{3}$ proved to be impossible. Safety concerns for handling $\mathrm{AlCl}_{3}$ and corrosion concerns during the maintenance made other alternatives highly desirable.

In August 1995, a second modification was made to reduce $\mathrm{AlCl}_{3}$ plugging. The existing condenser design was altered to create a co-current liquid contacting condenser. The goal was to desublime (condense from a vapor phase directly to a solid phase) $\mathrm{AlCl}_{3}$ in a circulating liquid product stream. The unit was restarted and operated successfully until the hydrogen feed line plugged. A plant preventive-maintenance shutdown in the adjoining FBR process forced the Pilot Plant to remain down for at least three weeks. The FBR process was the supplier of DPR to the Pilot Plant, and received vents from the Pilot Plant.

In September 1995, the reactor plug was investigated further. When the adjoining FBR started up after maintenance, the reactor was washed in place. This had been done successfully in small 
laboratory reactors, but proved to be unsuccessful in the Pilot Plant reactor. The reactor could not be cleaned in place. The vessel was removed from the process tower for cleaning via a water blaster.

Also in September, several meetings were held with department staff and plant personnel to review progress to date, problems in the Pilot Plant, and future plans. Based on these reviews, it was decided that the basic chemistry observed at the laboratory scale had been demonstrated in the Pilot Plant, but key questions about integrating the process in a commercial scale plant could not be answered at the Pilot Plant. The main uncertainty was the fate of $\mathrm{AlCl}_{3}$ in a commercial scale integrated process. Meetings were held with a metallurgical engineering consulting firm to review the materials of construction of the Pilot Plant and to design a corrosion coupon study to determine the best material for a larger scale reactor system.

In October 1995, a capital authorization request was submitted for preliminary engineering funds for Pilot Plant II. The project engineers devoted most of their time to creating the process technology package. The Pilot Plant reactor was safely cleaned. The vessel was returned to the process tower, but the Pilot Plant was not restarted for three months while Pilot Plant II design was completed. In November, the process technology package was completed and transferred to the site engineering department to begin detailed design for Pilot Plant II.

In December 1995, the Pilot Plant reactor was rebuilt. Modifications were made to allow alternative reactor configurations such as a jet loop reactor, a spray reactor, and a top-down plug flow reactor with a lower product removal. These were made to avoid reactor plugging. Changes were also made to improve product recovery and avoid plugging due to $\mathrm{AlCl}_{3}$ desublimation. Table 2 summarizes the 1995 campaigns.

Table 2: Summary of 1995 Campaigns

\begin{tabular}{|c|c|c|c|}
\hline Campaign & Began & Ended & Running time \\
\hline 1 & $17 / 05 / 954: 00$ & 17/05/9511:00 & 7 hours \\
\hline & 18/05/95 $1: 43$ & $19 / 05 / 952: 20$ & 25 hours \\
\hline 2 & $6 / 06 / 952: 36$ & $6 / 06 / 95 \quad 13: 57$ & 11 hours \\
\hline 3 & $13 / 06 / 950: 31$ & $15 / 06 / 95 \quad 14: 55$ & 62 hours \\
\hline 4 & 22/06/953:20 & $24 / 06 / 957: 30$ & 52 hours \\
\hline 5 & $19 / 07 / 9517: 00$ & $23 / 07 / 951: 56$ & 81 hours \\
\hline & 23/07/95 2:41 & $23 / 07 / 958: 19$ & 6 hours \\
\hline & $26 / 07 / 954: 30$ & $26 / 07 / 9512: 53$ & 8 hours \\
\hline 6 & $7 / 08 / 951: 55$ & $7 / 08 / 95 \quad 14: 18$ & 12 hours \\
\hline & $9 / 08 / 9520: 55$ & 10/08/95 0:30 & 4 hours \\
\hline Total time & & & 268 hours \\
\hline
\end{tabular}

\subsubsection{Experiments - Pilot Plant}

In January 1996, the Pilot Plant reactor was pressure tested at ambient temperature and purged to prepare for restarting the unit. During 1995, none of the distillation equipment had been commissioned due to other operational problems in the Pilot Plant. This equipment was checked and prepared for start-up.

In February 1996, the Pilot Plant was restarted. The system was leak tested at operating temperature and pressure with helium and held for 14 hours with zero leakage. Start-up approval was obtained from plant management for the distillation equipment which had not previously been commissioned. A complete emergency shutdown system check-out was performed and numerous modifications were made to allow reactor product to feed directly to the distillation column. On February 22, a one day experiment with the reactor was started in the spray reactor/distillation 
product recovery configuration. On February 26, a 55 hour experiment was started with the reactor in a bubble column feed mode and distillation product recovery mode.

In March 1996, several experiments were completed. The previous problems with $\mathrm{AlCl}_{3}$ were resolved with the change in product recovery methods. Direct injection of reactor product in the distillation still pot eliminated plugging due to pure $\mathrm{AlCl}_{3} \mathrm{crystallization.} \mathrm{Problems} \mathrm{were}$ encountered with throttling the high pressure product to the low operating pressure of the distillation system. Pressure control valve trim was changed several times to get the proper $C_{v}$, and the valve and downstream tubing had to be cleaned once. During this time, several modes of operation were tested. Spray feed, jet loop, and bottom product discharge proved to be no better than the standard bubble column configuration. A second fitting failure was discovered due to stress corrosion during the March 24 experiment.

In April, the lower reactor head was removed. A small crack was discovered and repaired in the lower reactor head. In May 1996, several attempts were made to start the unit. A failure of the feed pump prevented the unit from operating. Early in May, the unit was permanently shut down to clean out equipment that would be relocated to the new Pilot Plant II process. Table 3 summarizes the 1996 campaigns.

Table 3: Summary of 1996 Campaigns

\begin{tabular}{|r|r|r|r|}
\hline Campaign & Began & Ended & Running time \\
\hline 7 & $22 / 02 / 966: 00$ & $22 / 02 / 9619: 30$ & 14 hours \\
\hline 8 & $26 / 02 / 9621: 35$ & $29 / 02 / 964: 40$ & 55 hours \\
\hline 9 & $5 / 03 / 963: 50$ & $5 / 03 / 966: 45$ & 3 hours \\
& $7 / 03 / 960: 50$ & $7 / 03 / 965: 40$ & 5 hours \\
& $10 / 03 / 9621: 39$ & $11 / 03 / 9619: 41$ & 22 hours \\
\hline 10 & $18 / 03 / 966: 35$ & $18 / 03 / 968: 40$ & 2 hours \\
& $19 / 03 / 9620: 30$ & $20 / 03 / 9619: 30$ & 23 hours \\
& $24 / 03 / 9621: 45$ & $25 / 03 / 968: 30$ & 11 hours \\
& $26 / 03 / 964: 00$ & $28 / 03 / 9623: 00$ & 67 hours \\
\hline 11 & $2 / 05 / 9621: 00$ & $4 / 05 / 9620: 00$ & 47 hours \\
& $7 / 05 / 968: 40$ & $7 / 05 / 9613: 00$ & 4 hours \\
\hline Total time & \multicolumn{3}{|c}{} \\
\hline
\end{tabular}

Due to time constraints, designed experiments planned for the Pilot Plant were not completed before shutdown and demolition.

\subsubsection{Experiments - Pilot Plant II}

A new liquid hydrogen tank, two high pressure cryogenic pumps, vaporizers, storage cylinders and all associated equipment were installed and started up in January. The system was operated at high pressure. The new hydrogenolysis reactor was received and installed in the tower. The vessel was inspected by non-destructive testing and accepted. All equipment had been received and installed by the end of the month. Low pressure chlorosilane equipment installation, piping, electrical and instrumentation was completed. Hot oil piping fabrication and installation was underway. The start-up engineers completed daily inspections of the construction area. Spare parts purchases, preventive maintenance schedules, written operating procedures, automation specifications, preliminary experimental plans, and plant operator training were all underway

Installation of low pressure equipment was $99 \%$ complete by the end of February. The high pressure hydrogen system was $>95 \%$ complete. The main tower high pressure mechanical installation was $50 \%$ complete. Full day operator training was underway with the plant technicians who would operate the newly constructed process. 
Installation of low pressure equipment was $100 \%$ complete by the end of March. The high pressure hydrogen system was $99 \%$ complete. The main tower high pressure mechanical installation was $75 \%$ complete.

In April, the start-up team presented a second full-day training session to each shift of the plant technicians covering reactor operation, safety, and many other topics. Site management approved the start-up of the filter system. Equipment and instrument check-outs were completed. The entire filter system was successfully started up. The filter was operated well above design flow rates. A 32-run designed experiment was completed to optimize the filter operation. The hot oil system and reactor vessel were pressure tested with approval of the state vessel inspector. The hydrogen supply pipe was tested. The written standard operating procedures for the whole unit were completed.

No further work with the filter system was conducted in May. The hot oil system was conditioned. The reactor start-up was targeted for late-May, but was delayed due to the unsatisfactory performance of valves in high-temperature and/or high-pressure service. Despite the efforts of the start-up team, operators and visits on-site from the distributor and manufacturer, the ability of the valves to contain high-pressure gases was not acceptable. All "critical" valves were returned to the manufacturer for testing, re-work and re-testing under the observation of representatives from Dow Corning.

The hot oil electric heater tube bundle was sent to the manufacturer for repair in June. "Critical" valves were sent to the manufacturer. Upon visiting their site in Houston, Dow Corning's representatives decided that removing every valve for inspection and re-work was appropriate. "Spare" valves that had never been installed in the process were exhibiting flaking and pitting! Negotiations with the manufacturer continued.

The hot oil electric heater tube bundle was returned from the manufacturer and re-installed in July. Valve re-work and testing were underway in Houston. Numerous visits to the manufacturer's site were conducted by Dow Corning personnel in July. Poor process control by the first hard-surface contractor was identified as the root cause of failure for the first batch of valves. The re-worked carbon steel valves were returned to Dow Corning.

The filter system was started-up in August to verify operation after being idle three months. No decline in performance was observed. The hot oil system was re-commissioned in August. A wide range of operating temperatures was investigated; operation was satisfactory. Valve rework and testing was completed in Houston. Numerous visits to the manufacturer's site were conducted by Dow Corning personnel in August.

All valves were returned, re-installed and leak tested in September.

The filter operated well in October, providing feed material for the reactor. The filters did plug off late in the month, after approximately three months of net operation. Preparation, change-out, and re-start required a day. The used filters were sent to an off-site vendor for cleaning and testing. We planned to re-use them, if possible. The hot oil system experienced difficulty in October. The electric heater suffered repeated fuse failures. An on-site visit from the manufacturer's technical sales engineer revealed that the wrong fuse ratings had been used. Actual operation of the reactor with chlorosilane and hydrogen feeds commenced on 04 October 1997. Various feed strategies were investigated, with the first designed experiment initiated midmonth. A shutdown was required at month's end to address plugging in the bottom of the reactor. Product composition thus far has been better than expected.

The filter operated well in November, providing feed material for the reactor. The hot oil system experienced difficulty in November. New fuses were installed, but a total failure was experienced mid-month. The vendor repaired their shoddy workmanship on warranty, requiring only one week downtime. Operation of the reactor with chlorosilane and hydrogen feeds continued throughout much of the month, with the exception of the one-week heater repair. The first designed experiment, initiated in October, continued. 
The filters were changed out again in December. Previously used and cleaned filters were installed as replacements, and operated well. The hot oil system experienced difficulty in December. A total failure of the electric heater was experienced late in the month. Operation of the reactor with chlorosilane and hydrogen feeds was intermittent due to the aforementioned difficulties, but an eleven-day run was completed. The first designed experiment - initiated in October - was completed.

\subsubsection{Experiments - Pilot Plant II}

Throughout all of January, the process remained shut down due to the electric heater failure in late December. This down time was utilized to conduct miscellaneous minor maintenance. In addition, a wash of the reactor was conducted to ensure the reactor would be clean upon starting up. The chlorosilane preheater was water blasted due to fouling after an emergency shut-down (ESD) in late November. Prior to washout, visual inspection showed a film of fine black powder on the tube walls. After washout, cleanliness was verified. Met with various alternative valve distributors to discuss delivery times and costs. Updated the entire SOP and automation specification documents. Revised P\&ID's to reflect "post-start-up as-built".

The process was re-started in mid-February after installation of a new electric heater. The heater operated well. We attempted various reactor operating modes while monitoring filter and reactor performance. A feed pump failure was experienced late February. Tradesmen were able to solve the problem quickly. The piping spools that were removed from the process in January and tested off-site showed no cause for concern. This confirmed our choice of materials of construction. A Capital Authorization Request was approved to allow for the purchase and testing of various alternative valves. The first batch of valves was ordered.

Limited reactor operation was conducted in March prior to a planned FBR shutdown. The effects of total recycle of DPR on filter performance could not be evaluated due to high solids in the FBR reboiler. Two filter element changeouts were required in March, which was a concern. Four sets of filter elements were ordered to perform more trials. Calibration of the reactor's density meter was completed.

Operation was sustained from 13-19 April 98 and $23-30$ April 98. Down time at the beginning of the month was due to replacement filter delivery and installation. Down time from 19-23 Apr 98 was due to Fluid Bed Reactor system shutdown. The effects of totally recycling FBR DPR on filter performance was not evaluated due to poor performance of the new filter elements. A change in "filter rinse" material from liquid containing particulate to completely clean liquid was implemented during the 19-23 April 98 outage. Filter performance improved but was not acceptable. A Critical Technology Review was held in late April with the staff and key stakeholder. No fatal flaws in the technology were identified.

Operation was sustained throughout the month of May at an on line time of $90 \%$. This put year to date OLT at $42 \%$. A failure of a vent recovery component in a downstream process shut the hydrogenolysis reactor down for a few days. Availability was $99 \%$ with a brief shutdown to build some feed inventory due to poor filter performance. Overall conversion to useful monomers was as expected, including filter cake losses. The filters were not changed out during the month. However, the filter system could only support about two-thirds of the design capacity when feeding solids-rich slurry. Effort was focused on optimizing the liquid rinse The chlorosilane preheater showed signs of fouling

\subsection{Material Balances}

\subsubsection{Pilot Plant Data handling}

Raw data for all experiments have been compiled from laboratory notebooks. Six campaigns, in particular, were sustained runs believed to come to steady-state conditions and from which 
representative feed and product samples were obtained. The average run time for these campaigns was about 48 hours. Due to numerous problems encountered in the Pilot Plant, the system did not operate on a continuous basis for a sustained period longer than about 80 hours.

The discussion of results from the Pilot Plant will focus exclusively on the six sustained trials. Samples of the feed and product streams were taken during each campaign. Samples were analyzed using gas chromatography (methodology described in the experimental section) so that the depletion of undesirable reactants and production of useful monomers within the process could be quantified. These GC results were combined with flow rate data to account for the material balances of several different methylchlorosilanes. In turn, this data was used to calculate the reactor conversion.

Several assumptions and estimates were needed to calculate overall effluent compositions and conversions.

\subsubsection{Reactor Conversion}

Figure 3 illustrates the data for a representative run. The figure shows compositions of the inlet and overall outlet streams from the process. Qualitatively, the depletion of DPR is evident from the reduction of its three components: disilanes, silmethylenes, and high boilers (HB). The data show a slight depletion of $\mathrm{Me}_{2} \mathrm{SiCl}_{2}$ with a large production of $\mathrm{MeHSiCl}_{2}$, and small but significant production of $\mathrm{MeSiCl}_{3}, \mathrm{MeH}_{2} \mathrm{SiCl}$, and $\mathrm{Me}{ }_{2} \mathrm{HSiCl}$. 
Figure 3: Feed and Product Composition 1996

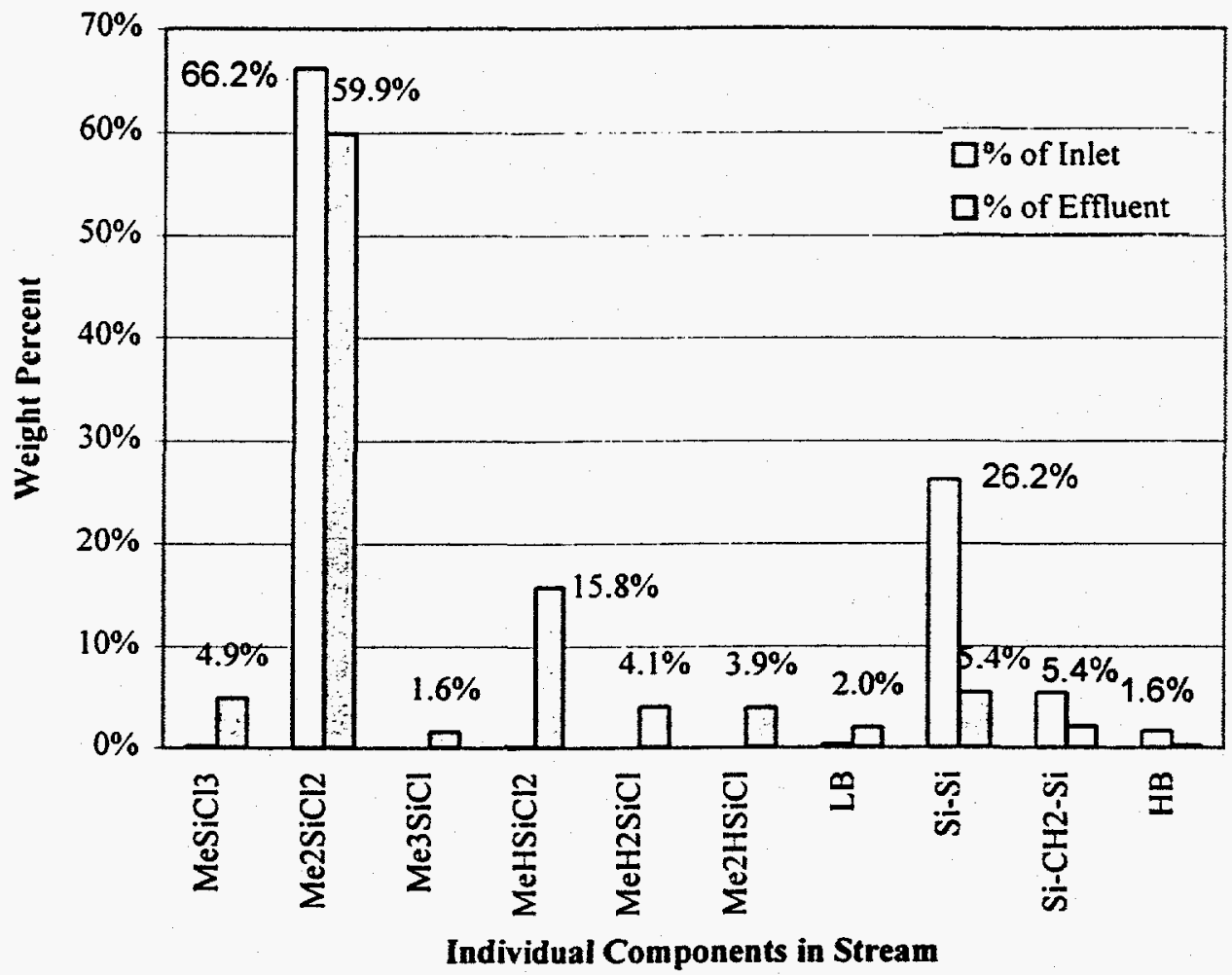

Conversion data has been included with other important process data summarizing each campaign in Table 4 below. In addition, average process data for the six sustained campaigns were calculated and included in the table. For the three 1995 campaigns, DPR conversion ranged from 30 to $78 \%$ with an average of $63 \%$. Disilane conversion ranged from 88 to $97 \%$ with an average of $93 \%$, and silmethylene conversion ranged from about 23 to $39 \%$ with an average of $30 \%$. On average, $\mathrm{Me}_{2} \mathrm{SiCl}_{2}$ made up about $17 \%$ of the overall effluent from the reactor, while $\mathrm{MeHSiCl}_{2}$ made up $20 \%, \mathrm{MeH}_{2} \mathrm{SiCl}$ made up $2.6 \%$ and $\mathrm{Me}_{2} \mathrm{HSiCl}$ made up $0.7 \%$ of the reactor output. The mass balance error for these campaigns averaged around $2 \%$. Similarly, DPR conversion for the three campaigns in 1996 ranged from 60 to $86 \%$ and averaged $72 \%$. Disilane conversion ranged from 79 to $93 \%$, and averaged $85 \%$. Meanwhile, silmethylene conversion ranged from 0 to $60 \%$ with an average conversion of $40 \% . \mathrm{Me}_{2} \mathrm{SiCl}_{2}$ was found to be consumed in two of the three runs at less than $10 \%$ conversion, while it was produced in the third run. $\mathrm{MeHSiCl}_{2}$ made up $17 \%$ of the overall reactor output, while $\mathrm{MeH}_{2} \mathrm{SiCl}$ and $\mathrm{Me}_{2} \mathrm{HSiCl}$ each made up about $4 \%$. The mass balance error for these campaigns averaged about $3 \%$.

The statistics in these tables are campaign averages. Instantaneous conversions were frequently much higher than the averages, particularly late in the campaigns. 
Table 4: Summary of Reactor Conversion and Mass Balances

\begin{tabular}{|c|c|c|c|c|}
\hline \multirow[b]{2}{*}{ Experiment " } & \multicolumn{2}{|c|}{1995 Campaizans } & \multirow[b]{2}{*}{$12172-4 x$} & \multirow[b]{2}{*}{ Avernke } \\
\hline & $12321-150$ & 12178.36 & & \\
\hline$R=$ Time (hr) & 63.7 & 390 & NIS & $57 \%$ \\
\hline Feed (bs) & 3586 & 1702 & 5340 & 35893 \\
\hline Fredect flow (bbs) & 3144 & $1+44$ & $\$ 7 \times 2$ & 31567 \\
\hline Yean Fow (Bbs) & $\$ 97$ & sh & 612 & $39 \% 3$ \\
\hline Acoumendation (bs) & 234 & $3 \times 3$ & 349 & 345.3 \\
\hline What Bence Error $(\%)$ & $-35 \%$ & $.3 .3 \%$ & 4). $T \%$ & $.2 .6 \%$ \\
\hline \multicolumn{5}{|l|}{ Cemersions \{\%\} } \\
\hline Disilanes & $895 \%$ & $\operatorname{sen} 6$ & $971 \%$ & $42.8 \%$ \\
\hline Total DPR & $580 \%$ & $296 \%$ & $7 \times .3 \%$ & $62.7 \%$ \\
\hline Faed Rete (lb/hr) & 56.3 & 617 & 66.9 & $\$ 2.2$ \\
\hline Strea Value Increasefeflb) & 11.05 & 750 & $10.0 \pi$ & 9.55 \\
\hline Wole Balmone Error (\%) & $.11 \%$ & $10 \%$ & $0.2 \%$ & \\
\hline 5 Mok Balance $(\%)$ & $-1920 \%$ & $-2.7 \%$ & $.3 .2 \%$ & \\
\hline Ke Vote Balange $(\%)$ & $-27.7 \%$ & $-210 \%$ & $.24+4 \%$ & \\
\hline O shoce Balance $(\%)$ & $0.1 \%$ & $19 \%$ & $+10 \%$ & \\
\hline
\end{tabular}

\begin{tabular}{|c|c|c|c|c|c|}
\hline \multicolumn{4}{|c|}{ 1996 Camporises } & \multicolumn{2}{|c|}{ Overall } \\
\hline $13162-9$ & 13162-103 & 13162.111 & Awerne & strente & Ton \\
\hline 545 & $30:$ & 21.3 & \pm 5 & \pm & 209 \\
\hline 2199 & 1801 & 764 & 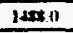 & 259 & 15232 \\
\hline 1719 & 1055 & 611 & $11 \times 3$ & $2 \leq 43$ & $12 \pi 55$ \\
\hline 630 & 520 & 226 & 4585 & $5 x$ & 2570 \\
\hline 45 & 1260 & 50.8 & $\pi 8$ & 90 & 1257 \\
\hline$-1.3 \%$ & $\$ 0$ & $-12.0 \%$ & $53 \%$ & $-50 \%$ & \\
\hline & & & & & Averages \\
\hline $78.9 \%$ & $897 \%$ & $93.1 \%$ & $251 \%$ & $\$ 7 \%$ & \\
\hline $763 \%$ & $595 \%$ & $86.0 \%$ & $73 \%$ & $55 \%$ & Heightred \\
\hline 40.4 & 375 & 359 & ish & 521 & Based in \\
\hline 781 & 7.4 & 14.38 & 1005 & 70 & Raun Tims \\
\hline $10 \%$ & -200 & $.7 .6 \%$ & & & \\
\hline$-1 \%$ & $-9=$ & $-14.6 \%$ & & & where \\
\hline$-39 \%$ & -0. & $-20.5 \%$ & & & \\
\hline $0.1 \%$ & $63=$ & $-9.2 \%$ & & & opponomate \\
\hline
\end{tabular}

\subsubsection{Evidence of an induction period}

Some type of "induction period" was observed at the beginning of each run before steady state conditions were reached and before substantial reaction of feed material began. Some depletion of disilanes in the system was seen within the first 12 hours of the run, but overall DPR conversion did not reach its peak until after 24 hours. From about 24 hours until the end of the run, DPR conversion was steady at about $60 \%$. Similarly, the percentage of $\mathrm{Me}_{2} \mathrm{SiCl}_{2}$ and $\mathrm{MeHSiCl}_{2}$ in the reactor effluent did not peak for 12 to 24 hours, but leveled off thereafter. At times, it was obvious that conversion of species in the feed material to useful monomers was still rising as far along as 36 hours into the run.

The conversion data shown in the table above were calculated for the entire experimental run, including the 12 to 24 hour induction period. For this reason, these conversion statistics are somewhat lower than expected conversions from a Commercial Plant process. Clearly, the kinetics of this hydrogenolysis reaction are complex. Insufficient detailed conversion versus residence time data was gained in the Pilot Plant to make definite conclusions about the reaction kinetics. However, if an induction period exists, a commercial reactor which is brought up and run at steady-state conditions on a continuous basis will yield better overall conversions and higher monomer production rates than those reported. For a steady-state commercial process, the conversions are expected to approach the steady-state values which were achieved in the Pilot Plant, as illustrated in Figures 4 and 5 below. 
Figure 4: DPR Conversion During an Experiment in 1996

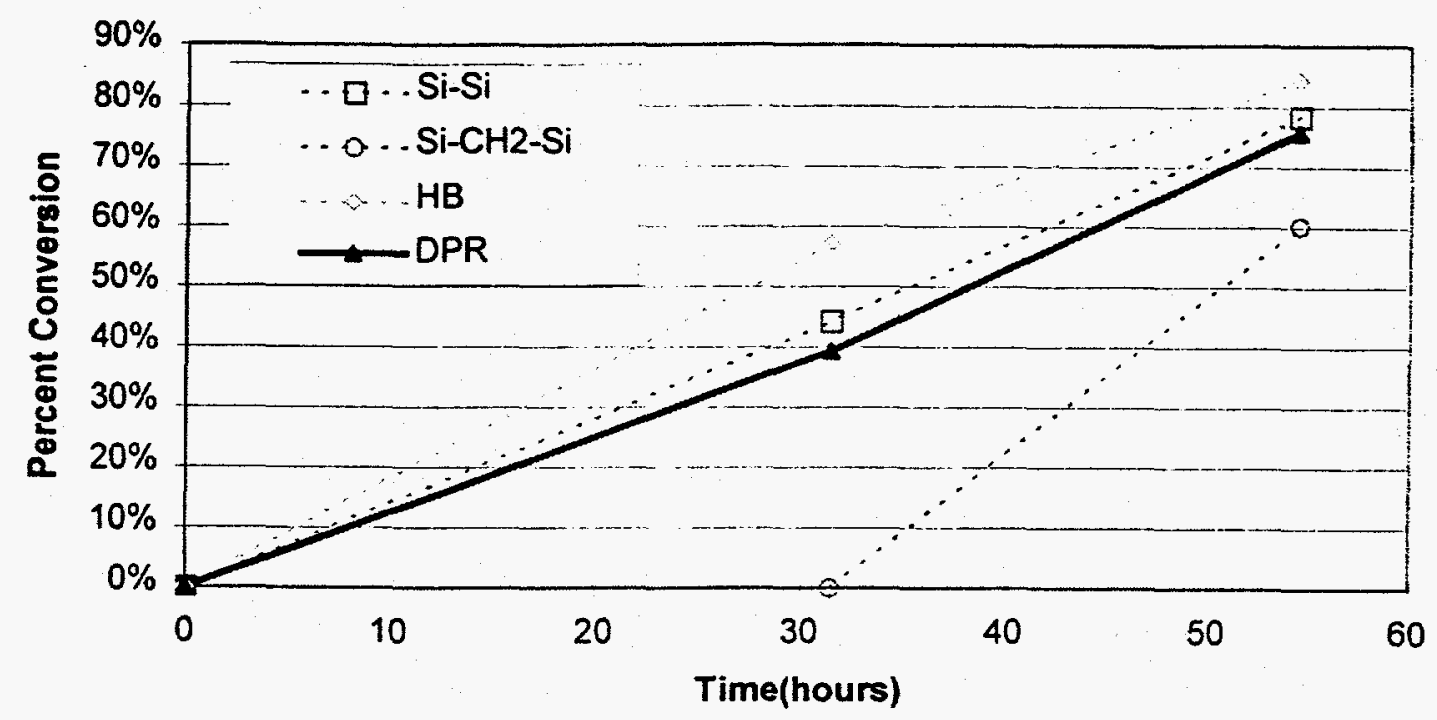

Figure 5: Product Composition During an Experiment in 1996

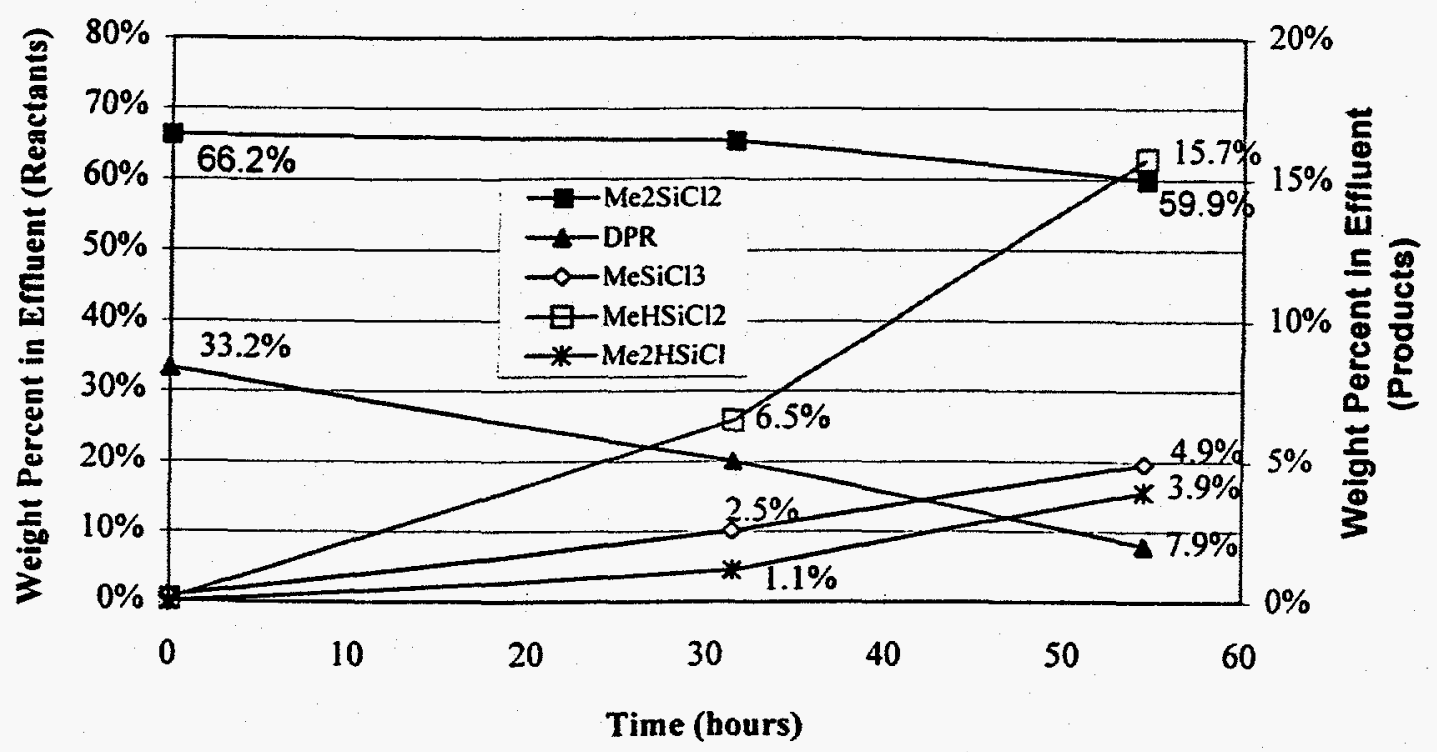




\subsubsection{Pilot Plant Filter}

A filter was used to remove silicon solids from DPR. The filter performed well throughout the life of the Pilot Plant.

Material balances on the Pilot Plant filter unit are discussed in in Internal TIS report [14]. Very small material balance errors were calculated for the filtration of DPR.

\subsubsection{Pilot Plant II Filter Designed Experiment}

A designed experiment was conducted in the Spring of 1997 for the purpose of optimizing filter operation. Construction was still in progress on the reactor portion of the process. This allowed the start-up team to focus solely on filter operations. Both filtrate and filter cake were recycled back to the site's DPR tank during this experiment. The experiment investigated five factors.

1. DPR slurry flow rate to the filter

2. Critical pressure-drop at which filtration would cease

3. Quantity of gas blowdowns per cycle

4. Frequency of rinse

5. Quantity of rinse material

A full-factorial, 32-run experiment was conducted wherein all combinations of the factor's "high" and "low" values were investigated..

\subsubsection{Results}

Maximum DPR throughput was determined during the experiment under the following conditions.

1. Filtrate flow setpoint $=$ high

2. Target $\mathrm{dP}=$ low.

3. Blowdowns per cycle $=$ low.

4. Number of filter rinses $=$ low.

5. Rinse volume was not an influential factor.

In essence, numerous small (low dP) filtration cycles gives more net filtration that a few big (high dP) cycles.

According to the statistics employed by the designed experiment software, the optimized DPR feed to the filter could be twice the design feed rate to the reactor, on average, and the filtrate rate $20 \%$ higher than the design feed rate to the reactor. These rates put the filter capacity above the reactor feed pump capacity, and thus the filter is not the current bottleneck. These data are averages that already account for cycle time.

The average cycle times during experimentation were: Idle $=0.9 \%$, Filtration $=61.4 \%$, Drain $=$ $20.1 \%$, Blowdown $=13.4 \%$, Rinse $=4.3 \%$. This was during "total recycle mode" when the filtrate rate was not limited by the downstream reactor. That is, both filtrate and filter cake were recycled back to the site's DPR tank, and filter rate was not constrained by reactor operation. A cycle through all six steps, start to finish, typically lasts 15 minutes. The relationship between cycle time and reactor through-put is shown in Figure 6. 
Figure 6: Filtration Performance To Support Reactor Through-Put

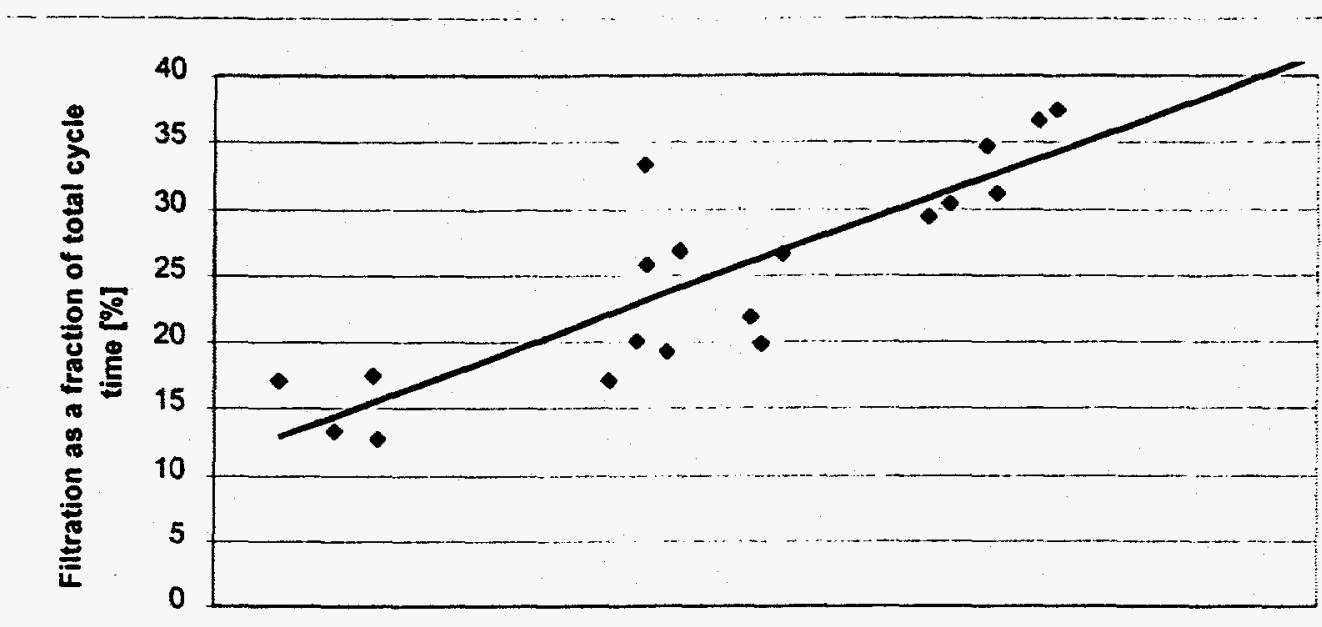

Chlorosilane feed rate to reactor

The "optimum" parameters have been chosen based on maximizing DPR rate. If instead we choose to optimize based on minimizing moisture in the filter cake, different parameters would result. Minimizing filter cake moisture would in effect maximize our filtrate-to-DPR ratio, but not necessarily maximize throughput. To achieve this goal the parameters would be $\mathrm{dP}=$ low, filtrate flow $=$ low, and cycles/rinse $=$ low. Blowdowns did not have a significant impact.

It may be questioned how a $120 \%$ average filtrate flow can be attained when the setpoint is only $125 \%$ and filtration occurs only $60 \%$ of the time. As stated previously, the filtrate is controlled by a recycle control valve. If the recycle valve is $100 \%$ open and the filtrate flow is above $125 \%$, there's nothing that can be done to reduce it. Only as $\mathrm{dP}$ starts to build will the flow drop toward $120 \%$ and the recycle valve start to pinch shut. Filtrate flow, therefore, is typically at or above setpoint throughout the filtration operation - so much so, that when averaged over the duration of the cycle is still greater than the absolute setpoint.

\subsubsection{Pilot Plant II Filter Changeouts}

During the course of start-up, it was necessary to change out the filters twice.

1. The first filter change-out took place on $230 \mathrm{Oct} 97$ after the equivalent of three months' operation. This life cycle was comparable to another similar application at Dow Corning, and seemed reasonable. In retrospect, it was the longest filter life that has been achieved. DPR had been obtained from the site's DPR tank during the experimental start-up phase. The start-up team was not strict about totally recycling the adjoining FBR's DPR only to the filter feed tank during the early days of reactor operation.

2. The second filter change-out took place on 15Dec97 after only one month's equivalent operation. Here, during the latter days of reactor experimentation, we were more strict about total recycle operation. Our hypothesis at this point was that $\mathrm{AlCl}_{3}$ and polysilane build-up shortened the filter life.

3. Filter life cycle has since deteriorated to an unacceptably short length. Solving this problem is a major thrust of the optimization work on-going in 1998.

\subsubsection{Pilot Plant Aluminum Material Balances}

Material balances on aluminum were performed primarily to investigate the fate of $\mathrm{AlCl}_{3}$ in the process. Incoming unfiltered DPR was periodically analyzed for aluminum and determined to contain about $0.6 \%$ by weight $\mathrm{Al}$ on average. This would correspond to about $3 \% \mathrm{AlCl}_{3}$ if all the 
Al present existed as $\mathrm{AlCl}_{3}$. Some of the aluminum could be elemental $\mathrm{Al}$ bound with silicon, or it could be aluminum oxide. Filtered DPR was analyzed to contain as much as $0.5 \% \mathrm{Al}(2.5 \%$ $\mathrm{AlCl}_{3}$ ). Accumulations of $\mathrm{AlCl}_{3}$ in 1995 plugged product condensers and caused numerous shutdowns of the process. Aluminum balances were impossible to close during the 1995 campaigns.

In 1996 the majority of the $\mathrm{AlCl}_{3}$ which was not removed in the filter passed through the reactor and was recovered as a soluble salt dissolved in high boilers in the reboiler of the distillation column. The $\mathrm{Al}$ content of the column bottoms was found to be as high as $2 \% \mathrm{Al}\left(10 \% \mathrm{AlCl}_{3}\right)$. The exact amount of product flow which accumulated in the reboiler before being sent to the product tank was not accurately measured. Based on reactor conversion and the higher volatility of product monomers, about $20 \%$ of the total product flow from the reactor passed through the reboiler as column bottoms.

$\mathrm{AlCl}_{3}$ losses in the Pilot Plant system were no higher than 20\%. The apparent loss of $\mathrm{AlCl}_{3}$ was most likely attributed to plating out in the reactor, but minor amounts also might have accumulated in the lower portion of the distillation column, in piping or in other equipment. A definite improvement in handling $\mathrm{AlCl}_{3}$ over 1995 methods was accomplished by the change in product condensation. Demolition of the Pilot Plant showed very little evidence of $\mathrm{AlCl}_{3}$ deposition in any equipment.

\subsubsection{Pilot Plant II Material Balances}

\subsubsection{General Discussion/Chronology}

Experimental data for the process are compiled using an automated main-frame computer system and captured in spreadsheets. Bi-hourly readings from the distributed control system (DCS) are recorded by hand and used to make operational decisions and verify the data. Operation of the unit in 1997 can be broken down into a number of distinctive experiments based on important changes in run conditions.

Initial experiments were "shakedown runs" with $\mathrm{MCDS}$ and $\mathrm{Me}_{2} \mathrm{SiCl}_{2}$ fed to the process in varying ratios. Also during this time, a 24 hour $\mathrm{DPR} / \mathrm{Me}_{2} \mathrm{SiCl}_{2}$ run was completed during which extensive sampling was initiated. An 11-run designed experiment was then completed in which DPR and $\mathrm{Me}_{2} \mathrm{SiCl}_{2}$ were fed in a $50 / 50 \mathrm{mix}$ to the reactor. A further discussion of the design and results of this experiment will follow. Finally, several low-hydrogen feed runs were completed at the end of operation in 1997 to help determine the effects of hydrogen feed rates, in response to the immediate needs of the full scale design team.

During each of the experimental runs, samples of the feed and product streams were taken and analyzed using gas chromatography. In general, feed samples and reactor bottoms samples were taken every 12 hours and analyzed in the Carrollton plant QA lab. Vapor product from the reactor was typically analyzed every $\mathbf{7 0}$ minutes by a dedicated on-line analyzer with results recorded in the automated main-frame system.

\subsubsection{Data Handling And Assumptions}

In performing material balances during start-up, it was necessary to make assumptions concerning the attainment of steady state, and the suitability of various samples for overall analysis.

First, it was assumed that for a given time period under consideration, the last vapor overheads analysis via the on-line gas chromatograph was representative of steady-state. Often, a set of run conditions (flows, temperatures, feed mix) were maintained for little more than a day. The overhead composition would be monitored as it changed with time, and then as two or three sets of data were observed to be constant, the run was assumed to be at steady state. Overheads analyses are available every 70 minutes via the on-line GC. 
Next, the hydrogen conversion was calculated based on the "vent method", which will be discussed in more detail later in this report. The calculated hydrogen conversion was then used to determine the overall overheads composition, to include unreacted hydrogen. The resultant molecular weight of the overheads stream led to the correction of the overheads flow rate. The overheads flow rate measurement is prone to error because it is a simple orifice-plate device that indicates mass flow indirectly via differential pressure. Using the corrected overheads flow and the known feed mass flows, a bottoms "blowdown" flow is determined by difference. Attempts to determine the bottoms flow using a characteristic flow parameter $\left(C_{v}\right)$ and valve opening were grossly inaccurate.

The final key assumption throughout the experimentation was that the liquid inventory in the reactor was homogeneous, and that samples taken at the end of a run were representative of steady state. In practice, when the overheads composition was observed to attain steady-state, a bottoms liquid sample was taken by the operator. This would typically be the only bottoms sample taken during the run, due to the hazardous nature of that particular sample. Shortly thereafter, new run parameters would be set for the process.

\subsubsection{Typical Results}

Figure 7 depicts the results for a representative run from the reactor designed experiment. Results from this experiment are presented here as an example of the type of results that may be expected for the process. Conversion of DPR is evident from the overall reduction from inlet to outlet of disilanes, silmethylenes, and highboilers. The amount of $\mathrm{Me}_{2} \mathrm{SiCl}_{2}$ present in the reaction mixture from inlet to outlet is essentially unchanged (this general trend will vary depending on the amount of $\mathrm{Me}_{2} \mathrm{SiCl}_{2}$ fed to the process). Finally, the production of valuable low boiling monomers such as $\mathrm{MeHSiCl}_{2}$ and $\mathrm{Me}_{2} \mathrm{HSiCl}$ is evident from the figure. Net production of $\mathrm{MeHSiCl}_{2}$ for this run was roughly $20 \%$ of the overall outlet from the reactor. Production of $\mathrm{Me} . \mathrm{HSiCl}$ was roughly $5 \%$, while that of $\mathrm{MeSiCl}_{3}$ was about $3-4 \%$ of the overall outlet, and that of $\mathrm{Me}_{2} \mathrm{HSiCl}$ and $\mathrm{Me}_{3} \mathrm{SiCl}$ were each around $1 \%$ of the effluent.

Figure 7: Typical Inlet And Outlet Compositions

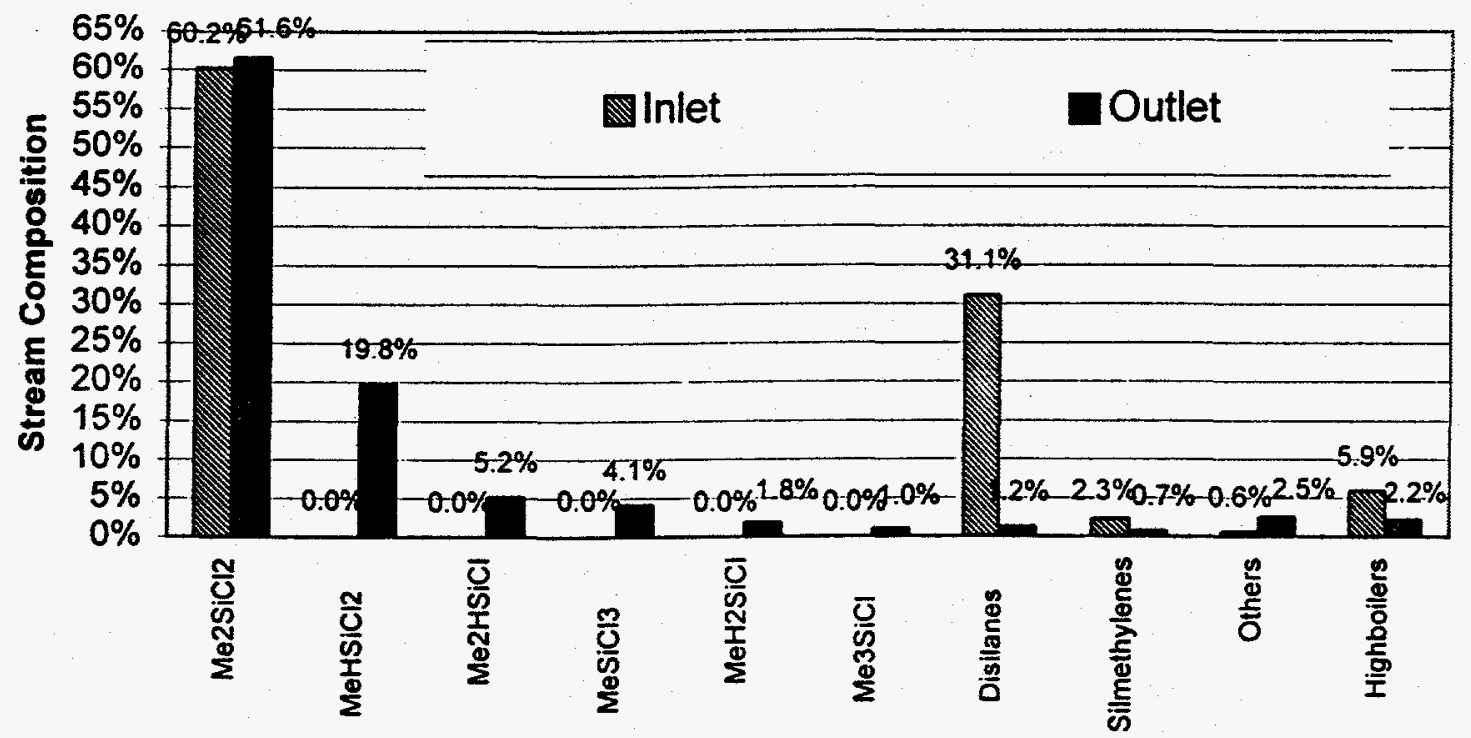




\subsubsection{DPR Conversion}

Conversion is calculated as the difference between the inlet flow and the total outlet flow of each component divided by its inlet flow, and is expressed as a percent. The run sheets for each experiment show conversions for each species in the inlet and outlet of the process, as well as composite conversions for groups such as disilanes, silmethylenes, and highboilers. An overall DPR conversion is calculated as the composite conversion of all of the DPR species.

Figure 7 above illustrates that the bulk of the DPR is the disilane fraction. These species react more quickly than the silmethylene or highboiler fractions and thus contribute the most to DPR conversion. Conversion of disilanes for these experiments ranged from about 90 to almost $100 \%$. In most cases, significant but variable conversion of silmethylenes occurred in these runs, ranging from about 20 to nearly $100 \%$ (excluding an isolated run in which an unexplained five-fold increase in silmethylenes was observed). The amount of highboilers in the overall outlet from the reactor in these experiments typically decreased slightly. but did increase in some cases.

Overall DPR conversion for the various experiments has ranged from just under $60 \%$ to over $90 \%$. Note that conversions were not calculated for some experiments in which important data were not obtained. In most of these cases, this means that a representative bottoms sample was not obtained.

Following startup of the process, an error was found in the identification of peaks on the on-line GC. The main outcome of the subsequent re-identification of peaks for the overhead vapor compositions from each experiment was a slight increase in DPR conversion over those originally calculated.

\subsubsection{Evidence of an induction period}

Induction periods similar to those observed at the Pilot Plant are encountered in the Pilot Plant II reactor when starting the unit from a shut-down state. Here. this phenomena is most often referred to in terms of a period during which the feeds are on to the reactor but the reaction has yet to "kick-off". In most cases, this kick-off has been a very noticeable and measurable event.

Conditions which appear to be important for initiation of the hydrogenolysis reaction with DPR feed are reactor liquid temperature, and relatively high hydrogen to chlorosilane feed rate ratio. In general, approximately 2-12 hour periods at the beginning of a reactor startup have been needed to initiate the reaction. This is highly dependent, however, on the ability to heat the reactor up to the appropriate temperature at an acceptable rate. Due to the poor operational performance of the electric hot oil heater in 1997, the initiation times experienced were probably excessive.

Figure 8 depicts several important reactor measurements over time during a reactor startup on $\mathrm{MCDS}$ and $\mathrm{Me}_{2} \mathrm{SiCl}_{2}$ feeds. The reactor liquid temperature rises very slowly over time during the early part of the period shown as the reactor continues to be heated up in an effort to start the reaction. The chlorosilane feed rate to the reactor is relatively low at about $25 \%$ of design, and the reactor pressure is steady at operating conditions prior to initiation (the first 10-12 minutes shown). At about 4:10 a.m., the reactor liquid temperature has reached what is now believed to be the minimum for initiation.

At this point, the reactor pressure begins to drop $10 \%$ over the next 10 minutes. The reactor pressure then begins to build again and overshoots normal operating pressure by $1 \%$, while the liquid temperature begins to decrease. This trend is believed to signal the initiation of the hydrogenolysis reaction. As the reaction kicks off, the hydrogen that has been flowing through the reactor as an inert gas is suddenly being consumed, which causes the reactor pressure to trend downward rapidly. This happens despite the fact that the overhead pressure control valve is now quickly closing. At this point, disilanes in the feeds are converted to low-boiling chlorosilanes, such as $\mathrm{MeHSiCl}_{2}$, which vaporize. This results in the dropping reactor liquid temperature and subsequent pressure rise in the vessel. A sharp increase in the reactor vapor temperature also 
results, beginning at about 04:35 a.m. At the same time, the reactor outlet vapor flow rises abruptly from about $30 \%$ of design to a peak at about $150 \%$ of design, and then settles to design rates. After reaction initiation has been established, the operator increases chlorosilane flow to the reactor at around 04:40 a.m.

The initial pressure drop and subsequent pressure rise upon initiation should be further discussed. We believe that the drop in pressure can be attributed to differences in the physical properties of hydrogen and the monomers which are produced. For example, if we assume that $\mathrm{MeHSiCl}_{2}$ is the only monomer formed, equimolar quantities of $\mathrm{MeHSiCl}_{2}$ are created in the reaction of $\mathrm{H}_{2}$ with DPR. In a simple gas reaction in which reactants and products had similar properties, this would not necessarily create the pressure swings described. However, $\mathrm{MeHSiCl}_{2}$ is more soluble in the chlorosilane liquid in the reactor and has different vapor-liquid equilibrium properties than hydrogen. Based on this, a pressure drop would result as hydrogen gas is consumed and $\mathrm{MeHSiCl}_{2}$ is produced because each mole of $\mathrm{MeHSiCl}_{2}$ produced will not take the place of each mole of hydrogen consumed. Rather, some amount of $\mathrm{MeHSiCl}_{2}$ will build up in the liquid before gas-liquid equilibrium in the chlorosilane mixture is reached. At this point, steady flow of $\mathrm{MeHSiCl}_{2}$ will begin.

Figure 8: Reaction Initiation, 08 Oct 97

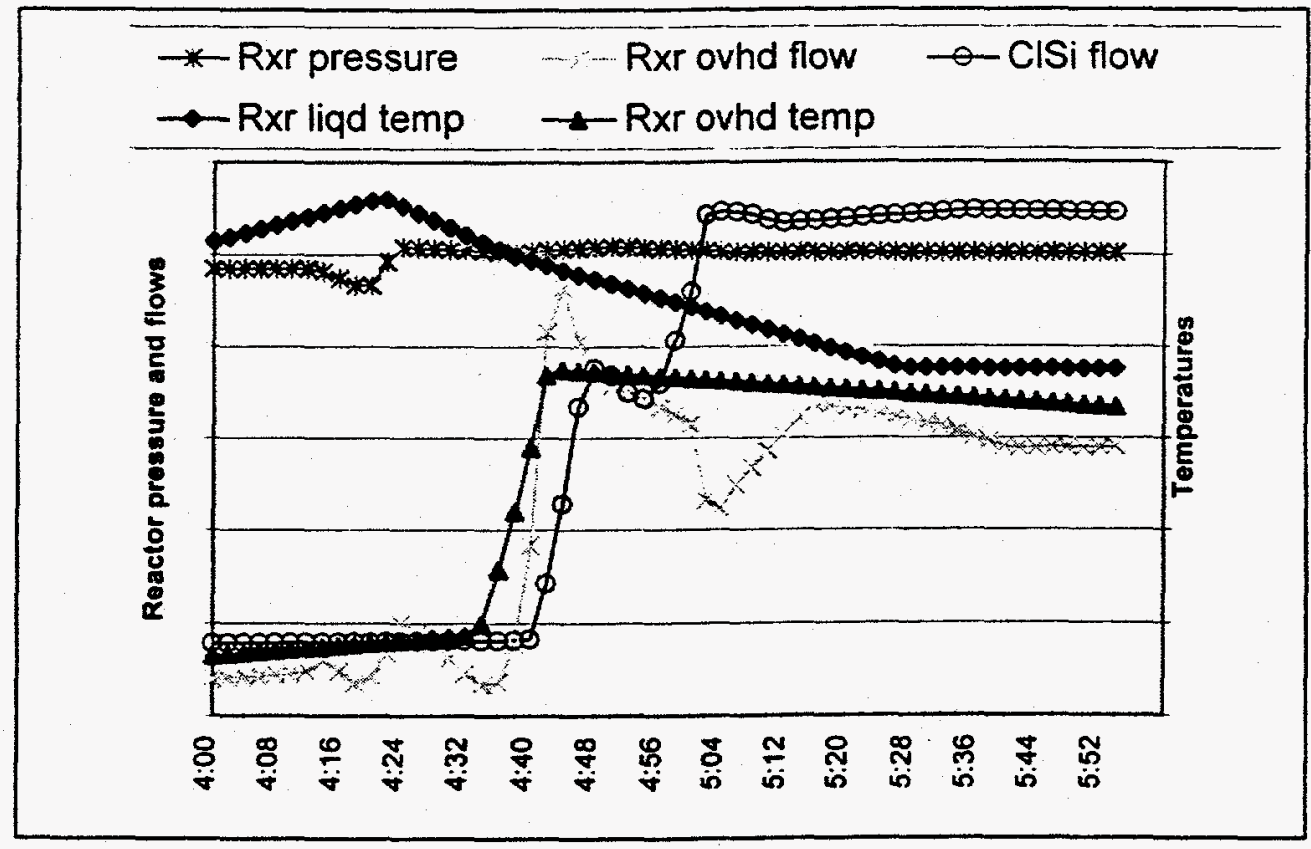

Figure 9 is analogous to the figure above, but shows data for a later reactor startup on DPR and $\mathrm{Me}_{2} \mathrm{SiCl}_{2}$ feeds. The same general trends in reactor pressure, liquid temperature, and vapor outlet flow can be seen for this time period. In fact, the pressure drop and subsequent rise for this case is even more pronounced than in the previous example. This figure does show a slight difference in the reactor vapor temperature during the initiation. A unique, initial drop in the temperature is followed by a sharp rise similar to that in the previous trend. This may have been caused by the fact that the hydrogen feeds were preheated to a higher temperature in the later runs than in earlier runs. This explains the higher vapor temperature in the second case prior to initiation. The subsequent drop results from the hot hydrogen being fully consumed, momentarily, by the initiating reaction, before the lower boiling chlorosilanes were being produced and vaporized in large quantities. 


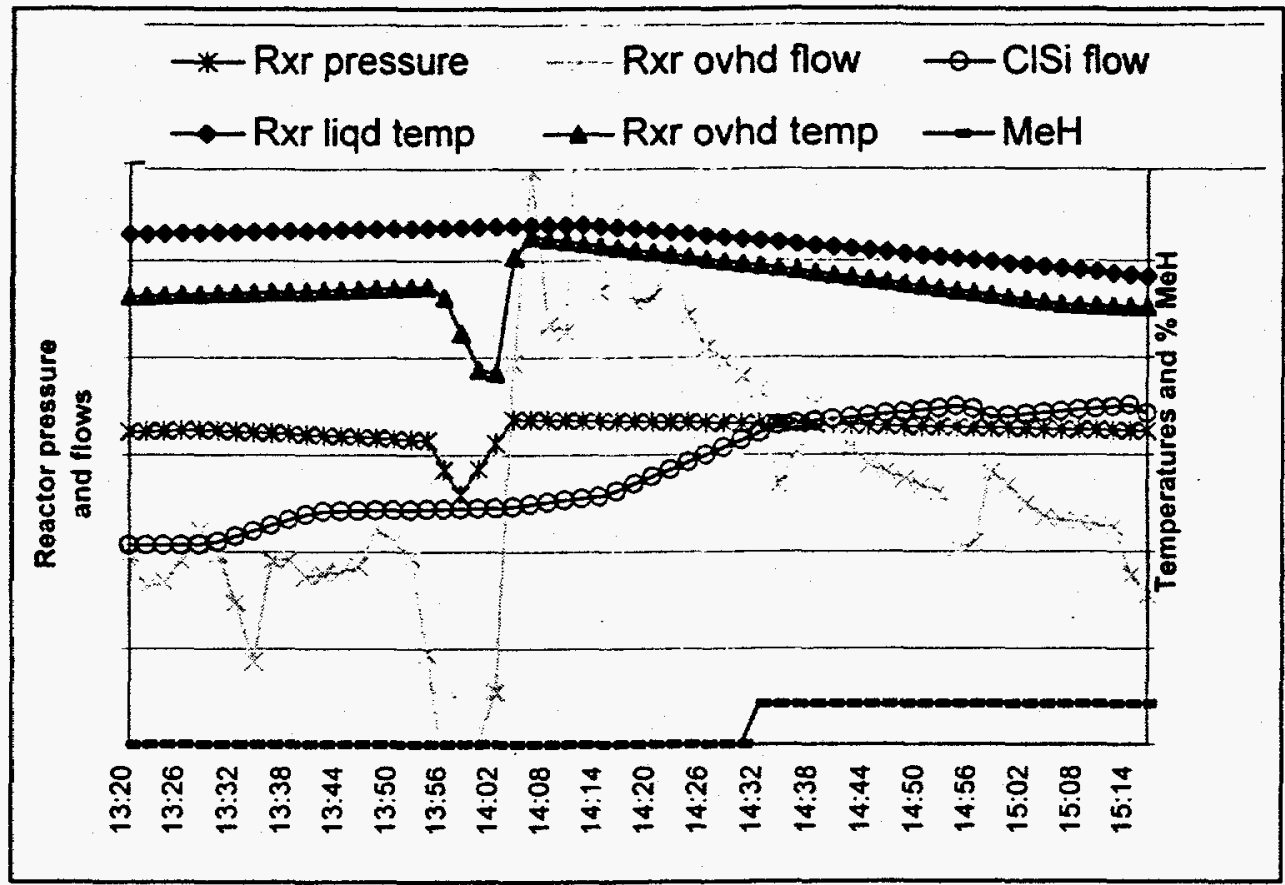

The percentage of $\mathrm{MeHSiCl}_{2}$ in the vapor product during the time period is also included in the figure. The on-line analyzer shows a sharp increase in $\mathrm{MeHSiCl}_{2}$ leaving the reactor in the first sample taken after the initiation. $\mathrm{MeHSiCl}_{2}$ in the vapor outlet stream rises after starting at essentially zero. This is an added signal that the reaction has begun. Another strong signal of initiation is an increase in $\mathrm{MeHSiCl}_{2}$ percentage in the adjoining FBR's "Process A" crude (PAC).

Experience with this phenomenon and ongoing support from the laboratory work may lend insight into how to more easily and quickly establish reaction in the reactor process. Doing 50 will minimize both hydrogen and chlorosilane waste from the reactor and impact the economics of the technology, especially for a full scale process unit. Some suggestions for better, more efficient initiation are to keep feed rates very low while heating the system up to initiation temperature, after initially filling the reactor to the desired level with liquid. This will decrease waste and better utilize heat input to the system to more quickly bring the existing inventory up to temperature. This approach could be extended to include a batch or semi-batch startup scheme. A semi-batch startup is probably preferred since maintaining hydrogen flow to the system is believed to be important during this period.

\subsubsection{Hydrogen Conversion}

Hydrogen is necessary for the reaction to take place. It is consumed in the reaction, joining with silicon molecules in the chlorosilanes to form "SiH-containing species" such as $\mathrm{MeHSiCl}_{2}$, $\mathrm{Me}_{2} \mathrm{HSiCl}$, and $\mathrm{MeH}_{2} \mathrm{SiCl}$.

Two methods are used to analyze the amount of hydrogen converted in the process to form these monomers. The "vent method" is to analyze for hydrogen in the process vent. This allows for a total hydrogen balance on the FBR area. The difference in the amount of hydrogen fed to Pilot Plant II and that which leaves with the FBR vent stream is the amount of hydrogen used in the reaction. Fortunately, the amount of hydrogen in the FBR vent due to FBR operation alone is both small and predictable. As a second method, "AdHSi", the number of hydrogen molecules 
added to silicon molecules in the hydrogenolysis reaction can be determined based on the component mass balances for the process. From this data, conversion of hydrogen to monomers may be calculated.

The FBR vent and the reactor outlet flow meters are orifice flow meters. These devices calculate a flow rate using differential pressure across an orifice plate, and are based on the properties of the fluid in the stream. Inherent in the calculation is the assumption of a fluid density and molecular weight. For many fluids and stream compositions orifice flow meters give accurate flow readings. For these three flow meters, however, errors have been observed based on fluctuating stream compositions. In particular, the amount of hydrogen in the respective streams at a given time has caused errors in the flow readings. For this reason, the flow rates as read by the meters have been corrected based on known stream compositions from on-line analyzers. Corrected flow rates have then been used in the analyses discussed here.

Figure 9 shows hydrogen flow rates in the FBR vent in October and November. Prior to Pilot Plant II startup in early October and during its shutdown periods, particularly late October through early November, there is essentially no hydrogen in the FBR vent. However, during Pilot Plant II operation, hydrogen in the FBR vent increases dramatically. This is because more than half of the hydrogen fed to the process is not used in the hydrogenolysis reaction. Comparing hydrogen fed with hydrogen in the vent, after first correcting for the baseline hydrogen vent rate from FBR, gives dependable hydrogen conversion data.

Hydrogenated monomers produced in Pilot Plant II are detected by the on-line vapor analyzer and used to calculate hydrogen conversion by the "AdHSi method" for the process. Upward trends in the adjoining FBR's PAC $\mathrm{MeHSiCl}_{2}$ and $\mathrm{Me}_{2} \mathrm{HSiCl}$ are also seen when Pilot Plant II is on-line, and these may be used as supporting data.

Figure 10: Hydrogen Flows, Oct - Nov 97

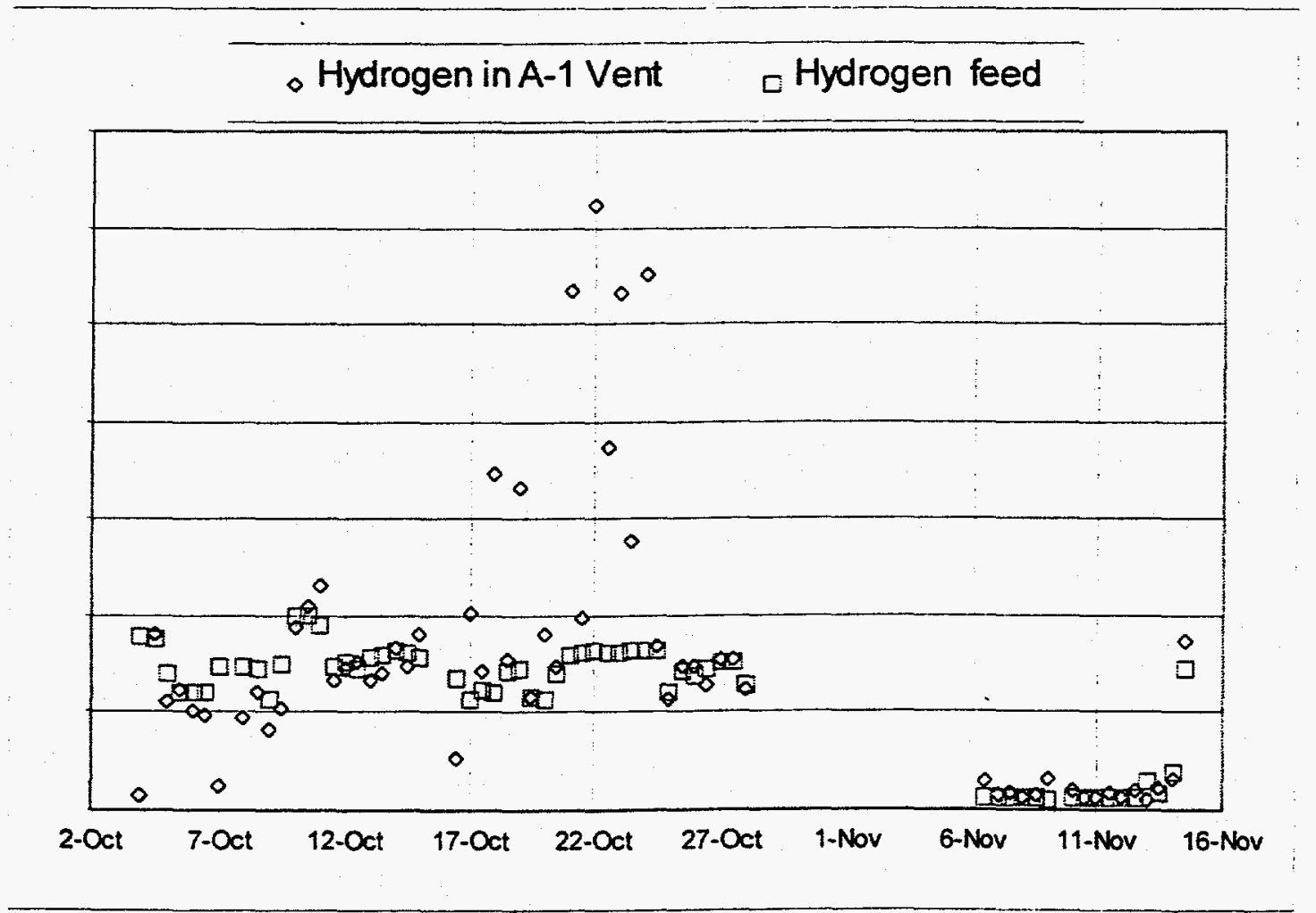


Figures 11 and 12 show 12 -hour averages of the percent $\mathrm{MeHSiCl}_{2}$ and $\mathrm{Me}_{2} \mathrm{HSiCl}$, respectively, in the adjoining FBR's PAC and Pilot Plant II overheads vapor. The amount of these monomers in the overheads vapor from the hydrogenolysis reactor is an order of magnitude higher than in the FBR. The trends in $\mathrm{MeHSiCl}_{2}$ and $\mathrm{Me}_{2} \mathrm{HSiCl}$ level in each of these streams can be compared despite their approximate 10-fold differences. As plotted, the amounts of each monomer are clustered together throughout the time period, and changes of each monomer in one stream are seen in the other stream. The order of magnitude differences in the percentages is easily explained by the typical magnitudes of the flow rates for each of the streams under investigation. Depending on the mode of operation of the adjoining FBRs (and also on the Commerical Plant operation), PAC flows are roughly 8 to 15 times that of the overhead flow from the hydrogenolysis reactor.

Figure 11: MeH Production, Oct - Dec 97

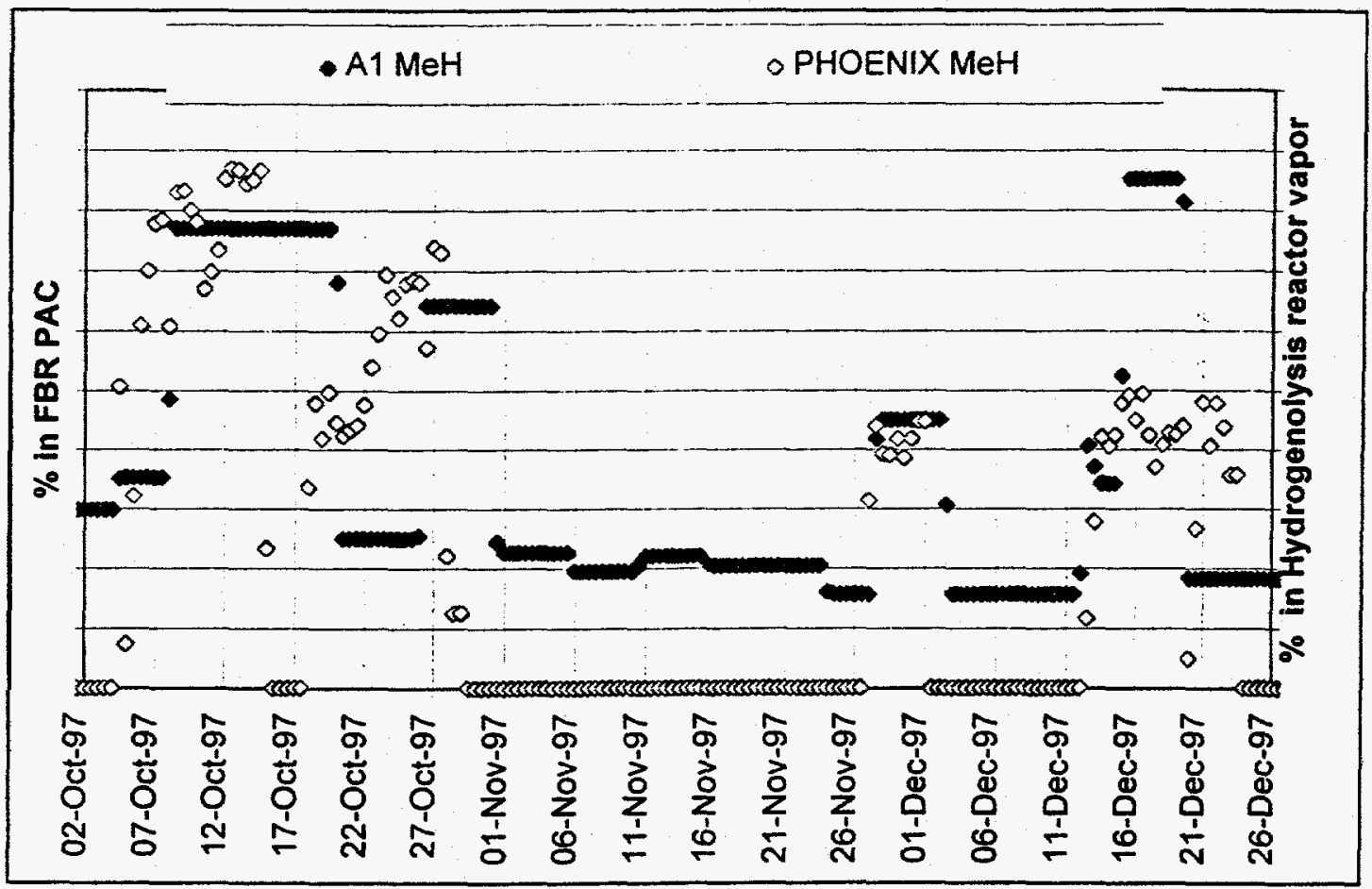




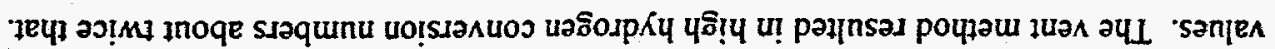

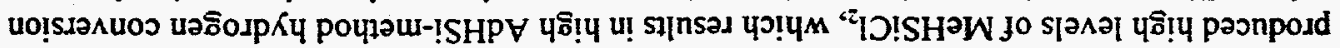

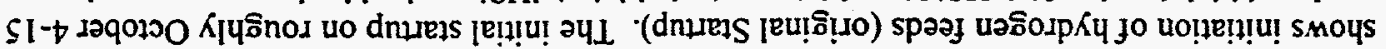

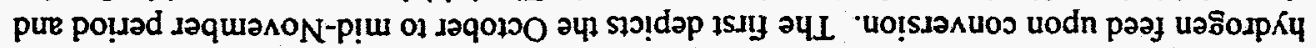

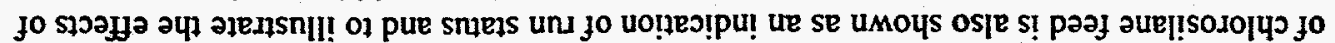

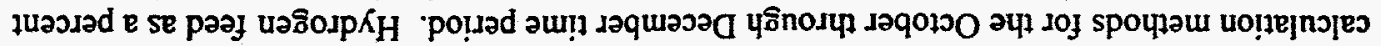

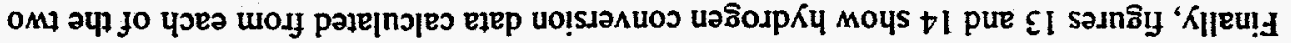

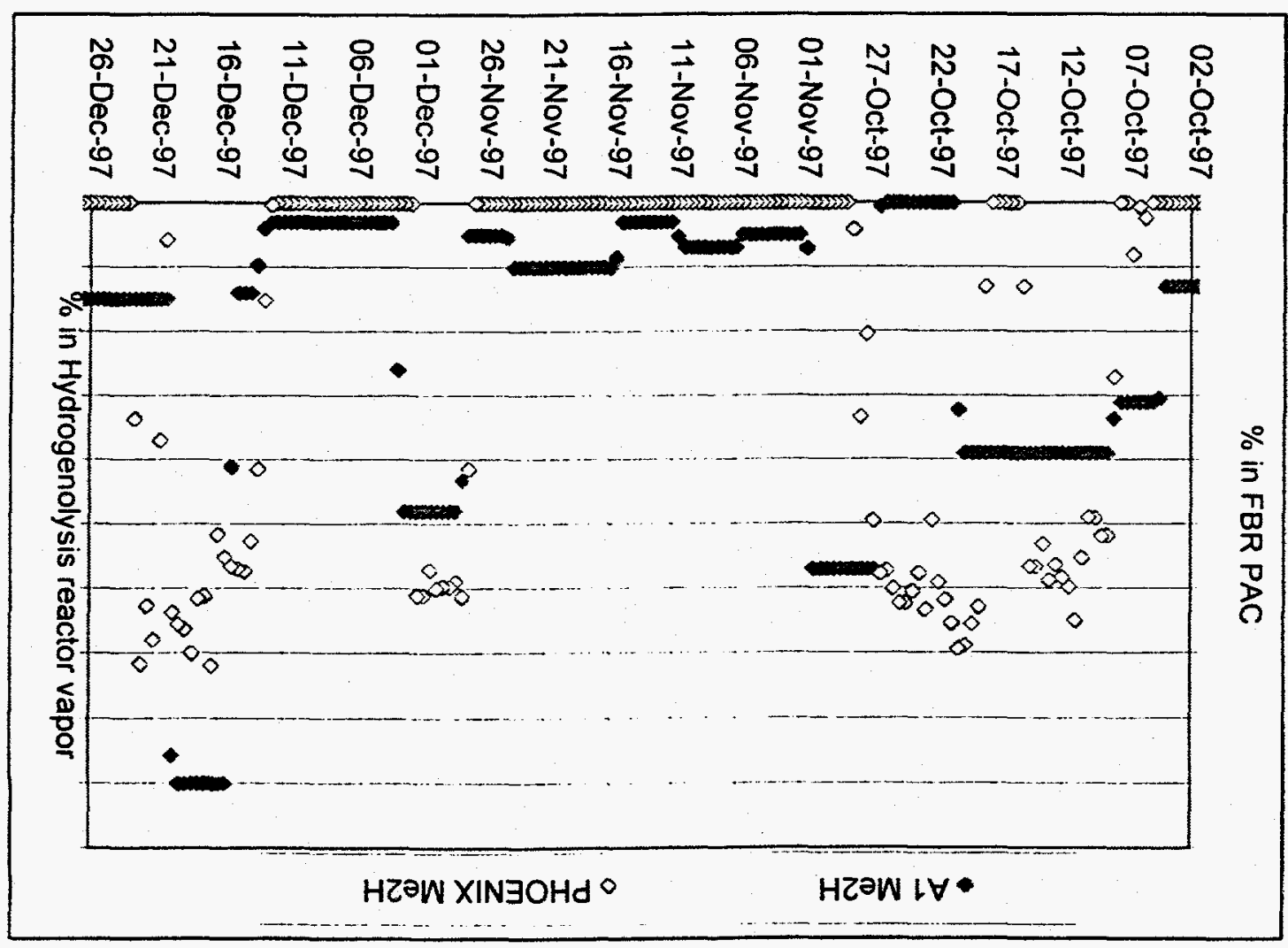

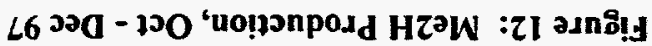


Figure 13: Hydrogen Conversion, Oct - Nov 97

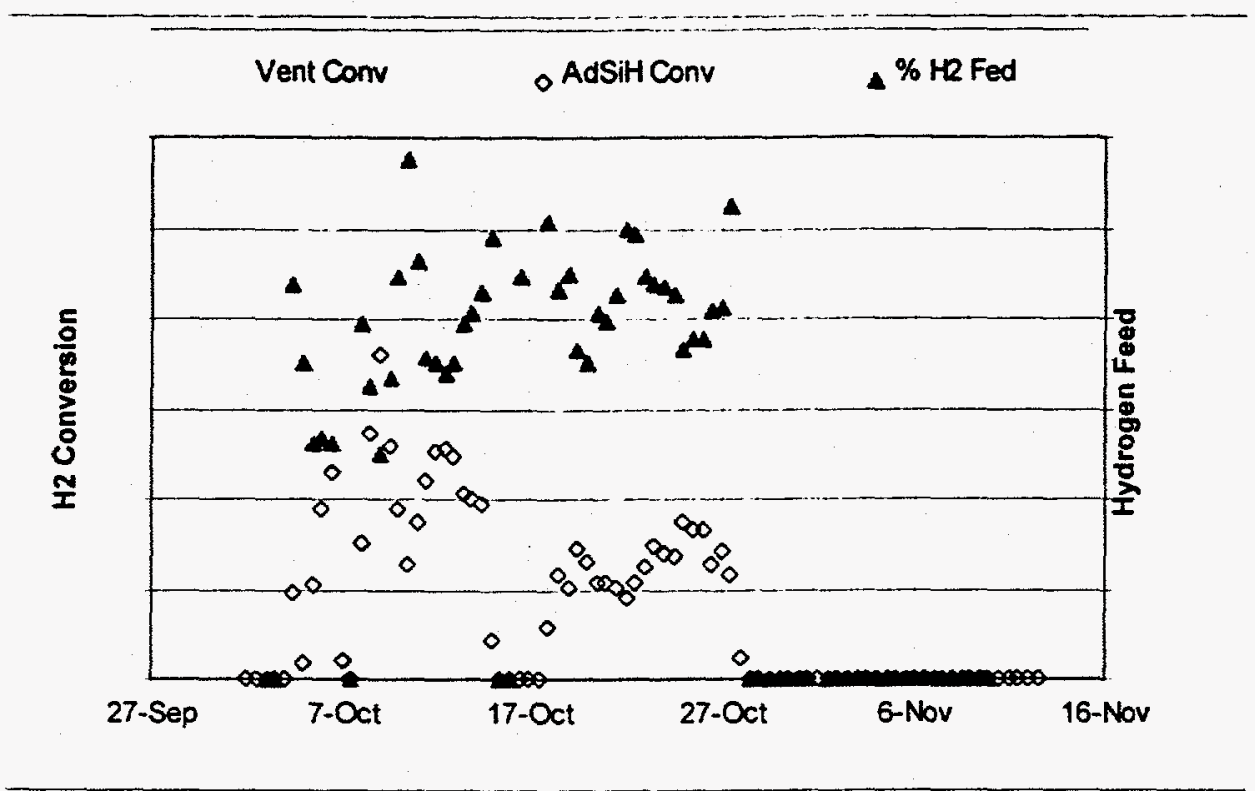

Figure 14: Hydrogen Conversion, Nov - Dec 97

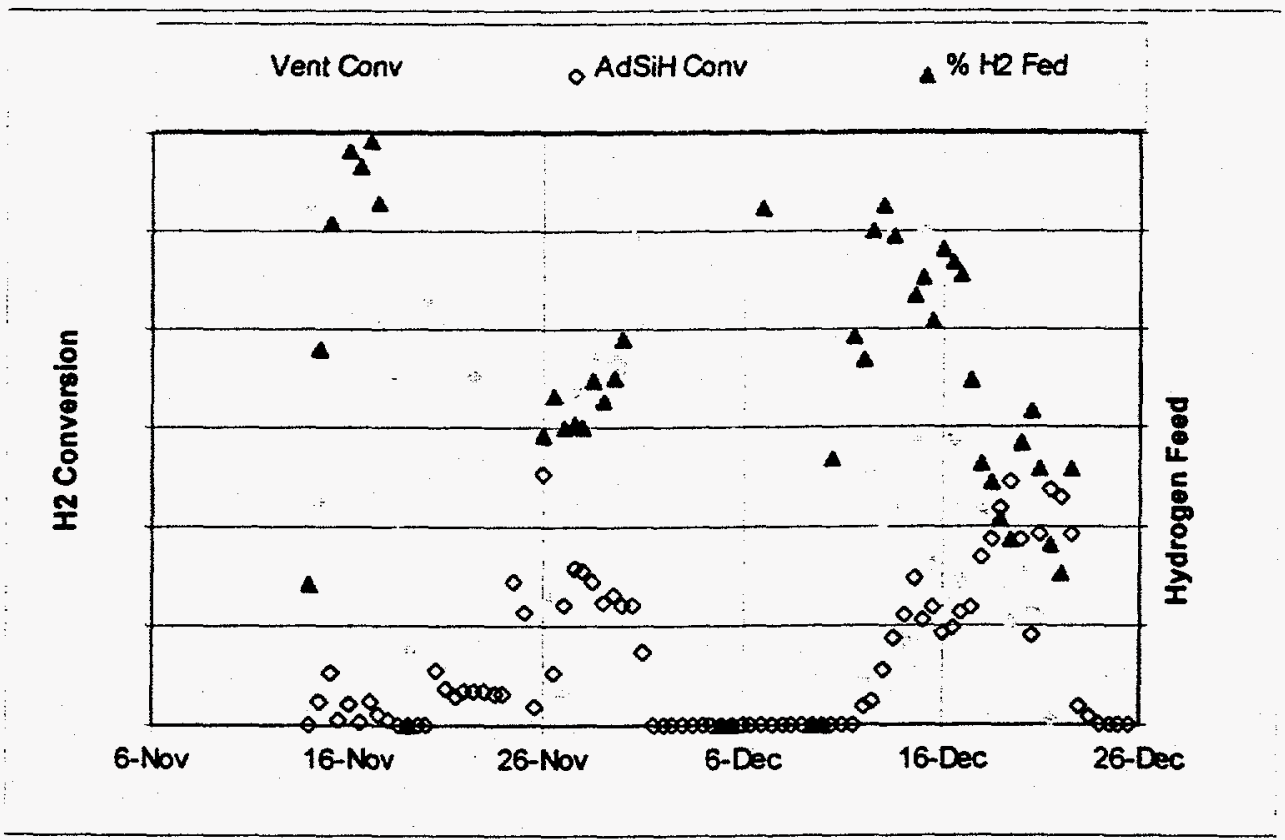

Initial DPR experiments in mid to late October produced slightly less SiH-containing monomers, resulting in low hydrogen conversions. Vent method conversions also dropped for this time period. The important point to notice about these data is that the trends in calculated conversion for either method are quite similar, despite the actual conversion numbers obtained. In either case, the conversions calculated from the vent method for these operating periods were roughly twice those as calculated by the AdHSi method. These differences may be due to errors in the respective methods used, or to consumption or losses of hydrogen not directly related to the production of $\mathrm{SiH}$-containing monomers. This could include actual losses of hydrogen or, more likely, unspecified side reactions in which hydrogen is consumed. 
Possible effects of hydrogen feed can also be seen in the trends for each calculation method. In general higher hydrogen to chlorosilane feed ratios result in higher hydrogen conversion. For instance, from October 17-22, 12-hour average hydrogen feed initially decreases, then rises back up by the end of the period During this same period, AdHSi conversion starts low, rises, and then

falls back to where it started.. Finally, vent conversion rises to almost twice it's beginning value before falling back to its original level. Again, the general trends in this data show, as would be expected, that hydrogen conversion will decrease as more excess hydrogen is fed to the reaction system.

Figure 14 shows similar data for the second operation period. Extended run periods in this time frame were from November 26-December 1, and December 10-23. For the first of these periods, vent method conversion was again two or more times that calculated using the AdHSi method. During the second extended run period, hydrogen feed began high, and steadily was lowered. Conversion of hydrogen during this period was roughly the same for both calculation methods. For the AdHSi method, conversion increased with decreasing hydrogen feed, as expected and as shown for both methods previously. For the vent method, the data is scattered throughout the range with a slight downward trend as hydrogen feed decreased. This is not as would be expected from theory or previous experience and suggests errors in the calculation method during the period.

In all, the data for hydrogen conversion in the reactor is quite variable. Intrinsic errors in the measurement techniques and necessary assumptions made in the two calculation methods contribute to this variability. In addition, a trend towards higher conversion for lower hydrogen feed ratios has been shown in most cases. Further refinement of the conversion measurement and calculation methods is needed for more reliable data to be collected in the future.

\subsubsection{Effects of Feed Composition Changes}

Feed composition changes have had a significant impact on reactor results in the laboratory and Pilot Plant hydrogenolysis experimentation. During the Startup of Pilot Plant II, feed composition changes consisted of feeding varying ratios of $\mathrm{Me}_{2} \mathrm{SiCl}_{2}$ with either DPR or MCDS. No changes in the monomer which was co-fed to the reactor were made.

The full effects of changes in feed composition can not be seen because adequate reactor bottoms liquid samples were not taken during the runs outside of the designed experiment. Based on this, a complete mass balance cannot be calculated for each of the runs in which feeds were not standard. Differences in the product mix from the other runs can be investigated, however, simply by comparing the vapor product stream compositions.

Figure 15 shows the net vapor outlet composition for various feed scenarios. This takes into account the percentage of $\mathrm{Me}_{2} \mathrm{SiCl}_{2}$ which is in the feed and subtracts it from the $\mathrm{Me}_{2} \mathrm{SiCl}_{2}$ in the vapor outlet to give the composition of the net monomer stream produced in the reactor from DPR hydrogenolysis and rearrangement. These numbers do not take into account monomers in the bottoms flow, nor do they account for variances in the actual feed composition from the specified $\mathrm{DPR} / \mathrm{Me}_{2} \mathrm{SiCl}_{2}$ ratio. For this reason, they do not necessarily represent all of the pertinent data for the experiments. They do, however, suggest some important qualitative information.

For instance, the net increase in $\mathrm{Me}_{2} \mathrm{SiCl}_{2}$ from feed to vapor product appears to be the same regardless of feed composition. Net production of $\mathrm{MeHSiCl}_{2}$ shows some signs of being affected by feed composition. Net production of $\mathrm{Me}_{2} \mathrm{HSiCl}$ appears to increase with $\% \mathrm{Me}_{2} \mathrm{SiCl}_{2}$ in the feed. $\mathrm{Net} \mathrm{MeSiCl}_{3}$ and net $\mathrm{MeH}_{2} \mathrm{SiCl}$ are both quite low. Both of these monomers appear to increase with increased silmethylenes/highboilers in the feed (e.g. DPR vs. MCDS or higher $\% D P R$ ). Net $\mathrm{Me}_{3} \mathrm{SiCl}$ production is very low and appears to decrease with decreased $\mathrm{Me}_{2} \mathrm{SiCl}_{2}$ and DPR in the feed. 
Figure 15: Net Vapor Product Composition For Various Feeds

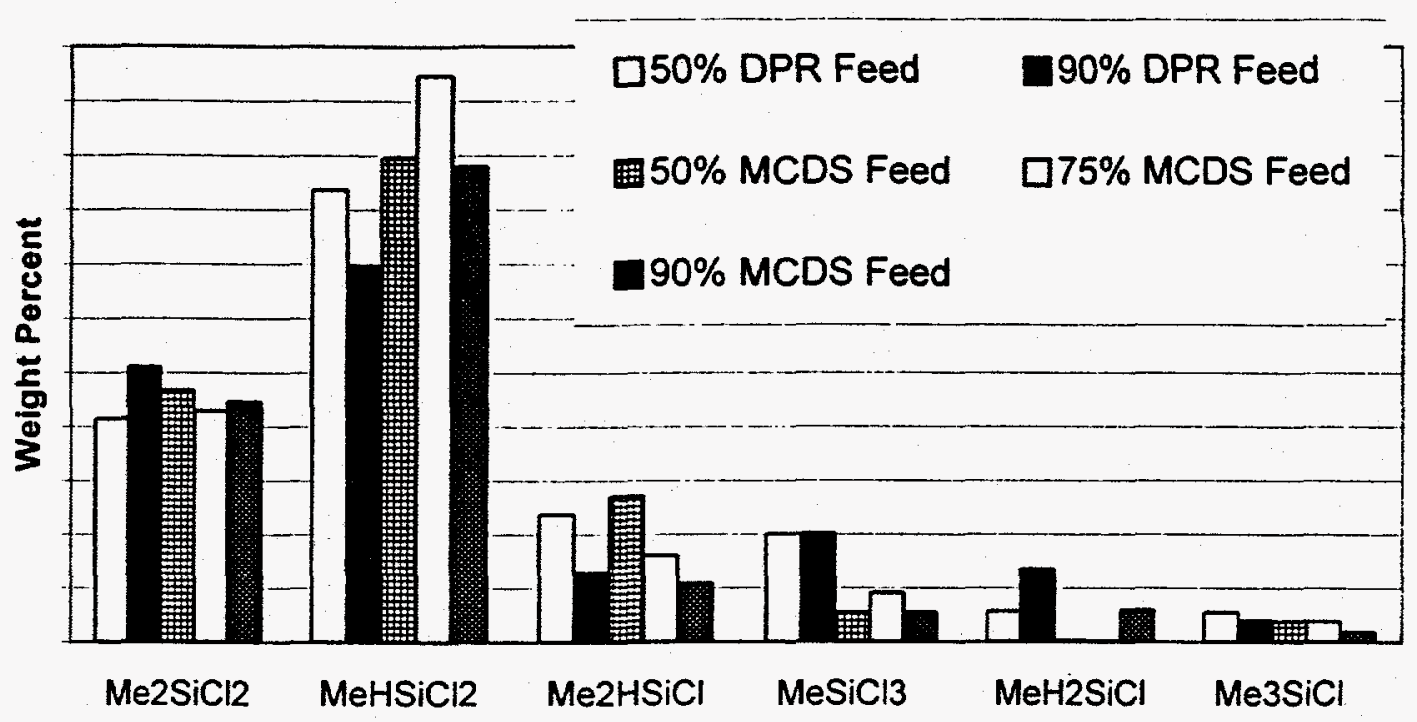

\subsection{Energy Balances}

\subsubsection{Pilot Plant}

\subsubsection{General}

Energy balances were conducted around the Pilot Plant reactor to determine the heat of reaction. This was important for scale-up because a highly endothermic reaction could require a large process heater, and a highly exothermic reaction could prove to be a safety hazard.

\subsubsection{Heat of Reaction Estimated from Heats of Formation}

Theoretical calculation of the heat of reaction was difficult to perform based on the complexity of the reaction, various uncertainties regarding how the reaction proceeds, and the lack of complete physical property data for the chemical species involved. Figure 16 depicts the process on a diagram of enthalpy versus temperature. 
Figure 16: Reaction Enthalpy

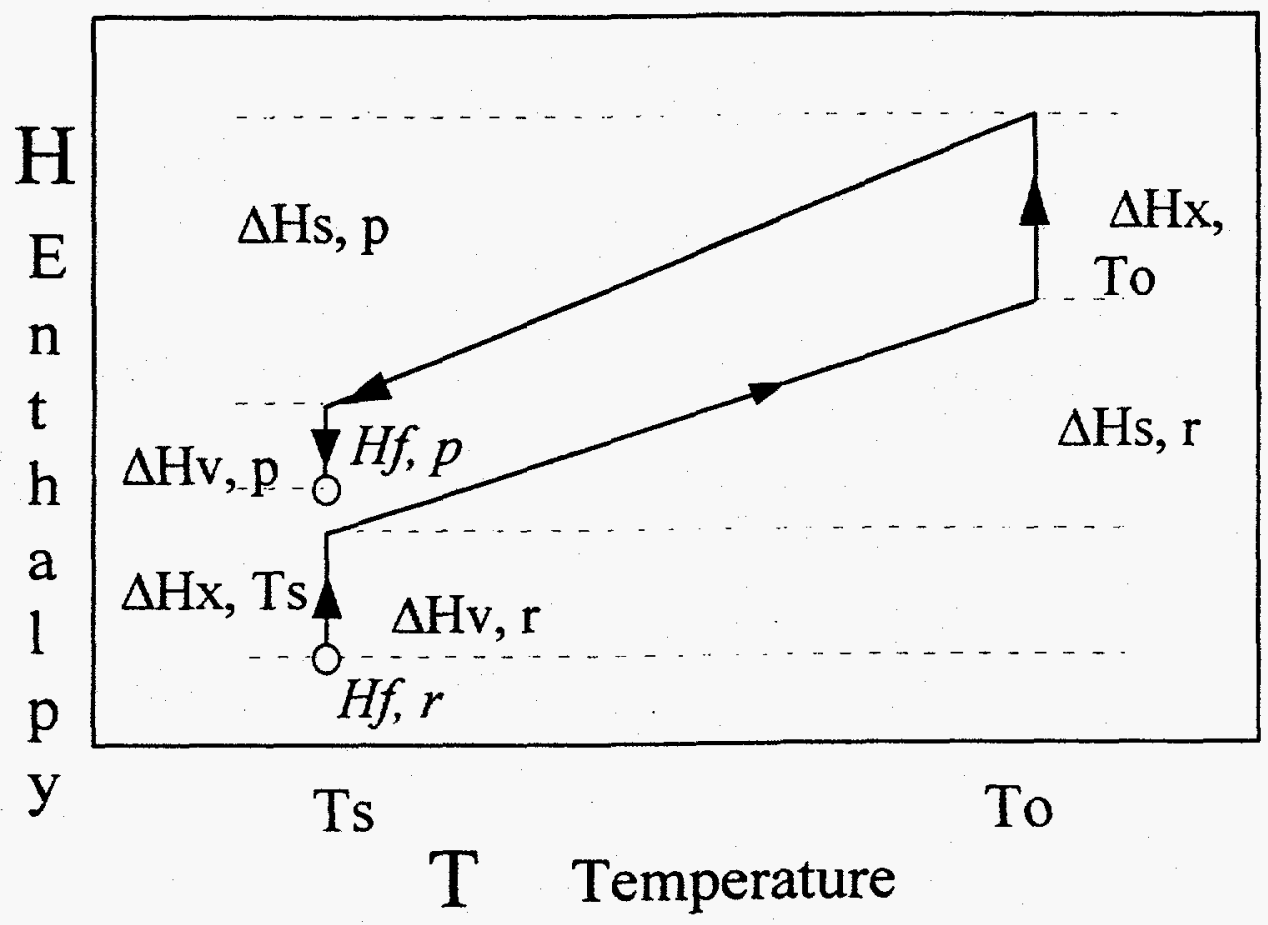

From the figure, the heat of reaction at operating temperature (To) can be calculated by the following equation:

$\Delta H x, T_{0}=H f, p+\Delta H v, p+\Delta H s, p-\Delta H s, r-\Delta H v, r-H f, r$ where $\mathrm{x}$-reaction, f-formation, $v$-vaporization, s-sensible, p-products, and r-reactants.

Estimating the reaction enthalpy in this manner yields the heat of reaction at standard pressure. Because no physical properties data (heat capacities, heat of vaporization, phase diagram with boiling points) are available at operating temperature and pressure, the nearest available data are used. Using this method, estimates of the heat of reaction for typical 1995 and 1996 runs were calculated. Inlet and outlet compositions were used to sum the enthalpy for the reactants and products. Necessary physical properties data for species involved were obtained from the Dow Corning physical properties database. The heat of reaction estimated using this method was slightly endothermic.

The same method was used to estimate the heat of reaction for a number of simplified potential reaction steps, each of which could contribute to the overall DPR hydrogenolysis reaction. These reactions were also found, theoretically, to be either endothermic or only slightly exothermic.

\subsubsection{Heat of Reaction Estimated from Energy Balances and Actual Process Data}

The heat of reaction was estimated from actual Pilot Plant data in the following manner. The amount of heat input to the system was calculated either from the change in temperature of the Syltherm $\otimes 800$ as it passed through the heater or as a function of the heater power. The heat transferred to both the chlorosilane and hydrogen feeds was calculated based on the temperature change of each stream as it passed through each respective feed preheater and subtracted from the heat input. Heat losses from the system were estimated and also subtracted from the heat input. This gave the amount of heat which was left to vaporize the reactants in the reactor and either 
supply or remove heat from the reaction. An estimate of the heat of vaporization of the reactants was subtracted to give a final estimate of the heat of reaction.

To better estimate the heat losses from the system, the above procedure was carried out for the process with actual data from a period when hydrogen was fed to the reactor at full temperature but no chlorosilane feeds were initiated. Thus, an estimate of heat losses from the system was obtained simply as the difference between the heat input and the amount of heat transferred to the hydrogen feeds. Using this method, the heat of reaction was estimated to be slightly endothermic. Experience and results from 1996 runs were similar.

\subsubsection{Pilot Plant II}

\subsubsection{Utilities}

Energy is transferred in Pilot Plant II from the electric heater to the Syltherm ${ }^{8} 800$ heat transfer oil. The hot oil then transfers the energy into the process at the feed preheaters and the reactor jacket. Energy balance calculations have been completed to provide insight into the operation of the preheaters, and provide valuable data regarding heat transfer at the reactor which, in turn, can be used to estimate the heat of the reaction.

Energy balance calculations are performed via the automated main-frame system for Pilot Plant II as the process operates. The energy supplied by the Syltherm $\otimes 800$ hot oil system is determined and compared to the energy transferred to the hydrogen preheater, chlorosilane preheater, and hydrogenolysis reactor by the hot oil.

For the Syltherm $\circledast 800$ system, $\mathrm{H}_{2}$ preheater, chlorosilane preheater, and reactor, the energy use was calculated by Syltherm $\otimes$ flow measurement, heat capacity and temperature differences.

\subsubsection{Heat Losses}

To effectively calculate an energy balance around the entire process, it is necessary to first determine the ambient heat losses from the system which are typical during operation. Overall heat losses are determined as the difference between the hot oil system energy and the sum of the energies of the three main process heat transfer units. Figure 17 shows the sum of the preheaters and reactor energies as it varies with time, along with the hot oil system energy and overall ambient energy losses. 
Figure 17: Heat Transfer Summary

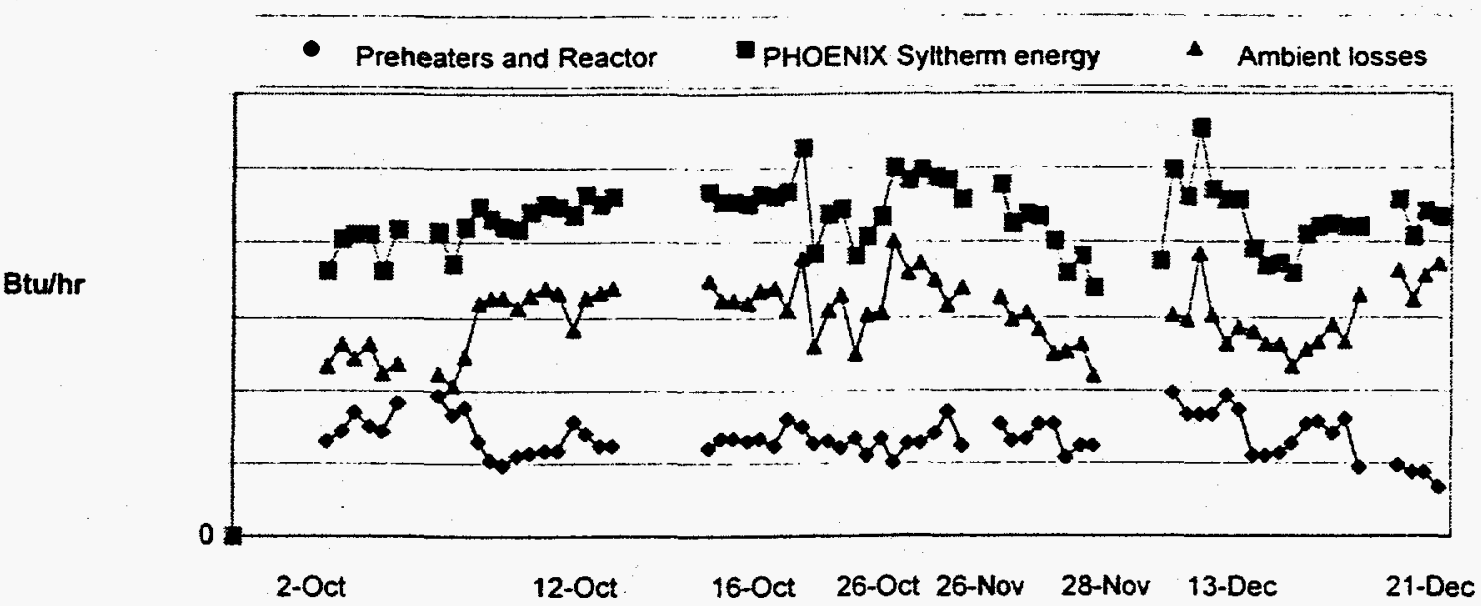

Each data point represents the 12 hour average for the measured parameter. Long shutdown periods have been deleted from the graph, while short shutdowns are evident as breaks in the data trends. The heat transfer data is quite variable. Much of this variability is because feed conditions were changed approximately every 12 hours during the start-up's experimental period. Changes in feed rates for both chlorosilanes and hydrogen affect the data. More importantly, steady state conditions are met and maintained only for several hours and not for several days. Therefore, the individual points on Figure 17 are, for the most part, averages for individual experiment runs with slightly different conditions.

Overall energy losses from the process are calculated as the difference between the heat input to the hot oil system and the sum of the heat transferred to the three units described above. Heat losses from the system averaged over $60 \%$ of the total heat input to the system.

Estimated losses for each piece of equipment are also calculated based on the difference between the heat duty calculated on the oil side of the unit and the heat duty calculated on the process side of the equipment. The process side duties measure actual heat transferred to the process but also contain more inherent error due to uncertain specific heats and slightly more variable temperatures. The following equations are used to calculate heat transferred to the process side of the respective units:

General Equation - process energy of a unit operation :

Hydrogen Preheater: (Hydrogen flow) $x$ (Hydrogen heat capacity) $x$ (Hydrogen temperature out of preheater - Assumed Hydrogen temperature in to preheater)

Chlorosilane Preheater: (Chlorosilane flow) $x$ (Chlorosilane heat capacity) $x$ (Chlorosilane temperature out of preheater-Chlorosilane temperature in to preheater)

Reactor: see section on heat of reaction

Table 5 lists energy duties for the hydrogen preheater, chlorosilane preheater and reactor jacket. These data are averaged actual data taken from the process during the start-up period. 
Table 5: Energy Balance Information (all unitless)

\begin{tabular}{|l|c|c|c|}
\hline Energy Duties & Hydrogen Preheater & Chlorosilane Preheater & Reactor \\
\hline Design & 6 & 3 & 5 \\
\hline Process Side Actual & 1 & 3 & 5 \\
\hline Syltherm Side Actual & 2 & 4 & 12 \\
\hline Estimated Losses & 1 & 1 & 6 \\
\hline
\end{tabular}

Hydrogen flows were designed to be two to three times greater than the normal operating flows established during start-up. This partially explains the difference between design and actual heat transfer to the hydrogen feed stream. Elsewhere, the design duties agree quite well with the actual process heat duties. Significant differences between the hot oil and process side energies for the three units, particularly the reactor, result in large ambient heat losses from the three units.

Thus, overall heat losses from the system are roughly $65 \%$ of the supplied energy from the electric hot oil heater. About $15 \%$ of this can be attributed to individual unit, while the remaining $50 \%$ are unspecified losses. For comparison, heat losses for the Pilot Plant process were estimated at approximately $40-60 \%$ of the total heat supplied to the system from the hot oil electric heater.

\subsubsection{Heat Of Reaction}

During operation of the reactor, the heat of reaction can be calculated as shown in the equation below:

\section{Overall heat balance equation:}

$Q_{\text {reactor, hot oil }}=Q_{\text {loss }}+Q_{\text {reaction }}+Q_{\text {process }}$

and $Q_{\text {process }}=Q_{\text {sensible, liquid }}+Q_{\text {vaporization }}+Q_{\text {sensible, vapor }}$

In the above equations, the liquid sensible heat is the energy needed to heat the reactor feed stream from the preheater temperature to the reactor temperature; the heat of vaporization is the energy needed to vaporize the reactor contents at process conditions; and the vapor sensible heat is the energy needed to heat the vapor from its original temperature (or that of the liquid) to the reactor vapor space temperature. Each of these quantities may be estimated based on known specific heats and heats of vaporization for the materials involved.

The typical estimated heat duty for the hot oil side of the reactor, as discussed above, was about 2.5 times the process energy. Ambient losses from the reactor unit were estimated during leak testing procedures. A calculated heat duty for the unit during a period with no inlet or outlet flow, and with the reactor empty except for high pressure helium and nitrogen, gives an indication of ambient losses. A relationship between reactor temperature and reactor heat losses has been developed based on several leak test periods during Startup. Figure 18 depicts the results of this development. For a given reactor liquid temperature, the ambient loss can be predicted.

The resultant heat of reaction is thus calculated to be $0 \mathrm{Btu} / \mathrm{lb}$. Approximations in heat capacities and heats of vaporization lead to uncertainity as to whether the heat of reaction is endothermic or exothermic 
Figure 18: Reactor Ambient Heat Losses During Leak Testing

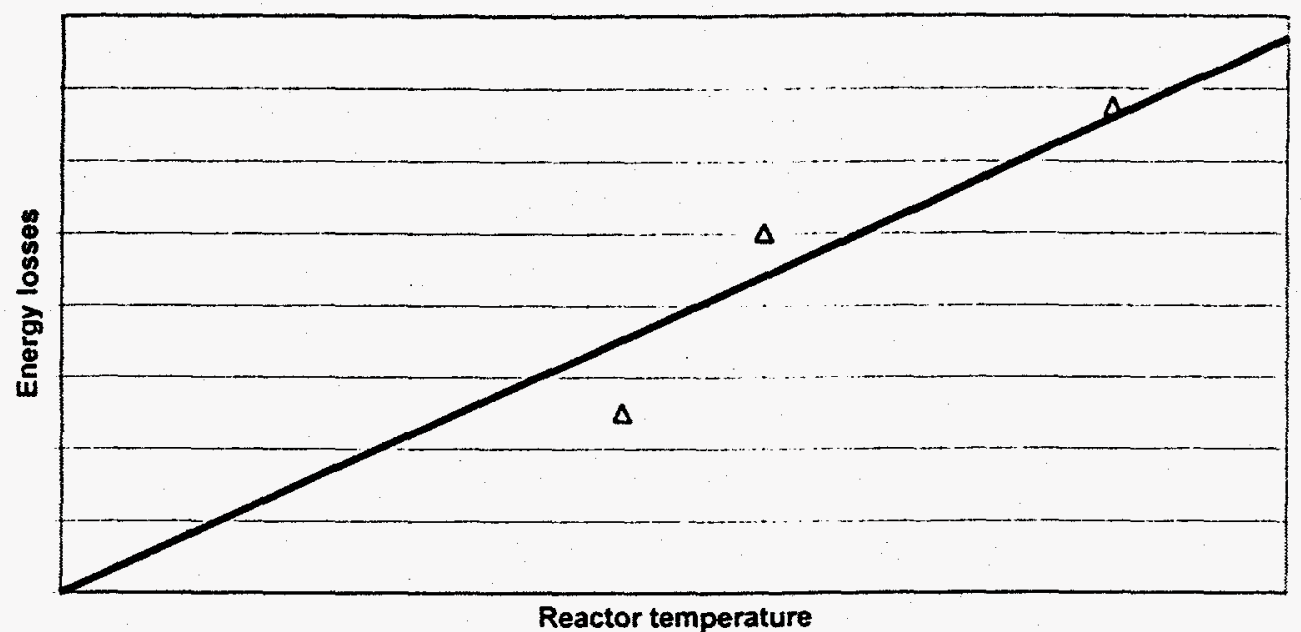

\subsection{Heat Transfer Coefficients}

Figure 19 shows heat transfer coefficients for each of the preheaters at different time periods in the Startup. They are lower than those expected during the design phase of the project for the reactor and chlorosilane preheater, but higher than that expected for the hydrogen preheater.

Figure 19: Overall Heat Transfer Coefficients

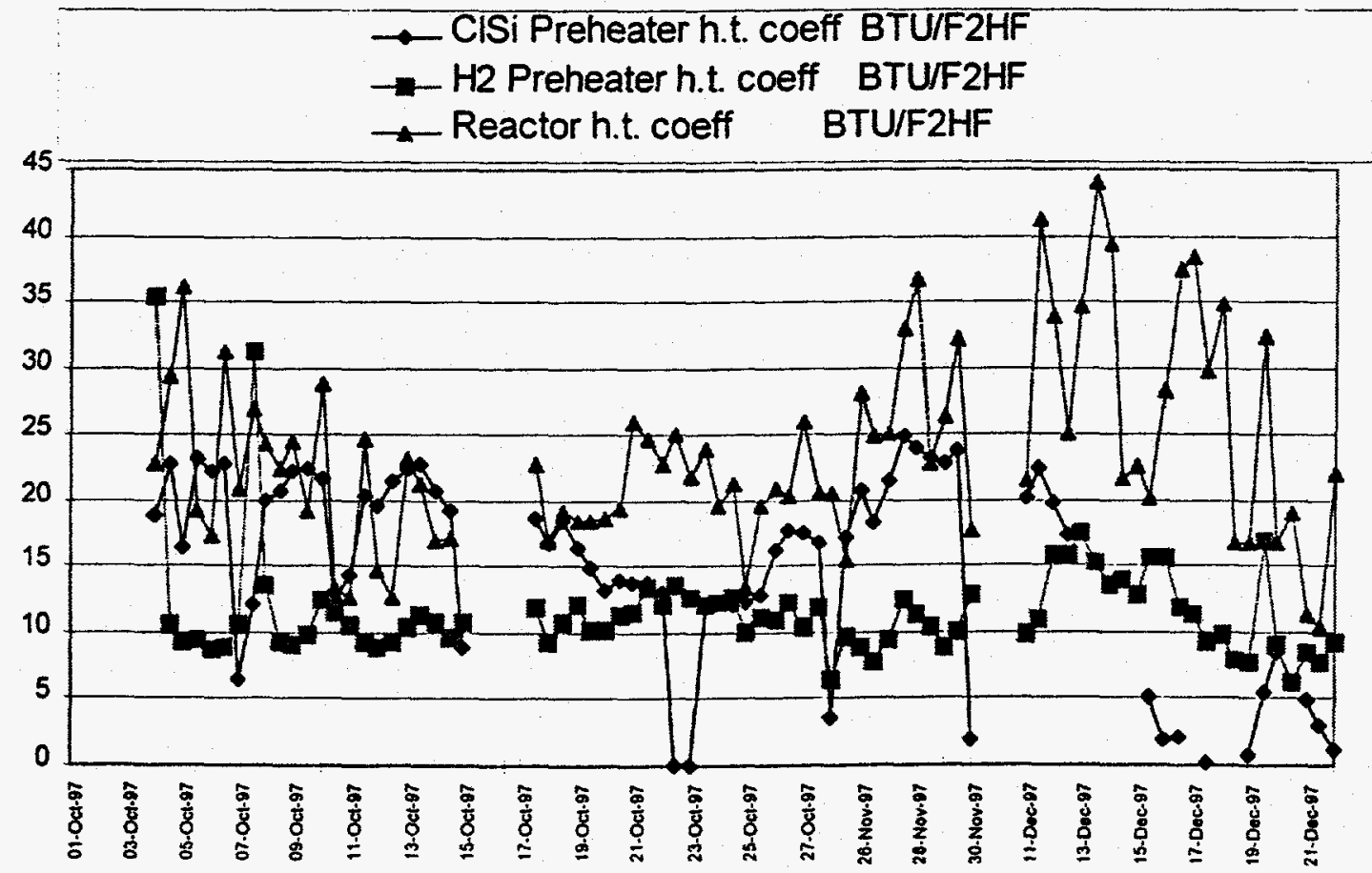




\subsection{Thermodynamic State}

\subsubsection{Background and Past Efforts}

Although laboratory reactors had been operated for several years, the phase of the reactor contents was unknown prior to experiments in the Pilot Plant. Whiteley and Hammers noted that the main chlorosilane monomer species are above their critical pressure and temperature, suggesting that there might be a single supercritical fluid phase [18]. A mean chlorosilane density was calculated based on known reactor volumes and collected weights of reactants trapped during operation. Warrick modified a laboratory batch reactor to withdraw samples from the upper and lower sections of the reactor [19]. Differences in composition were noted which suggested the presence of separate liquid and vapor phases.

\subsubsection{Description and Principals of Operation of Ronan Nuclear Density Meter}

To determine the reaction phase more precisely, a nuclear density meter was purchased from Ronan Engineering Company. The unit contained a ${ }^{137} \mathrm{Cs}$ radiation source encased in a vertical lead shield. The source was attached to a flexible tape that wound around a sprocket. The tape could be raised or lowered within the fixed lead shield by means of an electric motor. The motor contained instrumentation to determine the exact height of the radiation source. Radiation from the source was collimated to direct it straight through the reactor towards the detector mounted $180^{\circ}$ on the other side. Any mass between the radiation source and detector absorbed a fraction of the radiation so that the amount of radiation reaching the detector was less than what was transmitted. The strength of the signal reaching the detector was directly proportional to the mass of the material between the source and detector. The detector was a plastic scintillation crystal doped with phosphorous compounds. In the presence of radiation, the crystal became fluorescent, emitting a light signal proportional to the amount of radiation transmitted through the mass. The light signal was converted to an electronic signal and amplified. A microprocessor converted the signal to a density reading.

Figure 20: The Ronan Nuclear Density Meter on Pilot Plant Reactor

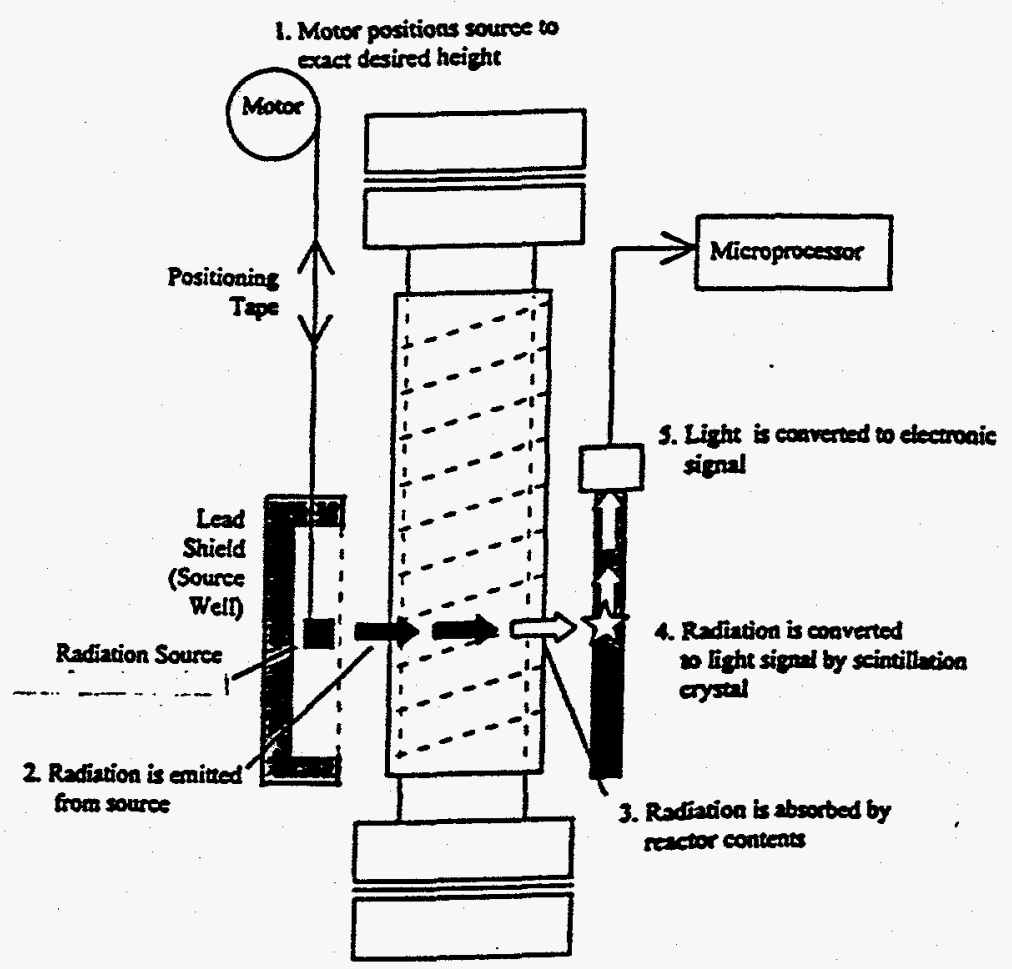


To read the density of the reactor contents, first it was necessary to obtain a baseline reading of the empty (nitrogen filled) reactor to subtract this from future readings. The baseline accounted for the masses of thermal insulation. reactor steel in the body and jacket, and heat transfer oil in the jacket. The baseline reading was stored permanently in a nonvolatile memory chip. After the baseline reading, all future signals showed the density of the reactor contents. All readings and position controls were displayed and set via the distributed control system.

There were three modes of control available to drive the radiation source up or down during operation. In the manual mode, the operator could direct the motor to move the source up or down to any desired height. The height and fluid density at that position were displayed. The source remained at that height until it was manually driven to a different position. In the profile mode, the source oscillated up and down in a sawtooth pattern at a fixed speed from its lowest point to its highest point giving the operator a view of the entire visible region of the reactor contents. In the interface tracking mode, two density readings were input to the instrument. The motor would drive the source up until the sensor detected that the fluid density reading at that height fell below a lower setpoint. (This might indicate, for example, that the sensor had just moved above the liquid level and was now detecting a gas phase.) Direction then automatically reversed, and the motor lowered the source until the density rose above the second input value. This would effectively track the level of the interface as it moved up or down during an experiment. All three modes of control were tested. The profile mode proved to be most useful since it gave the broadest view inside the reactor.

\subsubsection{Qualitative Results}

Data from the nuclear density meter provided qualitative and quantitative results. A typical trend display of data is shown in Figure 21. The data is shown as it was viewed on the distributed control system trend display with two variables plotted against time.

Figure 21: Trend Display from the Nuclear Density Meter in Profile Mode

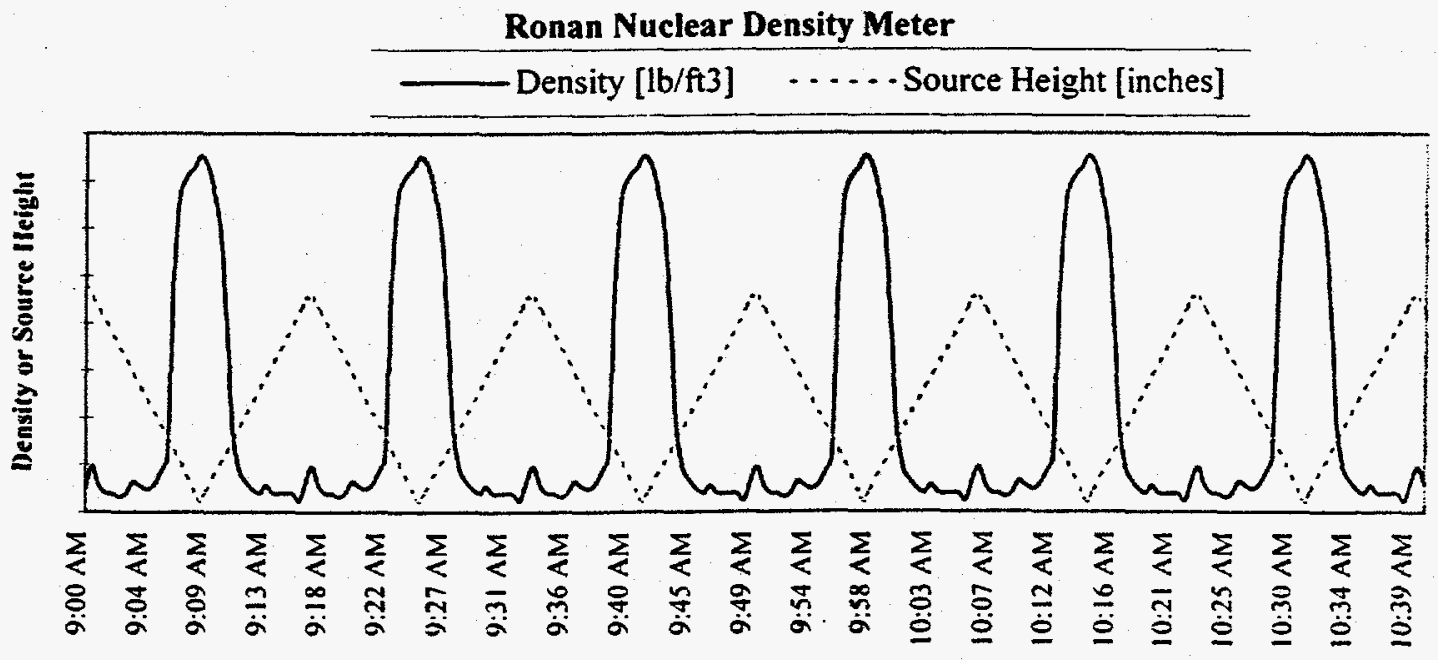

Time

On Figure 21, time is plotted on the horizontal axis. The radiation source height and fluid density are both plotted on the left vertical axis. The source was moved up and down at a constant rate to view the reactor contents. Typically, when the reactor was first started up, the vessel was filled with a low density gaseous phase. After feeds had been pumped to the reactor for several hours, a 
liquid phase could be seen in the reactor. Typical data are shown after the reactor had been operating for three days. Both the radiation source height and the density data are sawtooth patterns when plotted against time. As the source moves down to the bottom of the reactor where liquid is present, the density reading increases. As the source moves up into the vapor zone, the density reading decreases. The reactor weigh cells confirmed the added mass indicated by the density instrument.

Figure 22 shows data from the density meter on three consecutive dates when the reactor was operating. A single up and down scan from the instrument is overlaid for each date. The campaign started on 6/13/95 at approximately 12:30 am when liquid feed was started to the reactor. The unit had already been operating temperature and pressure. The first line on the graph (9:00 am 6/13/95) represents the density profile approximately 8.5 hours after starting chlorosilane feed. No liquid is present in the visible range of the instrument. One day later (9:00 am 6/14/95), an interface is visible at the very bottom portion of the visible range. On 6/15/95, a gas-liquid interface is apparent. The sigmoidal shape of the interface is believed to be due to scattering of the radiation signal, although bubbling, foaming, and splashing at the interface might also account for part of this. Readings from the reactor weigh cells confirmed the liquid mass in the vessel.

Figure 22: A Liquid Level Detected by the Nuclear Density Meter

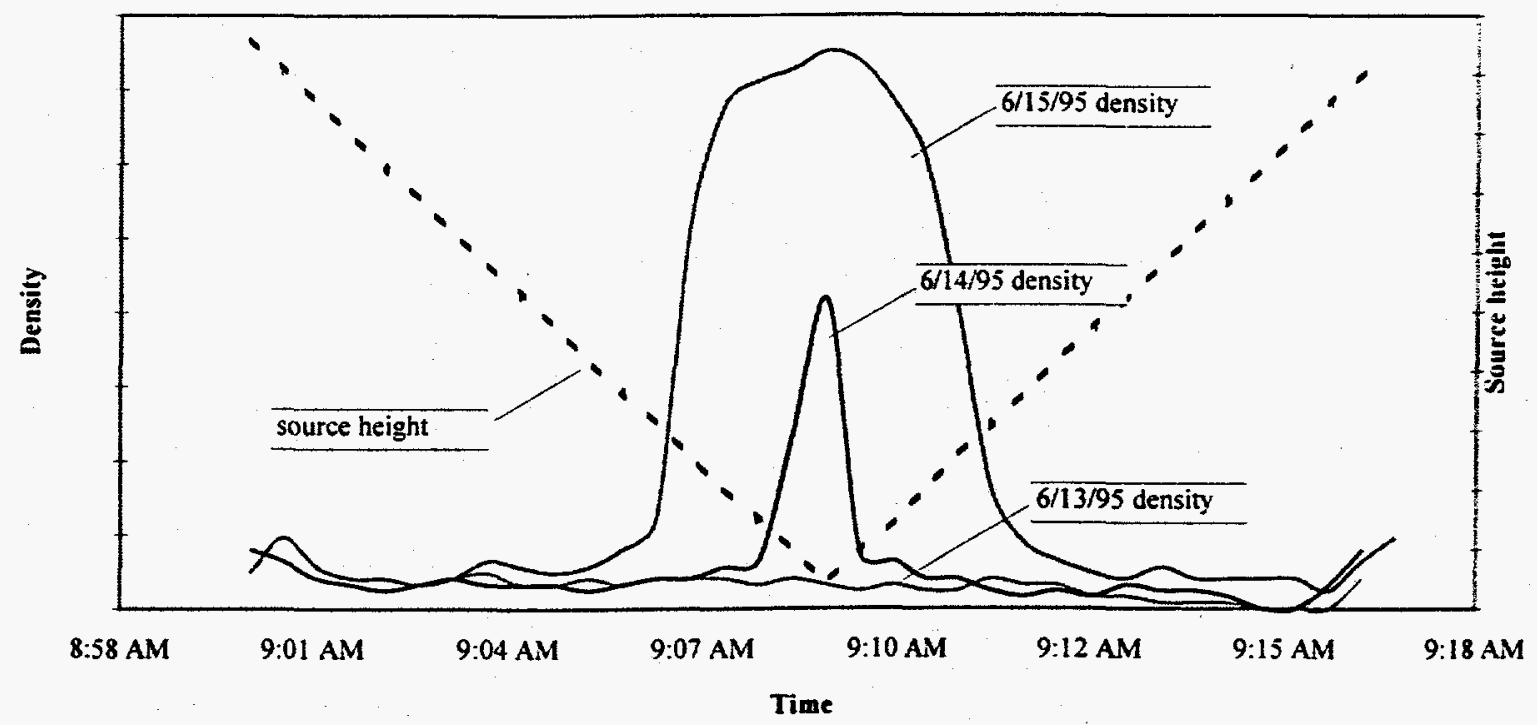

\subsection{Residence Time}

\subsubsection{Laboratory}

The residence time of laboratory continuous reactors was difficult to estimate because of the uncertain physical phase of the reactants $[18$, p. 12]. Laboratory batch experiments confirmed the relatively fast and complete reaction of disilanes compared to silmethylenes and high boilers [20, p. 9]. Disilanes react rapidly in a batch system with most disilane species being consumed in less than 2 hours [19]. Sampling of the liquid and vapor of batch reactors showed a higher concentration of silmethylenes and high boilers in the liquid phase than the vapor phase [19]. 


\subsubsection{Pilot Plant}

The presence of multiple phases in the Pilot Plant reactor required an unconventional method to determine residence time. Because the Pilot Plant unit operated as a bubble column reactor, feed material which was pumped into the lower section of the reactor could not exit the vessel until it vaporized. The varying liquid volume in the reactor demanded a residence time calculation method independent of fluid density.

To avoid density and volumetric uncertainties, the residence time for the pilot reactor was defined in terms of reactor mass accumulation and inlet mass flow rate. Electronic weigh cells on the reactor vessel proved to be a reliable means of measuring the reactor contents. Coriolis-type mass flow feed meters and feed tank weigh cells accurately measured the feed rates to the reactor. Table 6 below shows the residence time calculations for six typical experiments.

Table 6: Reactor Residence Time

\begin{tabular}{|c|c|c|c|c|}
\hline Campaign & Begin time & End time & $\begin{array}{c}\text { Reactor } \\
\text { residence } \\
\text { time [hr] }\end{array}$ & $\begin{array}{c}\text { DPR } \\
\text { Conversion }\end{array}$ \\
\hline $12321-149$ & $13 / 06 / 950: 49$ & $15 / 06 / 9516: 31$ & 2.26 & $58 \%$ \\
\hline $12178-36$ & $22 / 06 / 953: 00$ & $23 / 06 / 958: 02$ & 1.74 & $42 \%$ \\
\hline $12178-68$ & $19 / 07 / 9516: 30$ & $23 / 07 / 951: 01$ & 1.69 & $83 \%$ \\
\hline $13162-84$ & $19 / 03 / 9620: 30$ & $20 / 03 / 9619: 10$ & 2.35 & $72 \%$ \\
\hline $13162-103$ & $26 / 03 / 965: 00$ & $27 / 03 / 9623: 30$ & 3.38 & $67 \%$ \\
\hline $13162-111$ & $28 / 03 / 969: 00$ & $28 / 03 / 9621: 18$ & 0.70 & $86 \%$ \\
\hline
\end{tabular}

Residence time is calculated as follows. Total feed rate is calculated as the sum of chlorosilane plus hydrogen feeds divided by elapsed time of the experiment. Reactor mass is calculated as the difference of ending reactor weight minus beginning reactor weight. Residence time is the quotient of rẹactor mass divided by total feed rate.

\subsubsection{Discussion - Pilot Plant}

Residence time calculated above is a total system average. Since all liquid feed must vaporize to exit the reactor, and since higher molecular weight chlorosilanes are both less volatile and less reactive species, all species in the reactor do not have the same residence time in a continuously operated bubble column reactor. For example, it is likely that hydrogen has a relatively short residence time in the Pilot Plant reactor. From the low vapor density measured above the liquid phase, it is apparent that the vapor head of the reactor contains a high mole fraction of hydrogen. From the high density measurement of the liquid, it is clear that relatively little hydrogen is entrained in the liquid zone of the reactor. It appears that little bubbling occurs, and hydrogen is only entrained long enough for bubbles to coalesce and rise from the dense liquid.

Chlorosilane monomers are expected to have intermediate residence times in the reactor. From laboratory samples withdrawn from batch reactors, it is known that monomers are soluble in the reaction liquid [19]. Monomer concentrations in each phase should be dictated by an unknown supercritical vapor-liquid equilibrium. If this is the case, monomers might be leaving the liquid phase as they are generated (in the case of $\mathrm{MeHSiCl}_{2}$ ), fed to the reactor, or stripped from the reaction liquid by the hydrogen.

Chlorosilane oligomers such as disilanes and silmethylenes are expected to have longer residence times in the reactor. Disilanes will be less volatile that monomers, yet react reasonably rapidly to break down to monomers. Silmethylenes react slowly and should have lower volatility than 
smaller molecules. Thus, higher molecular weight components have significantly longer residence times than monomers in the bubble column reactor.

It is possible that very high molecular weight species are present in the reacting liquid. These may be fed to the reactor, as in the case of a poorly characterized high boiler species, or they might form in the reactor as a polymer resulting from an undesirable side reaction. Very high molecular weight species are expected to have longer residence times due to poor reactivity. It is possible that these species never vaporize. The lack of a high pressure, high temperature phase diagram makes this discussion speculative.

There appears to be little correlation between residence time and DPR conversion.

\subsubsection{Pilot Plant II}

Because the Pilot Plant II reactor was equipped with weight cells, nuclear density meter, and the ability to measure vapor procict take-off and liquid bottoms blowdown, a greater understanding of residence time was attained. Residence time was calculated for individual species such as monomers, disilanes, silmeth; lenes, and highboilers. The results of this work supported the hypothesis presented by Brinson and Pfanstiel in their Pilot Plant report, that the residence times of the various species would be inversely proportional to their vapor pressures.

Residence time in the Pilot Plant II reactor was calculated for individual species from on-line analysis of the vapor product and QA analysis of the liquid bottoms. The method involved calculating the gas and liquid inventory and the gas and liquid outlet flow. The gas inventory was calculated by difference using the weight of the total contents of the vessel, as indicated by the weigh cells, minus the weighs of the liquid, as determined by the liquid level and density. The nuclear density meter provides both level and density.

Figure 23 shows the calculated residence time of the three major component groups: monomers, disilanes and silmethylenes.

Figure 23: Average Component Residence Times

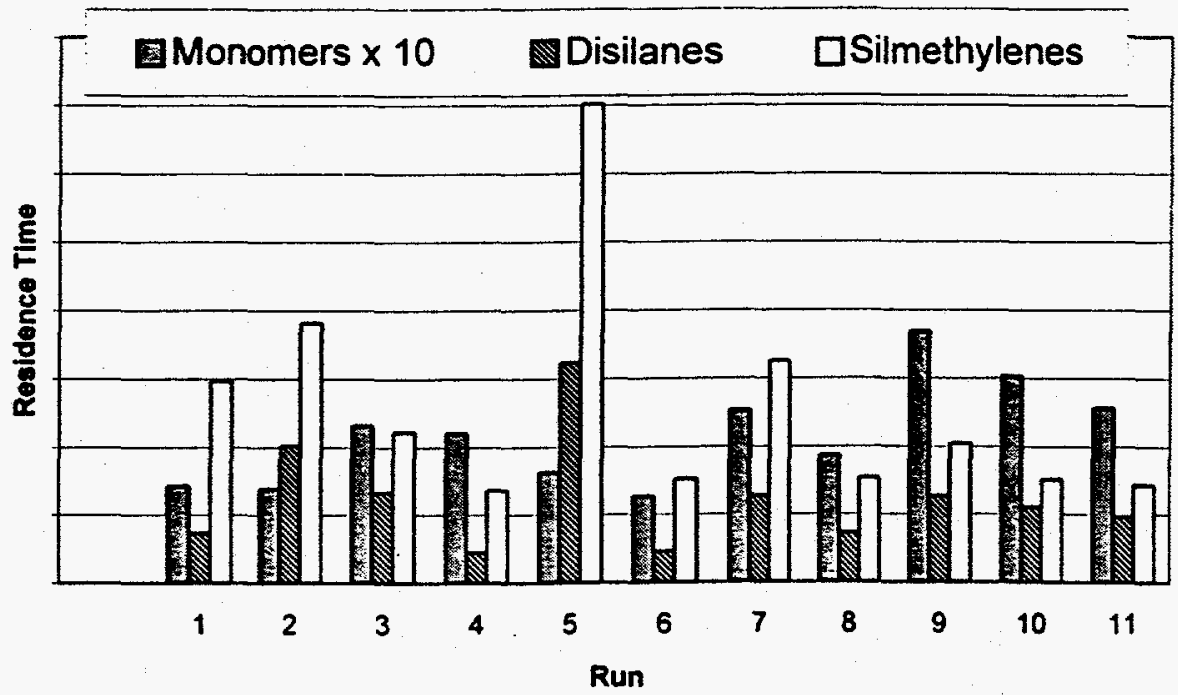

The results are as expected. Monomer residence time is quite low, as most of the monomer leaves the reactor in the vapor phase. Disilane residence times are longer, as some disilanes are converted to monomer and exit the reactor immediately, while some of the disilane remains unreacted in the liquid phase or even reacts to form polysilanes. Silmethylene reactivity is low, 
and thus the liquid hold-up of silmethylenes results in a longer residence time. A slight increase in monomer value is observed, however, with lower monomer residence times. Fundamental studies, as discussed earlier in the report, indicate that Pilot Plant II operation is on the "flat part of the curve" and that the system residence time would have to be decreased significantly to achieve any appreciable increase in monomer value.

\subsection{Pilot Plant Alternative Reactor Configurations}

To overcome perceived deficiencies of the bubble column reactor and to improve gas/liquid mixing, several modifications to the reactor were tested.

\subsubsection{Bubble Column Reactor}

Bubble column reactors are frequently used in industry for hydrogenating organics at high pressures $[21,22,23]$. The design is significantly simpler and safer than other reactors which may require sealing high pressure, high temperature rotating equipment. In laboratory experiments, bubble column reactors provided the highest DPR conversion rates [18].

The Pilot Plant bubble column reactor is shown in Figure 24. Chlorosilanes and hydrogen were fed to the bottom of the reactor. The hydrogen was fed to enhance mixing with the liquid in the reactor. Chlorosilanes entered the reactor side near the bottom. Product was taken from the top of the reactor.

Figure 24: Bubble Column Reactor Configuration

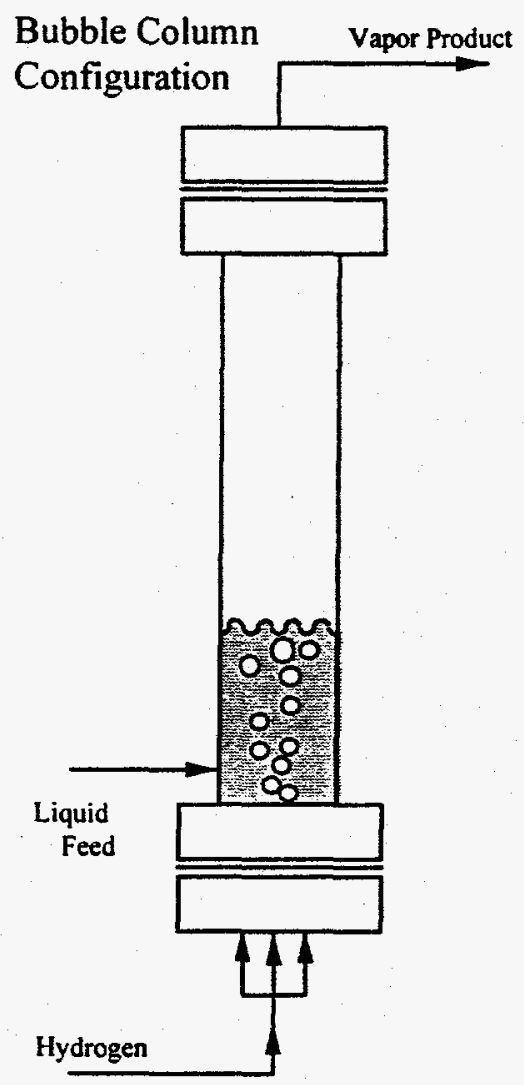

The bubble column reactor proved to be the most reliable configuration tested. 


\subsubsection{Alternative Hydrogen Spargers in the Bubble Column Configuration}

During the first campaign, hydrogen was fed through three fog nozzles spaced $120^{\circ}$ apart. The nozzles contained a $0.020^{\prime}$ pinhole feed port and an external impingement wire to break up the gas stream into tiny bubbles. The nozzles plugged during the second campaign and were removed from the reactor.

During the second campaign, the hydrogen spargers were replaced with homemade sparger tubes. These consisted of $1 / 8$ " tubing bent in a hook shape. These spargers were set facing the center of the reactor and directed down.

To accommodate a jet loop reactor, one hydrogen sparger was removed from the reactor, leaving just two spargers in the campaigns in 1996. During the last campaign, the 1/8" spargers were changed to $1 / 4 "$ bent tube spargers.

No particular hydrogen sparger proved to be superior than others tested, but the spargers with larger holes (1/4" instead of $1 / 8$ " or 0.020 " openings) were less prone to plugging. On one occasion (3/18/96), chlorosilanes flowed backwards from the reactor and plugged the hydrogen feed line approximately 3 feet from the reactor.

\subsubsection{Jet Loop Reactor}

At the end of 1995, changes were made to test a jet loop reactor configuration. Also known as an external draft tube reactor, this design was intended to increase turbulence in the liquid zone of the bubble column without the addition of a mechanical mixer. The jet loop reactor is shown in Figure 25. Like the simple bubble column reactor, a liquid level existed in the jet loop configuration. From a side port on the reactor, liquid containing no hydrogen flowed down a l" tube to the gas injection point. Hydrogen was sparged directly into the bottom of the l" tube. As hydrogen entered the liquid, a bubbly mixture was formed. The bulk density of this bubbly mixture was lower than liquid in the external tube. The difference in density caused a natural convection of fluid as dense liquid flowed down the external tube and bubbly liquid rose up from the gas injection point. 
Figure 25: Jet Loop Reactor Configuration

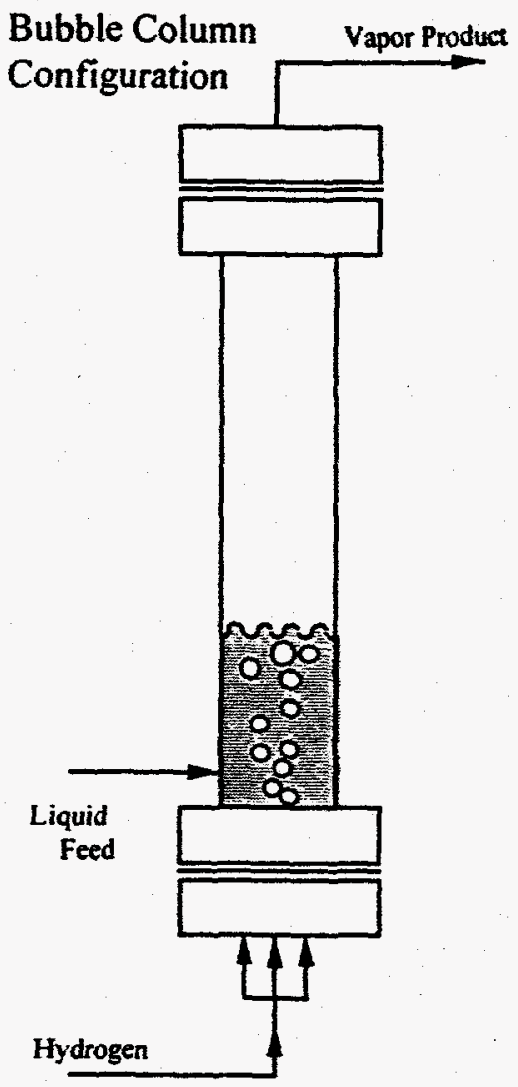

No hydrogen sparger was used in the jet loop reactor.

The jet loop reactor did not prove to be superior to the simple bubble column configuration. Flow of liquid down the external tube was difficult or impossible to measure.

\subsubsection{Spray Reactor}

The objective of this reactor configuration was to improve mass transfer by spraying chlorosilanes through a large volume of hydrogen to increase the surface area of the gas/liquid interface. The configuration is illustrated in Figure 26 . It was theorized that there might be a competing reaction that occurred in zones of the reactor where poor gas/liquid mixing occurred. 
Figure 26: Spray Reactor Configuration

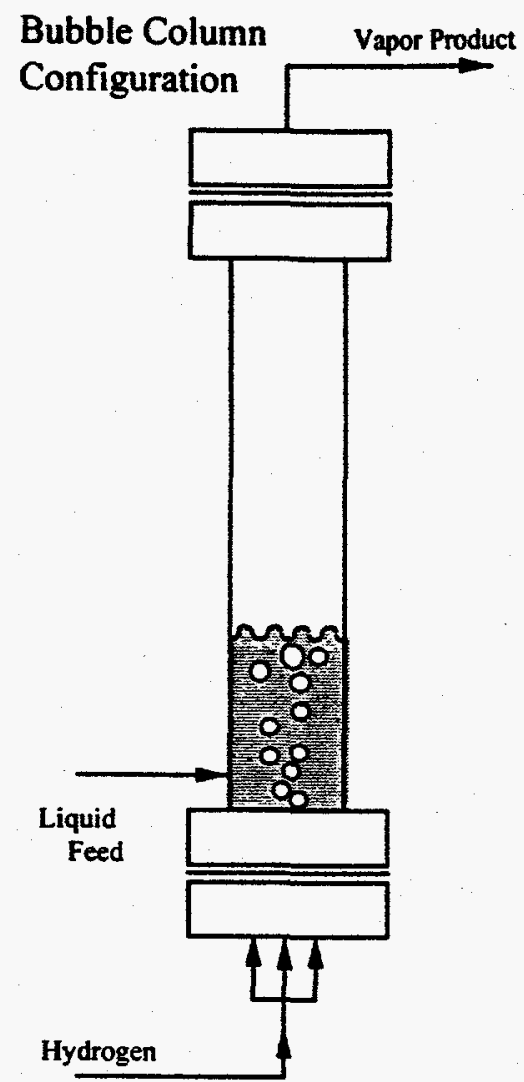

Two types of spray nozzles were installed on the top of the reactor for chlorosilane feed. The first nozzle was a high pressure unijet spray nozzle. The second nozzle was a hydraulic atomizing nozzle. Both nozzles plugged.

In addition to plugging the sprayer nozzles, there were problems plugging the product line when vapor was withdrawn from the bottom of the vessel. Solids formed in the product line causing blockages in the pressure control valve and the transfer tubing. Plugging problems with vapor product withdrawal from the bottom of the reactor ultimately ended the experiments with spray nozzles.

\subsection{Pilot Plant Product Recovery}

\subsubsection{Background}

In the laboratory, product was typically condensed from the batch and continuous reactors at high pressure in steel bombs submerged in a bath of dry ice and solvent (approximately $-50^{\circ} \mathrm{C}$ ). This same approach was adapted for the Pilot Plant. Originally, Pilot Plant product from the reactor was cooled in a service water heat exchanger at high pressure prior to entering the product tank. This proved to be an unworkable process due to plugging of the product cooler by aluminum chloride. 


\subsubsection{Discussion of Physical Properties of $\mathrm{AlCl}_{3}$}

At room temperature and atmospheric pressure, $\mathrm{AlCl}_{3}$ is a solid. At one atmosphere, it sublimes at $192{ }^{\circ} \mathrm{C}$ [24]. At $22 \mathrm{psig}$, pure solid $\mathrm{AlCl}_{3}$ melts to form a liquid at $186^{\circ} \mathrm{C}$. A high pressure, high temperature phase diagram has not been located in open literature.

Aluminum is present in DPR at levels of approximately $0.6 \%$ weight [6]. Aluminum enters the direct process in an elemental form with feed silicon and also as aluminum oxide slag in silicon. In the fluid bed reactor, it is believed that elemental aluminum reacts with chlorosilanes to form $\mathrm{AlCl}_{3}$. It is also possible that aluminum might react with methyl chloride to form organoaluminum halides [24].

2.7.3 Solubility of $\mathrm{AlCl}_{3}$ in Chlorosilanes at the Pilot Plant

\subsubsection{Prior Work}

In 1985, a methylation Pilot Plant was operated at the Carrollton site. The unit reacted elemental aluminum with $\mathrm{MeCl}$ and $\mathrm{Me}_{2} \mathrm{SiCl}_{2}$ to form $\mathrm{AlCl}_{3}, \mathrm{Me}_{3} \mathrm{SiCl}$, and $\mathrm{Me}_{4} \mathrm{Si}$ [25]. Separation of pure $\mathrm{AlCl}_{3}$ from the chlorosilane products was a major difficulty for the technology development.

The solubility of aluminum chloride in various methylchlorosilane monomers was tested by Flaningam in 1987 [26]. In 1993, Flaningam studied the solubility of aluminum chloride in $\mathrm{SiCl}_{4}$ and $\mathrm{HSiCl}_{3}$ [27]. Two Russian papers containing solubility studies were also summarized by Flaningam [27]. A summary of the known solubility of aluminum chloride in chlorosilanes is shown in Table 7.

Table 7: Solubility of Aluminum Chloride in Chlorosilanes

\begin{tabular}{|l|r|r|l|}
\hline & $\begin{array}{r}\text { Wt fraction of } \\
\text { soluble AlCl } \\
\text { at } 25^{\circ} \mathrm{C}\end{array}$ & $\begin{array}{r}\text { Wt fraction } \\
\text { soluble as Al at } \\
25{ }^{\circ} \mathrm{C}\end{array}$ & Source of data \\
\hline $\mathrm{Me}_{4} \mathrm{Si}$ & $0.30 \%$ & $0.06 \%$ & Flaningam, 1987 \\
\hline $\mathrm{Me}_{3} \mathrm{SiCl}$ & $4.70 \%$ & $0.95 \%$ & Flaningam, 1987 \\
\hline $\mathrm{Me}_{2} \mathrm{SiCl}_{2}$ & $0.04 \%$ & $0.01 \%$ & Frye, 1953 \\
\hline $\mathrm{MeSiCl}_{3}$ & $0.04 \%$ & $0.01 \%$ & Flaningam, 1987 \\
\hline $\mathrm{HSiCl}_{3}$ & $0.0010 \%$ & $0.0002 \%$ & Devyatyh, 1984 \\
\hline $\mathrm{SiCl}_{4}$ & $0.0017 \%$ & $0.0003 \%$ & Krasnova, 1985 \\
\hline
\end{tabular}

The solubility of $\mathrm{AlCl}_{3}$ in larger chlorosilane oligomers is currently unknown.

\subsubsection{Aluminum Levels in the Pilot Plant Feed DPR}

Aluminum was measured in DPR slurry and filtered DPR at the Pilot Plant. $\mathrm{AlCl}_{3}$ content was not directly measured. Aluminum testing was achieved by the following procedure. The sample was digested in acid to yield an aqueous solution. The aluminum content was quantified by ICP-OES (inductively coupled plasma with optical emission spectroscopy). Results in Table 7 are reported as weight fraction $\mathrm{Al}$ and $\mathrm{AlCl}_{3}$, but the exact form of the aluminum is not known. It is assumed to be aluminum chloride.

Filtrate DPR samples averaged slightly less aluminum that the feed DPR slurry samples. The form of the aluminum removed by the filter is not known. It is speculated that the aluminum was either elemental aluminum bound in the silicon removed or aluminum oxide. It is possible that 
aluminum removed was precipitated $\mathrm{AlCl}_{3}$ above its saturation point, but this does not seem likely because there is no consistent lower threshold of aluminum level among different samples.

In the filtrate samples, it is obvious that $\mathrm{AlCl}_{3}$ is soluble at concentrations significantly higher than the solubility of $\mathrm{AlCl}_{3}$ in the main product monomers, $\mathrm{Me}_{2} \mathrm{SiCl}_{2}$ and $\mathrm{MeSiCl}_{3}$. Aluminum chloride has very low solubility.

\subsubsection{Aluminum Solubility in the Reactor Product}

In the Reactor product, soluble Al levels tested were quite low. In all samples taken in 1995, a fine gray-white precipitate formed on the bottom of sample containers. (Product samples taken in 1996 did not contain a precipitate because of a change in product recovery configuration discussed below.) The precipitate was assumed to be aluminum chloride. The precipitate was expected from the prior studies by Flaningam and others showing low solubility of aluminum chloride in the chlorosilane monomers which made up the product.

Thus $\mathrm{AlCl}_{3}$ entered the process dissolved in disilanes, silmethylenes, and high boiling chlorosilanes. Consumption of these highly solvating oligomers made $\mathrm{AlCl}_{3}$ insoluble in the reactor product samples.

\subsubsection{Pilot Plant condenser configurations}

\subsubsection{Original Condenser}

The original product recovery system utilized a horizontal shell and tube condenser. Hot vapor entered one end of the tube side of the exchanger. Water flowing on the shell side condensed the vapor and also condensed (desublimed) the aluminum chloride contained in the vapor. Pure aluminum chloride was deposited inside the tubes and eventually plugged the condenser completely. Attempts were made to blow out the plug with very high differential pressure, but these were unsuccessful. Further attempts were made to dissolve or melt the plug by boiling the reactor. This also failed. In June 1995, the condenser was removed from the Pilot Plant and cleaned. It had plugged after 157 hours in service. The condenser was never returned to service.

\subsubsection{Vertical Pipe Condensers}

Vertical double pipe condensers were fabricated and installed in July 1995. It was theorized that condensing aluminum chloride might be settling in the horizontal tubes of the original condenser. By setting the condensers in a vertical position, it was hoped that small $\mathrm{AlCl}_{3}$ crystals would flow down out of the condensers before accumulating as a mass that would plug. Two parallel condensers allowed one unit to be cleaned in place while the other unit was on-line.

The new units did not solve the plugging problem. They plugged after 81 hours in service. After cleaning, the units were returned to service and plugged a second time after 14 hours in service.

\subsubsection{Liquid Contacting Condenser}

A further modification was made to reduce plugging in the vertical condensers. Liquid product was pumped from the product tank pump up through a water cooler to the top of the vertical condensers. Thus condensing product vapor from the reactor was contacted not with a cold metal wall for condensation, but rather with a circulating chilled liquid product stream. This liquid contacting condenser plugged twice within 16 hours.

\subsubsection{Other Alternatives Considered}

Several other alternatives were investigated to solve the aluminum chloride plugging problem, but were deemed to be unfeasible. These discarded options included a bag filter downstream of the 
condenser, condensing product vapor under a liquid level in the disengagement tank, carbon adsorption of the feedstock to remove aluminum chloride prior to the reactor and a condenser design which incorporated a mechanical scraper device.

\subsubsection{Product Recovery in the Pilot Plant}

\subsubsection{Background}

The product recovery scheme which proved most successful was condensation of the reactor vapor in a reboiler pot under a distillation column. Originally, the distillation column was installed to provide samples of unconverted DPR to the By-Product Chlorosilane Hydrolysis Pilot Plant operated in a laboratory at the Silicon Methyl Intermediates (SMI) department at Carrollton. Due to the problems with aluminum chloride plugging, project engineers were not able to start up the distillation equipment in 1995.

\subsubsection{Modifications}

Computer process-simulations of the system were made to verify that the column and condenser could be retrofitted. Lines from the overhead reactor vapor were gradually sloped down to the reboiler pot. All lines were sized up from 1/4" original tube diameter to 1/2" diameter. The line from the reactor was traced with hot oil to avoid condensation prior to the reboiler. The product vapor containing hydrogen, chlorosilanes and $\mathrm{AlCl}_{3}$ vapor was injected directly in the bottom of the still pot. In February 1996 all modifications were completed, and all experiments in 1996 utilized this mode of product recovery.

\subsubsection{Results}

No pure aluminum chloride plugs were discovered in the reactor vapor lines or the distillation column after the change to direct vapor injection in the column. Samples of the overheads accumulator product and reboiler bottoms proved that aluminum chloride was exiting the column in the bottoms in a soluble form. Very little $\mathrm{AlCl}_{3}$ exited overhead with the monomers.

\subsubsection{Non- $\mathrm{AlCl}_{3}$ Solids Formation in Piping Downstream of Reactor}

No aluminum chloride plugging was discovered after the 1996 change.

\subsection{Materials of Construction}

\subsubsection{Background}

Carbon steel is typically used for process equipment in chlorosilane service. High temperature, high pressure hydrogen attacks carbon steel. Copper, Monel, low alloy $\mathrm{Cr}$-Mo steels and stainless steels (SS) are generally recommended for hydrogen service. For the Pilot Plant, 316 SS was chosen as material of construction for the Pilot Plant due to cost, availability and delivery of equipment. Reactors and tubing constructed of 316 SS in the SMI laboratories performed well for at least three years. There were no outstanding safety recommendations for use in the Pilot Plant for expected operating times of less than fifteen months. Chloride stress corrosion cracking was considered, but was deemed to be a low risk. 


\subsubsection{Two Tubing Unions in Reactor Overheads Piping}

In July 1995, two 5/8" x 1/2" Swagelok reducing unions failed in the reactor overhead product line. The first fitting failure resulted in a slight vapor leak. The line contained hydrogen and chlorosilane vapor at high pressure and temperature.

The fittings were on two ends of a coiled, finned tube air cooled condenser. The coil was removed earlier in the month to change some tubing. It is probable that these fittings on the tube ends were exposed to atmospheric moisture when the coil was disconnected. When the coil was first installed in April 1995, it was hydrostatically pressure tested with water and blown dry with nitrogen before installation. It is possible that moisture was left in the tubing in April 1995. Moisture left in the tubing from either disconnection would form $\mathrm{HCl}$ on contact with chlorosilanes. $\mathrm{HCl}$ is known to attack $316 \mathrm{SS}$.

The fittings were prime candidates for stress corrosion cracking if chloride ions were present. The fitting had been subjected to high process temperatures. The fittings were high stress components due to sharp machined surfaces, high process pressure, and the stresses induced by tightening the nuts on the fitting bodies.

Similar 316 SS Swagelok fittings are used throughout the Carrollton plant in chlorosilane service, but no one contacted by the Pilot Plant engineers recollected a fitting failure such as this. It is possible that the high operating pressure made this failure more obvious.

It is also possible that the corrosion began from the outside of the fittings. Dye penetrant testing was completed on nearby tubing sections to insure no other cracks existed. Dye testing was also performed on the outside of the lower reactor head. Pressure and leak testing was performed on all the reactor overhead tubing through the product condensers at maximum allowable working pressure (MAWP) with helium.

Metallurgists advised that there was a reasonably low potential for a catastrophic failure in the unit due to this sort of corrosion. The rest of the Pilot Plant 316 SS was hydrostatically tested with oil, not water. At the time the leak was discovered, there was believed to be no other high temperature, high pressure piping that had been exposed to moisture. The failure mode of these fittings was obvious leakage, not a sudden rupture. Based on this information, the Pilot Plant was restarted after the pressure testing.

Two leaking fittings were forwarded, each to a different engineering firm. Metallurgists at both companies confirmed chloride stress corrosion cracking caused the fitting failures $[28,29]$.

Consultations began with a metallurgical engineering company specializing in corrosion control. They examined tubing and valves removed from the Pilut Plant which had not failed. There was evidence of minor staining and etching inside the tubing [30]. On the outside there were surface blemishes due to "under deposit corrosion", a localized crevice corrosion. Minor pits were noted. Despite the minor corrosion, no significant damage was reported. A potential for future stress cracking from the pitting was noted. The firm recommended installation of test coupons to evaluate several different potential steels and alloys for a commercial reactor. Recommendations were made for handling and cleaning the reactor to avoid stress corrosion cracking. The firm further recommended that no water cleaning of the reactor be performed if it could possibly be avoided. Recommendations were made for passivating $316 \mathrm{SS}$ with nitric acid, citric acid, or hydrogen peroxide.

Separate consultations were made with a Teltech expert on 316 SS with extensive experience in the silicones and chlorosilane industry [31]. This materials expert advised that water cleaning could be done safely without damaging the steel. He also advised that well cleaned $316 \mathrm{SS}$ would "auto-passivate" if exposed to moist air for several days. The reactor was opened and water 
blasted. The vessel was thoroughly cleaned and dried. It was left open to the air for several days to auto-passivate as recommended.

\subsubsection{Tee Failure in Reactor Relief Line}

On March 25, 1996 a 1/2" Swagelok x 3/4" female NPT branch tee failed in the reactor vapor piping. Like the prior failure, the failure mode was a vapor leak. The process was depressurized and purged with nitrogen, then an attempt was made to tighten the fitting. When the system was leak tested with helium the leak was worse. Further tightening cracked the fitting.

Prior to this failure, in January 1996, several piping modifications were made at the Pilot Plant. The section of tubing connecting the reactor to the relief valve was disassembled and modified. This section of tubing contained the failed fitting. It is believed that like the first fitting, either atmospheric moisture entered the tubing or chlorosilanes inside the tubing dripped out onto the outer tube fitting surface. In February following the maintenance, the reactor was pressure tested at ambient temperature, then at operating temperature and pressure with helium for 14 hours with zero leakage.

At the time the unit was restarted, the crack definitely did not exist. The crack formed during many hours of operation. Metallurgists described this as an incubation period.

The fitting was replaced, and the unit was restarted and operated two more days. No formal examination of the fitting was conducted by a metallurgist.

\subsubsection{Crack in the Lower Reactor Head}

Two days after the failed reactor tee was discovered and replaced, the unit was shut down due to FBR maintenance. During the shutdown, the reactor lower flange was removed. No water washing was planned.

While the lower head was off the reactor, it was inspected via dye penetrant testing by the site non-destructive testing group. Three minor stains were noted. One stain or crack was in the area of a weld and appeared to be a porous weld or rolled metal surface. A second minor crack on the raised flange area was filed slightly and dye tested again. No crack was visible on re-test. A third possible crack was noted outside the area of the flange gasket. Though all dye stains were small and none of the potential cracks were felt to affect the integrity of the reactor head, the third stained area was sufficiently suspicious that further examination was deemed appropriate.

The dye penetrant test was repeated to locate the third crack on the reactor head. The crack was approximately 0.300 " [32]. The area was polished, and a replication of the crack area was taken on thin film. Examination of the replication indicated a network of fine, branched cracks penetrating deep into the metal surface. Little surface corrosion was apparent. The metallurgical engineer reviewing the crack concluded that the damage was caused by stress corrosion cracking.

The area was ground and welded to repair the crack. The reactor was operated briefly in May after the repair. The numerous corrosive failures were a significant factor affecting the decision to shut down the Pilot Plant permanently.

\subsubsection{Discussion of Chloride Stress Corrosion Cracking}

Chloride stress corrosion cracking has been noted in many Dow Corning processes where austenitic stainless steels such as 304 and 316 SS are used in an environment of chloride ions. Dry chlorosilanes are not corrosive, but any amount of water contact, even very small quantities, can form aqueous $\mathrm{HCl}$. Hydrochloric acid also causes pitting and generalized corrosion in stainless steels, but the failures in the Pilot Plant were all on relatively clean metal surfaces. All three failures occurred in areas of high temperature and high pressure. They all occurred in the reactor or immediately attached tubing. High stresses in the tube fittings could have been due to 
the stresses imparted during fitting pull-up and tube swaging, residual stresses from fitting manufacture, or from sharp edges on the fitting bodies. High stresses in the flange could have been transmitted from the stressed flange bolts. All areas were subjected to thermal and pressure cycling due to frequent Pilot Plant start-ups and shut-downs.

\subsubsection{Discussion of Hydrogen Corrosion}

Carbon steels exposed to high temperature, high pressure hydrogen are prone to decarburization, embrittlement, fissuring and cracking [33]. Steels containing low weight fractions of chromium and molybdenum (commonly called "low alloy" steels) are preferred to manufacture high pressure hydrogenation vessels up to approximately 13,000 psig due to the high expense of stainless steels. Low alloy steel slabs up to $450 \mathrm{~mm}$ (approximately $18^{\prime \prime}$ ) have been tested for application in high pressure hydrogenation vessels $[34,35]$.

Hydrogen diffuses into steel at elevated temperatures and pressures. Various theories of hydrogen degradation have been proposed [36]. In carbon steels, hydrogen reacts with carbides, forming methane. The steel is weakened by loss of the carbide particles. Methane molecules are too large to diffuse out of the steel. Methane formation causes blistering and surface cracking when the vessel is depressurized.

Hydrogen is also believed to accelerate other corrosion mechanisms. Even in austenitic stainless steels, hydrogen can cause loss of ductility, surface cracking, and crack growth [36]. It is likely that the combined effects of chloride stress corrosion cracking and hydrogen embrittlement were responsible for the failures noted in the Pilot Plant.

The Petrochemical Industry has many years of experience with high pressure, high temperature hydrogen. Based on the collective successes and failures of materials in hydrogen service, G.A. Nelson constructed a graph which gives operating limits for steels in hydrogen service to avoid decarburization and fissuring [33]. The graph shows that at high pressures and temperatures, carbon steel is prone to hydrogen attack. At these conditions and above, various chromoly steels are necessary. In general, austenitic stainless steels are not decarburized in hydrogen at any pressure or temperature. But as noted earlier, they are prone to stress corrosion cracking.

\subsubsection{Open Literature on Materials of Construction for Chlorosilane Hydrogenation}

Little open literature exists on corrosion in systems similar to the hydrogenolysis performed at Dow Corning. One study by Mui compared the performance of various alloys in a hydrogenation reactor containing $\mathrm{SiCl}_{4}, \mathrm{H}_{2}, \mathrm{Si}, \mathrm{HSiCl}_{3}$ and $\mathrm{HCl}$ [37]. The study was conducted at high temperature and pressure for 87 hours. The metals and alloys studied were nickel, copper, Monel, carbon steel, 304 SS, Incolloy, and Hastelloy. For each of the metals tested, samples gained weight after exposure to the reactor contents. Scanning electron microscopy and elemental analysis verified the formation of a protective metal-silicide layer which formed on each of the metal samples. Nickel, copper, and carbon steel had the highest rates of silicide formation (200500 mils per year). The Incolloy and Hastelloy had the lowest formation rates of silicide (25-35 mils per year). The fast growth rates of silicide were cited as a serious problem due to erosion of the reactor walls. The study concluded that the Incolloy and Hastelloy alloys were superior materials of construction for this system.

Application of these results for the selection of materials for a DPR hydrogenolysis reactor is unclear. The hydrogenation reactor cited operated at significantly higher temperature and contained elemental silicon. However, the conclusion that the high chrome, high molybdenum nickel based alloys were superior materials in this hydrogenation reactor is significant because it supports the studies from the Midland cracker. 


\subsubsection{Corrosion Coupon Study Results from the Pilot Plant}

In October 1995, metallurgical engineers fabricated corrosion coupons for testing in the Pilot Plant reactor. Coupon racks containing stressed (bent), welded and crevice-containing 316L, Inconel, Monel, Hastelloy, Incolloy, and Cr-Mo steel were received and installed in the upper (vapor) and lower (liquid) sections of the reactor. The alloys selected for the coupon test were recommended based on information from engineers operating the Midland cracker.

Results from the study are summarized in Table 8. The coupons were mounted in the lower section of the reactor and were exposed to vapor and liquid. The total exposed time at high temperature was 190 hours.

Table 8: Corrosion Rates of Metals Tested in the Reactor

\begin{tabular}{|c|c|c|l|}
\hline Alloy & $\begin{array}{c}\text { Liquid zone } \\
\text { corrosion rate } \\
\text { [mils/year] }\end{array}$ & $\begin{array}{c}\text { Vapor zone } \\
\text { corrosion rate } \\
\text { [mils/year] }\end{array}$ & Visual Observations \\
\hline Inconel & none & none & No attack, no stress cracking, no crevice attack. \\
\hline Hastelloy & none & 0.017 & No attack, no stress cracking, no crevice attack. \\
\hline Incolloy & 0.093 & none & No attack, no stress cracking, no crevice attack. \\
\hline Monel & 0.083 & 0.607 & Possible light etching. No cracking. \\
\hline $316 \mathrm{~L}$ & 0.150 & none & Possible light etching. No cracking. \\
\hline $\mathrm{Cr}-\mathrm{Mo}$ & 9.807 & 3.520 & $\begin{array}{l}\text { General attack, possibly more severe at crevice. } \\
\text { No stress cracking. No weld attack. }\end{array}$ \\
\hline
\end{tabular}

\subsubsection{Open Literature and Expert Consultation}

A consultant for the Nickel Development Institute, was contacted prior to startup of Pilot Plant II in regards to materials of construction [38]. He felt the reactor's cladding material of Inconel was acceptable for the service. He did however inquire why Hastelloy was not chosen instead. Based on previous Dow Corning experience at the Midland MCDS thermal cracker and the fact that there may be traces of ferric chloride or other oxidizing contaminants in the reactor, he agreed that the higher chromium bearing grade (Inconel) was necessary. He also confirmed that the reactor's chromium - molybdenum steel backing was adequate for the partial pressure of hydrogen and the operating temperatures, according to the Nelson curves.

This information was also confirmed with materials experts at Inco Alloys International [39] and Haynes International [40]. Both agreed with the comments from the Nickel Devlopment Institute.

\subsubsection{Process-Specific Materials Of Construction}

Based on the information available in open literature, consultation with experts, and the past successes and failures at Dow Corning, the materials of construction for Pilot Plant II were chosen. Table 9 lists the various process conditions in Pilot Plant II and the materials of construction selected to combat the two main corrosion mechanisms, chloride stress corrosion cracking and hydrogen attack. 
Table 9: Materials Of Construction

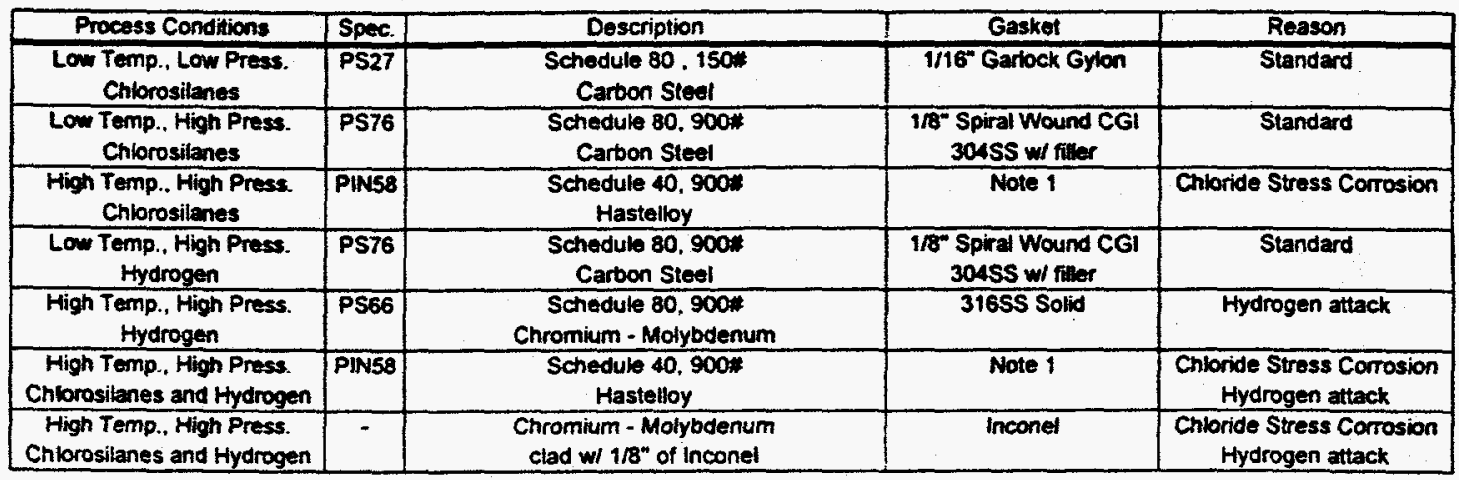

Note 1: Flanges $11 / 2$ " and below will have Hastelloy solid gasket. Flanges above $11 / 2$ will have 1/8" thick Spiral Wound CG with Hastelloy windings wf graphite filler.

\subsubsection{Preventive Maintenance Program}

Because of insufficient knowledge on materials of construction in DPR Hydrogenolysis environments and the potential hazards of Pilot Plant II, a rigorous Preventive Maintenance program was developed. The program was developed to include manufacturer testing and routine non-destructive testing. The sections below break down Pilot Plant II by major pieces of equipment and piping specifications. The material of construction and process conditions are listed first, followed by the testing methods and frequencies.

In general, the first set of pre-startup tests revealed no significant material of construction concerns. The six month post operational checks had not been completed because of limited operational time in 1997. These preventive maintenance checks are scheduled to occur in June of 1998.

\section{Pilot Plant II Reactor:}

- The reactor is constructed of a chromium - molybdenum shell, clad with $1 / 8$ " thick Inconel@.

- Process conditions in the reactor are high temperature and high pressure.

- Chemicals in the reactor include chlorosilanes and hydrogen.

$>$ Manufacturer performed testing included dye penetrant, hardness testing, hydrostatic pressure testing, and weld overlay analysis.

$>$ DCC performed testing included hydrostatic pressure testing, pneumatic leak testing, and ultrasonic testing (UT).

$>$ After 6 months of operation, re-perform another UT as well as a dye penetrant test. Depending on results increase or decrease frequency as appropriate.

$>$ Visually inspect when performing other testing.

$>$ No thickness testing of Syltherm $\otimes$ jacket.

\section{Chlorosilane Preheater:}

- The chlorosilane preheater has tubes constructed of carbon steel.

- Process conditions in the chlorosilane preheater are moderate temperature and high pressure

- Chemicals in the preheater are chlorosilanes. 
$>$ Manufacturer performed testing included helium leak test

$>$ DCC performed testing included hydrostatic pressure testing and pneumatic leak testing.

$>$ Visual inspection when appropriate.

\section{Hydrogen Preheater:}

- The hydrogen preheater has tubes, tube sheets, and head flanges constructed of chromium molybdenum steel.

- Process conditions in the hydrogen preheater are moderate temperature and high pressure.

- Chemicals in the preheater are hydrogen.

$>$ Manufacturer performed testing included helium leak test and other tests according to DCC standards.

$>$ DCC performed testing included hydrostatic pressure testing and pneumatic leak testing.

$>$ Hardness testing was performed.

$>$ Visually inspect when appropriate.

Hastelloy@ piping (Spec PIN58):

- Process conditions in the Hastelloy $\otimes$ piping are high temperatures and high pressures.

- Chemicals in the Hastelloy ${ }^{\circledR}$ piping include chlorosilanes and hydrogen.

$>$ DCC performed testing included hydrostatic pressure testing, pneumatic leak testing, weld radiographs, UT analysis, and thickness measurements.

$>$ DCC provided sample fittings to metallurgical testing company for material analysis.

$>$ After 6 months of operation, re-perform additional weld radiographs as well as UT testing. Also, perform thickness testing. Depending on results increase or decrease frequency as appropriate.

$>$ After 6 months of operation, remove several in-service spools and have analyzed for metallurgical change.

$>$ Visually inspect when performing other testing.

\section{Chromium - Molybdenum steel piping (Spec PS66):}

- Process conditions in the Chromium - Molybdenum steel piping are medium temperature and high pressure.

- Chemicals in the Chromium - Molybdenum steel piping include hydrogen.

$>$ DCC performed testing included hydrostatic pressure testing, pneumatic leak testing, weld radiographs, magnetic particle testing, and thickness measurements.

> After 6 months of operation, re-perform additional weld radiographs, magnetic particle testing, and thickness testing. Depending on results increase or decrease frequency as appropriate.

$>$ Visually inspect when performing other testing.

\section{Carbon Steel piping (Spec PS76):}

- Process conditions in the PS76 carbon steel piping vary. Generally temperatures are ambient, but may be at high pressure.

- Chemicals in the PS76 carbon steel piping include chlorosilanes. Also bydrogen is transferred in the PS76 carbon steel piping. 
$>$ DCC performed testing included hydrostatic pressure testing, pneumatic leak testing, weld radiographs, and thickness testing.

$>$ After 2 years of operation, re-perform thickness testing. Depending on results increase or decrease frequency as appropriate.

$>$ After 5 years re-perform weld radiographs on $>25 \%$ of welds.

\section{Carbon Steel piping (Spec PS27):}

- Process conditions in the PS27 carbon steel piping vary. Generally temperatures and pressures are moderate.

- Chemicals in the PS27 carbon steel piping include chlorosilanes and DPR.

$>$ DCC performed testing included pneumatic pressure testing.

$>$ No additional testing of the PS27 carbon steel piping is planned.

\subsubsection{Corrosion Coupon Study}

The corrosion coupons used in the Pilot Plant were exposed to process conditions for only 190 hours (estimated) and they showed very little corrosion [15]. Thus, the same corrosion coupons were reused in Pilot Plant II reactor. The corrosion racks contain stressed (bent), welded, and crevice-containing coupons of Hastelloys $\AA$, Inconels $\circledast$, Monel $\circledast$, 316L, and $\mathrm{Cr}-\mathrm{Mo}$ steel. The coupon racks were mounted in the upper and lower section of the reactor. Table 10 below summarizes the pertinent information about the coupon racks, and a schematic of a coupon rack is shown in the adjoining figure. It is worth noting that the coupon racks were actually installed in March of 1997 but the installation date in the table represents the first time the coupons were exposed to process chemicals. The actual number of hours the coupons were exposed to process chemicals will need to be calculated upon their removal. Since the coupons have not been removed from the reactor, there are no quantifiable results from the corrosion coupon study. 
Table 10: Corrosion Coupon Study

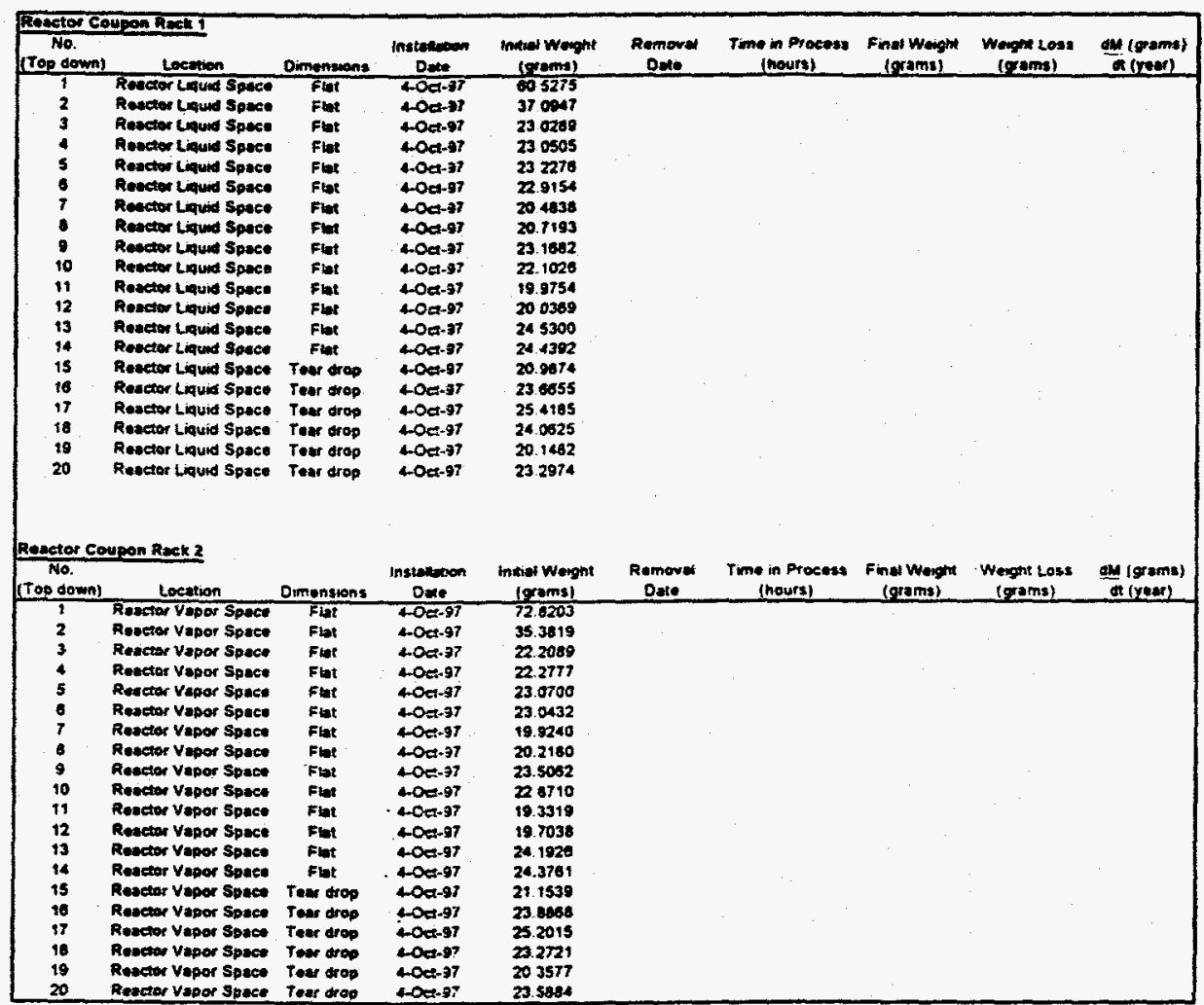

Figure 27: Schematic Diagram Of Reactor Coupon Rack

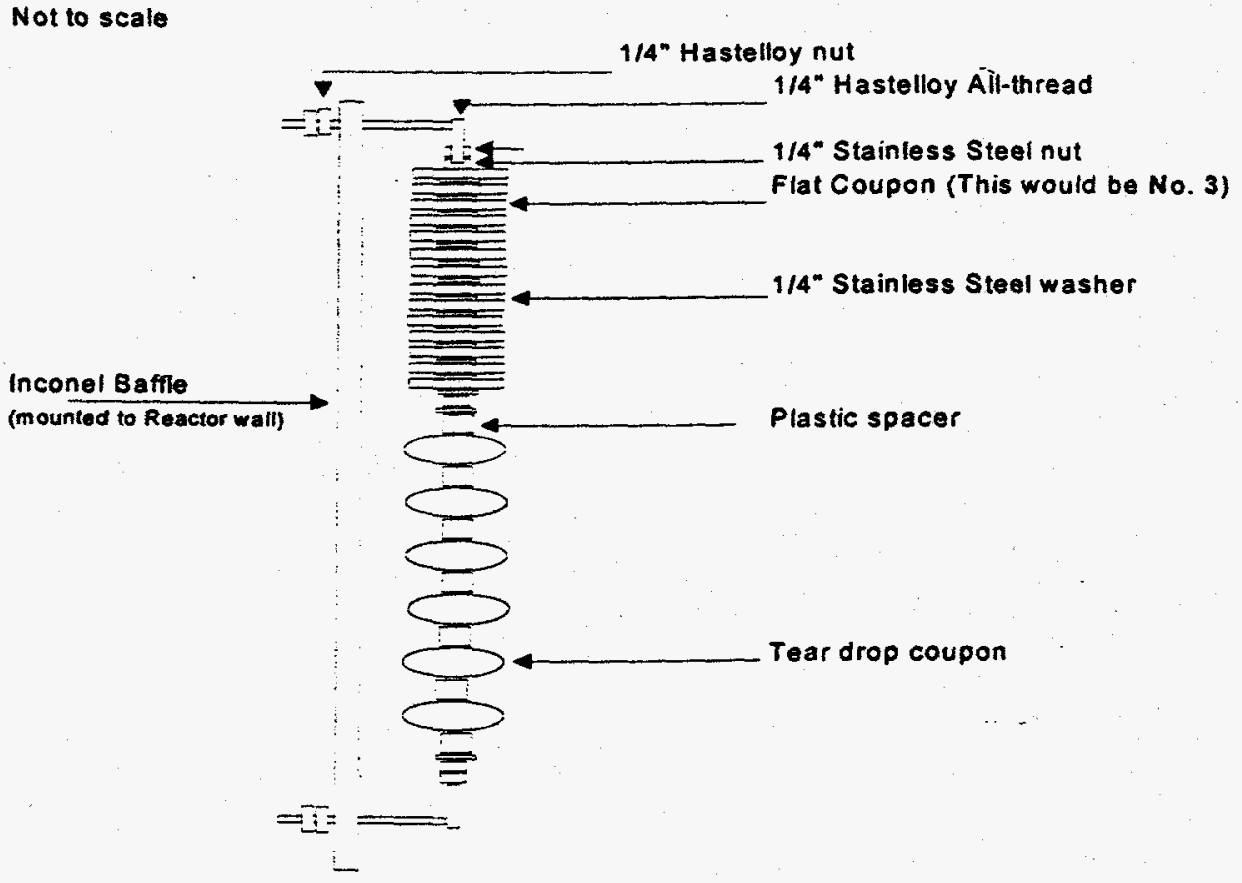




\subsubsection{Sample Spool Metallurgical Analysis}

On February 6, 1998 two piping spools of the Hastelloy@ piping (PIN58 specification) were removed from Pilot Plant II. One was a 1 " $x 3 / 4$ " reducing spool that was located upstream of the check valve on chlorosilane feed line into the top of the reactor. This line had been exposed to high temperature, high pressure chlorosilane feeds and any reactor vapors that may have weeped through the check valve. The other was a 3" $\times 2$ " reducing spool that was connected on a bottom nozzle of the reactor. This spool was used for reactor clean-outs and was a dead-leg. It had been exposed to high temperature, high pressure chlorosilanes and hydrogen. Both of these spools had been in service from October 4, 1997 to February 6, 1998. Because the unit did not have $100 \%$ on-line time over this period the spools actually experience 1,200 service hours.

\subsection{Unreacted DPR Recovered From Pilot Plant Still Pot}

\subsubsection{Analysis of the Unreacted DPR Fraction}

DPR which did not react was recovered from the bottom of the distillation column. This material was analyzed with the typical composition found in Table 11.

Table 11: Composition of Unreacted DPR Fraction

\begin{tabular}{|l|r|}
\hline Specie & Weight fraction \\
\hline Monomers & $5.3 \%$ \\
\hline Disiloxanes & $2.1 \%$ \\
\hline Disilanes & $0.2 \%$ \\
\hline Disilmethylenes & $40.9 \%$ \\
\hline Unidentified high boilers & $5.7 \%$ \\
\hline Non-elutables & $45.8 \%$ \\
\hline
\end{tabular}

As seen above, disilane conversion in the reaction is virtually complete. The unreacted DPR consists of silmethylenes and high molecular weight species. Metals testing was also completed.

\subsubsection{Further Reaction of Still Pot Bottoms in the Laboratory Reactor}

Experiments were planned in the Pilot Plant to determine if this material could be further hydrogenated on a second pass through the reactor, but the experiments could not be completed. To answer the question, samples were reacted in the laboratory $500 \mathrm{ml}$ reactor. No monomer cofeed was added, but all other conditions were similar to the Pilot Plant. The reactor batch time was approximately five hours. Results are shown in Table 12. 
Table 12: Conversion Rates for Second Pass Hydrogenolysis

\begin{tabular}{|l|r|r|}
\hline Specie & $\begin{array}{r}\text { Product weight } \\
\text { fraction }\end{array}$ & $\begin{array}{r}\text { Second Pass } \\
\text { Conversion }\end{array}$ \\
\hline $\mathrm{MeHSiCl}_{2}$ & $6.2 \%$ & - \\
\hline $\mathrm{MeSiCl}_{3}$ & $11.5 \%$ & - \\
\hline $\mathrm{Me}_{2} \mathrm{SiCl}_{2}$ & $30.9 \%$ & - \\
\hline Other monomers & $5.6 \%$ & -3 \\
\hline Disiloxanes & $2.8 \%$ & $-35 \%$ \\
\hline Disilanes & $0.0 \%$ & $100 \%$ \\
\hline Disilmethylenes & $5.9 \%$ & $86 \%$ \\
\hline Unidentified high boilers & $2.3 \%$ & $60 \%$ \\
\hline Non-elutables & $34.8 \%$ & $24 \%$ \\
\hline Total DPR & $45.8 \%$ & $52 \%$ \\
\hline
\end{tabular}

As seen above, more than half of the DPR was converted on the second pass through the reactor. Solids were also formed. No species is identified which is impossible to hydrogenate. This result indicates that unreacted DPR might successfully be recycled to the feedstream for higher overall efficiency in a commercial scale process.

\subsection{Process Chemistry}

\subsubsection{Discussion of Mechanisms Proposed Earlier}

Ferguson and Cannady speculated that DPR hydrogenolysis occurs via the following sequence of reaction steps $[41,42]$. First, a disilane decomposes by means of a 1,2-ligand shift to form a highly reactive silylene and a monomer. Next, the silylene reacts with hydrogen. Finally, monomer ligands redistribute. The overall reaction sequence is shown below:

Figure 28: Proposed Disilane Reaction Sequence

Step 1: Ligand transfer and silylene formation.<smiles>C[Si](Cl)[Si](Cl)(Cl)[Si](C)(Cl)Cl</smiles>

Step 2: Silylene insertion in hydrogen.<smiles>C[C+]Cl</smiles><smiles>C</smiles><smiles>C[SiH2]Cl</smiles> 
Step 3: Rearrangement<smiles>C[Si](Cl)(Cl)[C@H]1CCCCC1(Cl)Cl</smiles>

The formation of silylene intermediates from disilanes is well documented in literature [43-47]. This proposed reaction sequence explains the disappearance of disilanes. It explains the reaction of chlorosilanes with hydrogen and also explains the appearance of the main product monomers. Pilot plant product distributions are consistent with the proposed reaction sequence. Small concentrations of $\mathrm{MeH}_{2} \mathrm{SiCl}$ were formed in every campaign. Redistribution reactions with methylchlorosilanes are also well documented in literature $[48,49]$. The change in product distributions due to $\mathrm{Me}_{2} \mathrm{SiCl}_{2}$ co-feed in the Pilot Plant and subsequent laboratory reactions with $\mathrm{MeHSiCl}_{2}$ and $\mathrm{Me}_{3} \mathrm{SiCl}$ support the hypothesis that ligands rearrange in the DPR hydrogenolysis sequence to form a product mixture closer to that expected by redistribution equilibrium.

Whiteley and Hammers proposed a two step sequence to explain the reaction of silmethylenes with hydrogen [18].

Figure 29: Proposed Silmethylene Reaction Sequence

Step 1: Hydrogen ligand exchange

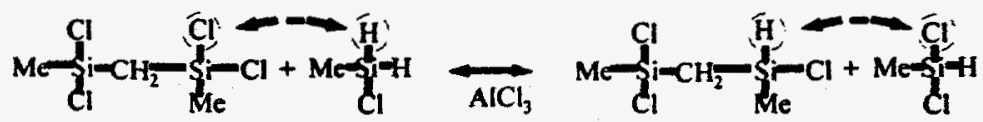

Step 2: Silmethylene decomposition

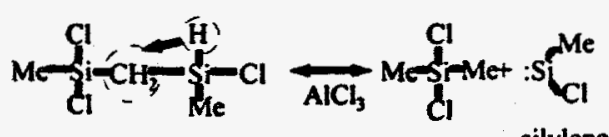

$$
\text { silylene }
$$

There is no literature outside Dow Corning to support the proposed silmethylene reaction sequence. Outside literature on silmethylenes is less available than disilane chemistry. The appearance of hydrogenated silmethylenes in the Pilot Plant product mixture does support this hypothesis.

\subsubsection{Potential Hypervalent Mechanisms}

Recently, several journal articles have appeared regarding hydrogenation of methylchlorosilanes and disilanes. See references 53, 54, 55 for examples. Experimenters used Lewis bases (such as diazadienes) and metal hydride in solvent to decompose and hydrogenate disilanes. The reactions were hypothesized to occur via a hypervalent nucleophilic attack of the catalyst on silicon. The appearance of methylchlorooligosilanes with up to seven silicon atoms is noted by the researchers. Application of these new hypervalent routes to DPR hydrogenolysis is currently uncertain. Review of this work was conducted between the Pilot Plant and Commercial Plant operations..

\subsubsection{Potential New Mechanisms}

Laboratory studies of DPR hydrogenolysis were taking place concurrent with the start-up of Pilot Plant II. Based on these experiments, and new explanation of the complex mechanisms has been proposed [50]. 


\subsection{Pilot Plant II Safety Incidents}

During start-up there were five spills, one fire, one first aid call, one near-miss, and one incident requiring personnel to enter a safety shower/eye wash. None resulted in personal injury. Summaries of some of the incidents follow.

\subsubsection{Syltherm $\circledast$ Spill, 09 Apr 97}

Personnel were adding a drum of Syltherm (ब) to the surge tank in preparation for the hydrostatic testing of the system. A portable pump was being used to add the material. The wand was inserted into the drum and the valve on the suction hose was left open. The worker then opened the valve on the discharge hose without starting the pump. The material that was in the surge tank flowed backwards through the pump and overfilled the drum. Four gallons of Syltherm $\otimes$ spilled to the process pad before the worker shut the valve stopping the flow. This incident occurred because an improper procedure was used in adding the material. Inadequate training and the lack of a check valve in the pump discharge line contributed to the incident.

\subsubsection{Trimethylchlorosilane Skin Exposure, 14 Apr 97}

The job being performed was the removal of a strainer from the suction side of a pump to investigate poor pump performance. Two technicians drained the pump and piping between closed valves on the suction and discharge sides of the pump. In order to fully drain the chlorosilanes from the system, a vent valve on the discharge side was opened to eliminate vapor lock and allow $\mathrm{Me}_{3} \mathrm{SiCl}$ to drain through a drain port on the suction side. The strainer was removed, checked for blockage, and replaced. The vent valve was mistakenly left opened. A valve in the suction side of the pump was cracked open to drain more material from the supply line to check for further blockage. A release of $\mathrm{Me}_{3} \mathrm{SiCl}$ through the open vent valve resulted in skin exposure to the face and neck of one of the technicians involved. The technician proceeded quickly to the nearest safety shower (approximately 10 feet away) and S\&LP responded. The tech was observed by S\&LP technicians and the site nurse and returned to work approximately an hour later. No chemical burns were sustained.

\subsubsection{Reactor Relief Opened, $30 \mathrm{Apr} 97$}

The start-up team was hydrostatically pressure testing the reactor at $80 \%$ MAWP with Dow Coming 200 fluid $\otimes$. Testing was completed during day-shift. The normal relief valve settings on the reactor are at MAWP, and so these normal operation relief valves were being relied upon for over-pressure protection. The 3-way valve below the relief assemblies was locked, leaving only one rupture disk/relief valve assembly available. During the day, warm ambient conditions caused expansion of the Dow Corning 200 fluid $\otimes$, resulting in pressure rise. The frangible disk ruptured and the relief valve opened, spraying less than five gallons of Dow Corning 200 fluid $\odot$ onto the ground. Furthermore, a gasket had not been installed in the flange between the rupture disk and relief valve. The start-up engineer on the midnight shift did not realize that the gasket was absent and the 3-way valve locked. This was due to lack of communication at shift-change. Eventually, the 3-way was unlocked and the valve swapped over. A good practice to follow is to bleed off pressure when hydrostatic testing is complete to eliminate thermal expansion concern. Also, if a device is being used for "protection", it must be fully functional.

\subsubsection{Hydrogen Meter Near Miss, 26 Aug 97}

While leak testing the hydrogen transfer line at nitrogen header pressure, a MicroMotion $₫$ mass flow meter failed. Check valves had allowed chlorosilanes to back into the meter approximately two-and-one-half months earlier, when manual valves had been removed for rework. Combined with a flange that had been left open (allowing atmospheric moisture to enter), this led to the 
corrosion of the $316 \mathrm{~L}$ stainless steel meter that failed. The meter has been replaced with a smaller meter, for better accuracy at low hydrogen flow rates, constructed of inconel@ 625.

\subsubsection{Syltherm Out The Vent Line, 01 Oct 97}

The start-up team was leak testing the reactor prior to startup. The Syltherm@ was being used to thermal cycle the system up to operating temperature. The level gauge on the surge tank gave a false-low reading due to decoupling of the magnetic float. A drum of Syltherm $(B$ was added. As the Syltherm heated up and pressurized the surge tank, its vent valve opened, allowing Syltherm@ to escape through the vent line. The high-level switch did not activate. To correct the situation, the system was cooled, the excess quantity of Syltherm $\$$ was drained from the tank, and the high-level switch was repaired. The root cause was the over-filled tank due to a decoupled magnetic level gauge float and high-level switch failure.

\subsubsection{Frangible Fire, 21 Nov 97}

Gel formation on the outside of the reactor's east frangible holder indicated the need to change the frangible. A 3-way valve exists below the dual frangible/relief valve assembly. The section of pipe between the 3-way valve and leaking frangible was purged and vented to atmosphere. A work permit was issued to the relief shop crew. The 3-way valve was locked out, directing the flow away from the frangible to be changed. After bolts were removed, and the frangible was "tugged" for removal, small flames appeared. After letting it sit for a few minutes, black/gray smoke emanated from the loose flanges. The flanges were re-bolted and tightened, and left to purge overnight. The frangible was successfully replaced the next day. At that time, sparks were produced during gentle cleaning of the frangible holder with a paint scraper. No injuries to personnel and no equipment damage were sustained as a result of the incident.

The fire flames were yellow/orange in appearance and smaller than a cigarette lighter flame. Based on past fire observations, this appears to have been the rapid oxidation of either: highly $\mathrm{SiH}$ - or AlH-functional chlorosilane material, or branched polysilane material, which is shock (i.e., pressure) sensitive. $\mathrm{AlCl}_{3}$ is present in the hydrogenolysis system, but in and of itself, the $\mathrm{AlCl}_{3}$ would not have flamed in this manner.

\subsubsection{Syltherm@ Spill, 06 Dec 97}

A very small (less than a $1 / 2$ gallon) spill occurred while leak testing the Syltherm $\otimes$ tracing. The tracing is used to keep reactor product lines warmer than $200^{\circ} \mathrm{C}$, to prevent desublimation of $\mathrm{AlCl}_{3}$. The tracing had been recently modified during maintenance. A vent valve was left open that had been used to drain the line fully. When the line was charged with Syltherm $\circledast$ it passed through for about one minute before it was noticed. The Syltherm $\otimes$ tracing is a tangled web of $1 / 2$ " tubing that is difficult to track and account for. In the future, the technicians and engineers must ensure that the Syltherm $\otimes$ tracing is walked down every time prior to re-starts!

\subsubsection{First Aid Call, 10 Dec 97}

Shop personnel had removed a control valve so that a new trim kit could be installed. When the valve was pulled from the process it looked "pretty clean". Two start-up personnel picked up the valve (approximately three feet long and weighing $45 \mathrm{lbs}$ ) and started carrying it downstairs. When the valve was tipped to carry downstairs, a bit of chlorosilane liquid dripped out of the valve body and onto the pants leg of one of the start-up members. The liquid caused an immediate stinging from acid attack. The affected person immediately showered in the locker room, despite this not being the approved Dow Coming procedure. Then, the affected person followed up with a first aid call to Safety \& Loss Prevention. No physical injury or damage was sustained. 


\subsection{Pilot Plant II Emergency Shutdown Systems And Process Interlocks}

\subsubsection{Level 3 - Emergency Shutdown Hardware (ESD)}

The Level 3 - ESD system offers the highest level of emergency shutdown protection. It is equipped with a hardwire hand switch and four hardwired process trips. The ESD system utilizes sensors / instruments that are independent of the Level 2 - ESS system. Upon tripping, the ESD trips the ESS which duplicates the emergency shutdown actions. This offers a level of redundancy which provides added emergency shutdown protection. Table 13 below summarizes the hardwired process trips and the resulting actions.

Table 13: Level 3 Emergency Shutdown System (ESD)

\begin{tabular}{|c|c|}
\hline ESD CAUSE & ACTIONS \\
\hline Reactor Hardwire Hand Switch & Hydrogen Feed On'Off valve - Closed \\
\hline Reactor High Pressure & Hydrogen control valve - Closed \\
\hline Reactor High Temperature & Chlorosilane Feed Pump - Off \\
\hline Adjoining FBR Process ESD & Chlorosilane Feed On/Off valve - Closed \\
\hline \multirow[t]{11}{*}{ VentRecovergompresshutdow } & H2 preheater Syltherm \& control valve - Closed \\
\hline & CISi preheater Syltherm $\otimes$ control valve - Closed \\
\hline & Syltherm heater power - Off \\
\hline & Syltherm cooler fan - On \\
\hline & Syltherm cooler bypass valve - Closed \\
\hline & Sylthermo cooler valve - Open \\
\hline & Nuclear density meter - Retracted \\
\hline & Reactor product On/Off valve - Closed \\
\hline & Reactor pressure control valve - Closed \\
\hline & Reactor over-pressure control valve - Closed \\
\hline & Reactor Level control valve - Closed \\
\hline
\end{tabular}

There are various reasons for the hardwired hand switch and four hardwired process trips. The purpose of the hardwired hand switch is to enable the timely emergency shutdown of the process when an uncontrollable event such as a severe weather emergency or site evacuation occurs. The first and second process trips are directly related to Pilot Plant II while the third and fourth are related to processes that are connected in some way with Pilot Plant II. For all of these process trips, the resulting actions remove the energy from the reactor by stopping the feed pump, turning off the Syltherm $\otimes$ heater power, going to full cooling, retracting the nuclear density meter, and closing feed and effluent valves.

The first process trip occurs if the reactor pressure goes above 67\% MAWP. This emergency shutdown is in place to prevent over pressurization of the reactor. This shutdown, as well as the emergency relief valve(s), ensures that the maximum allowable working pressure of the reactor is not exceeded. A similar emergency shutdown occurs if the reactor temperature goes $15 \%$ above 
normal operating temperature This shutdown is in place to prevent exceeding the maximum allowable working temperature of the reactor.

The third process trip occurs if the the adjoining FBR's Process has an emergency shutdown. This process trip originally encompassed nine individual trips which included: FBR Reactor and Recovery System hand switch, FBR Reactor(s) hand switch (two), FBR Reactor(s) high temperature (two), FBR Reactor(s) high pressure (two), and FBR Recovery System high pressure(s) (two). This process trip was in place because the reactor and FBR process jointly utilize the FBR's DPR column. Later this process trip was simplified to just three individual trips which are the FBR Reactor and Recovery System hand switch and the Recovery System high pressure(s) (two). The simplification was made because operation of the FBR Reactor is not affected by, or necessary for, operation of Pilot Plant II; only operation of the FBR DPR column is necessary. The final process trip happens if a shutdown occurs at the Vent Recovery Secondary Compressor.

The Vent Recovery Secondary Compressor is necessary for the recovery of hydrogen and to prevent overloading the Vent Adsorber. Also, it is required to prevent pressurization of the vent handling system. This process trip was latter simplified and changed from a Level 3 - ESD to a Level 1 - Process Interlock. The primary reason for this change was because the only action required if the Vent Recovery Secondary Compressor shuts down is the termination of hydrogen flow to Pilot Plant II Reactor. By stopping the hydrogen flow, there is no hydrogen to recover and pressurization of the vent handling system is prevented.

During startup operation of Pilot Plant II Reactor in 1997, several Level 3 - ESD occurred. The majority of these emergency shutdowns were because of a shutdown at the Vent Recovery Secondary Compressor and none of these emergency shutdowns were due to high pressure or high temperature in Pilot Plant II Reactor.

\subsubsection{Level 2 - Emergency Shutdown Software (ESS)}

The Level 2 - ESS system offers an intermediate level of emergency shutdown protection. It is equipped with a software / touchscreen hand switch and five software process trips. The ESS typically has lower trip points than the ESD and utilizes independent sensors / instruments. Table 14 summarizes the software process trips and the resulting actions.

Table 14: Level 2 Emergency Shutdown System (ESS)

\begin{tabular}{|l|l|}
\hline \multicolumn{1}{|c|}{ ESS CAUSE } & \multicolumn{1}{c|}{ ACTIONS } \\
\hline Reactor TouchScreen Hand Switch & Hydrogen Feed On/Off valve - Closed \\
Reactor High Pressure & Hydrogen control valve - Closed \\
Reactor High Pressure & Chlorosilane Feed Pump - Off \\
Reactor High Temperature & Chlorosilane Feed On/Off valve - Closed \\
Adjoining FBR Process ESD & H2 preheater Syltherm@ control valve - Closed \\
& CISi preheater Syltherm@ control valve - Closed \\
& Syltherm® heater power - Off \\
& Syltherm® cooler fan - On \\
& Syltherm® cooler bypass valve - Ramped Closed
\end{tabular}




\begin{tabular}{|c|c|}
\hline ESS CAUSE & ACTIONS \\
\hline & $\begin{array}{l}\text { Syltherm@ cooler valve - Ramped Open } \\
\text { Nuclear density meter - Retracted } \\
\text { Reactor product On/Off valve - Closed } \\
\text { Reactor pressure control valve - Closed } \\
\text { Reactor over-pressure control valve - Closed } \\
\text { Reactor Level control valve - Closed }\end{array}$ \\
\hline
\end{tabular}

The reasons for the touchscreen hand switch and five software process trips are the same as for the ESD. The emergency actions taken during any one of these trips is similar to the ESD with the exception that the Syltherm $\otimes$ Cooler Bypass Valve is ramped closed and the Syltherm $\otimes$ Cooler Valve is ramped open at a rate of $1 \%$ per second. The advantage of the ESS shutdown is that it is a "softer" shutdown with the energy being removed from the reactor in a more controlled manner.

During startup operation of the Pilot Plant II Reactor in 1997, several Level 2 - ESS occurred. Again, the majority of these emergency shutdowns were because of a shutdown at the Vent Recovery Secondary Compressor and none of these emergency shutdowns were due to high pressure or high temperature in the reactor.

\subsubsection{Level 1 - Process Interlock}

In addition to the ESD and ESS systems, Pilot Plant II has several Process Interlocks. These Process Interlocks were developed in an attempt to prevent abnormal conditions from causing an ESD or ESS. These Process Interlocks are the first level of emergency shutdown and are in place to mitigate an emergency condition before it escalates to an ESD or ESS. In general, the Process Interlocks are divided between the Reactor, Syltherm 1 , and Filter systems.

\subsubsection{Reactor system}

There are eleven Process Interlocks that effect the Reactor system. These eleven interlocks can be further broken down into four categories based on the interlock actions that occur. The first category consists of those Process Interlocks which are most critical. Therefore, the actions taken . by the Process Interlocks are more exhaustive than the others. These interlocks are primarily tripped due to an upset condition in the Reactor system. The second, third, and fourth categories of Process Interlocks are due to upsets in the hydrogen feeds, chlorosilane feeds, DPR column, and the Vent Recovery Secondary Compressor.

Table 15 summarizes the first category of reactor Process Interlocks and the actions taken upon tripping.

Table 15: Reactor System Process Interlocks

\begin{tabular}{|l|l|}
\hline \multicolumn{1}{|c|}{ INTERLOCK CAUSE } & \multicolumn{1}{c|}{ ACTIONS } \\
\hline Reactor High Pressure & Hydrogen Feed On/Off valve - Closed \\
Reactor High Pressure & Hydrogen control valve - Closed \\
Reactor High Temperature & Chlorosilane Feed Pump - Off \\
Reactor High Temperature & Chlorosilane Feed On/Off valve - Closed
\end{tabular}




\begin{tabular}{|l|l|}
\hline \multicolumn{1}{|c|}{ INTERLOCK CAUSE } & \multicolumn{1}{c|}{ ACTIONS } \\
\hline Syltherm® Exp. Tank High Pressure & H2 preheater Syltherm® control valve - Closed \\
& CISi preheater Syltherm® control valve - Closed \\
& Syltherm® heater power - Off \\
& Syltherm® cooler fan - On \\
& Syltherm® cooler bypass valve - Ramped Closed \\
& Syltherm® cooler valve - Ramped Open \\
& Nuclear density meter - Retracted \\
& Reactor Sequence to Suspend \\
\hline
\end{tabular}

The purpose of the two redundant high pressure Process Interlocks (from different sensors / instruments) is to prevent over pressurization of the reactor. Similarly, the purpose of the two redundant high temperature Process Interlocks is to prevent exceeding the maximum allowable working temperature of the reactor. The final Process Interlock was put in place in case the hydrogen preheater developed a leak which allowed high pressure hydrogen to enter the Syltherm ${ }^{\circledR}$ system. In each of these cases the interlock actions remove the energy to the reactor by stopping the feed pump, tuming off the Syltherm $\left({ }^{\circledR}\right.$ heater power, going to full cooling, and retracting the nuclear density meter. By taken these actions, the cause of the Process Interlock should mitigate itself.

Table 16 summarizes the second category of reactor Process Interlocks and the actions taken upon tripping.

Table 16: Hydrogen And DPR Column Process Interlocks

\begin{tabular}{|c|c|c|}
\hline INTERLOCK CAUSE & & ACTIONS \\
\hline $\begin{array}{l}\text { Hydrogen Supply Low Pressure } \\
\text { Hydrogen Feed Flow } \\
\text { DPR Column High Pressure }\end{array}$ & BAD VO & $\begin{array}{l}\text { Hydrogen Feed On/Off valve - Closed } \\
\text { Hydrogen control valve - Closed } \\
\text { Chlorosilane Feed Pump - Off } \\
\text { Chlorosilane Feed On/Off valve - Closed } \\
\text { Reactor Sequence to Suspend }\end{array}$ \\
\hline
\end{tabular}

The purpose of the high reactor effluent flow Process Interlock was to prevent high amounts of reactor effluent from upsetting the DPR column operation. By stopping the hydrogen and chlorosilane feeds to the reactor, this situation was quickly remedied. However, this Process Interlock was deleted because during reactor initiation the flow often exceeds $150 \%$ of design. Also, the DPR column is able to operate stabily with effluent flow rates above this from the reactor. The second and third Process Interlocks are in place to stop feeds to the reactor when there is a low hydrogen supply pressure or the hydrogen flow meter is reading BAD VOO. These interlocks prevent back flow from the reactor and also alert the operators to a hydrogen supply failure. The final Process Interlock occurs when the DPR column reaches high pressure. This Process Interlock is in place to prevent further pressurization of the DPR column. By stopping the feeds to the reactor, any effluent flow from the reactor to the DPR column is unlikely. 
The third category of reactor Process Interlocks and their actions taken upon tripping are summarized in Table 17.

Table 17: Chlorosilane Feed Process Interlocks

\begin{tabular}{|l|l|}
\hline INTERLOCK CAUSE & \multicolumn{1}{|c|}{ ACTIONS } \\
\hline $\begin{array}{l}\text { Chlorosilane Feed Flow } \\
\text { BAD VOO }\end{array}$ & Chlorosilane Feed Pump - Off \\
$\begin{array}{l}\text { Chlorosilane Feed High Pressure (delay) } \\
\text { Chlorosilane Feed Low Pressure (delay) } \\
\text { Reactor P }\end{array}$ & Chlorosilane Feed On/Off valve - Closed \\
\hline
\end{tabular}

The purpose of these Process Interlocks is to detect upset conditions in the chlorosilane feeds. The chlorosilane feed flow BAD V/O and the chlorosilane feed low pressure Process Interlocks prevent back flow from the reactor. These Process Interlocks may also indicate feed pump problems. The chlorosilane feed high pressure prevents over-pressurization of the feed line if a blockage develops.

The final category of reactor Process Interlocks and the actions taken upon tripping are summarized in Table 18.

Table 18: Secondary Compressor Process Interlocks

\begin{tabular}{|l|l|}
\hline INTERLOCK CAUSE & \multicolumn{1}{c|}{ ACTIONS } \\
\hline $\begin{array}{l}\text { Vent Recovery Secondary Compressor } \\
\text { Shutdown }\end{array}$ & Hydrogen Feed On/Off valve - Closed \\
& Hydrogen control valve - Closed \\
\hline
\end{tabular}

This Process Interlock is a simplified version of the removed ESD and ESS trips. This Process Interlock is needed because operation of the Vent Recovery Secondary Compressor is necessary for the recovery of hydrogen and to prevent overloading the Vent Adsorber. Also, it is required to prevent pressurization of the vent handling system. By stopping the hydrogen flow, there is no hydrogen to recover and pressurization of the vent handling system is prevented.

\subsubsection{Syltherm System}

There are seven Process Interlocks that effect the Syltherm (2) system. The Process Interlocks occur because of Syltherm (1) level, flow, pressure or temperature trips. Below is a discussion of the Process Interlocks and the actions that occur. Also, the reason for the Process Interlock is included.

The Syltherm (emperature control valve for the chlorosilane preheater is closed if the chlorosilane flow is low. The purpose of this Process Interlock is to prevent fouling the chlorosilane preheater by overheating chlorosilanes that are stagnant in the preheater. A similar interlock occurs if the hydrogen flow is low. Another interlock to prevent fouling the chlorosilane preheater occurs if the outlet temperature from the preheater becomes excessive. If this occurs the temperature control valve is closed.

If the Syltherm \& flow from the electric heater is low the electric heater power is turned off. The purpose of this interlock is to prevent "burning up" the electric heater due to a lack of heat sink (Syltherm (B). Similarly, the electric heater power is turned off if the outlet temperature exceeds 
its design maximum. This may indicate a internal temperature indicator failure and shutdown is necessary to protect the heater.

High or low Syltherm $\otimes$ expansion tank levels shut off the Syltherm $\otimes$ pump and this in tum shuts off the electric heater. The purpose of these Process Interlocks is to prevent overfilling the Syltherm (B) tank and to prevent "burning up" the electric heater. Also, the low level interlock prevents cavitation of the Syltherm® pump. However, these interlocks will not occur if there is an ESD or ESS in action. This enables cooling of the reactor to continue if an emergency shutdown had occurred.

\subsubsection{Filter System}

There are five Process Interlocks that affect the Filter system. The Process Interlocks occur because of high tank pressure or high tank level. Below is a discussion of the Process Interlocks and the actions that occur. Also, the reason for the Process Interlock is included.

High pressure or level in the site's DPR tank will cause the filter system to interlock. The filter system interlock consists of closing all feed and transfer valves. The only valves that are opened are the tank recycle valves and a thermal expansion valve on the filter. The reason for these interlocks is to prevent venting nitrogen gas during the filter blowdown process if the site's DPR tank has high pressure and to prevent discharging filter cake to the adjoining FBR's DPR tank when a high level exists.

Another filter system interlock occurs on high level in the Mix tank. Again, the filter system interlock consists of closing all feed and transfer valves. The only valves that are opened are the tank recycle valves and a thermal expansion valve on the filter. This interlock is in place to prevent overfilling this tank during monomer addition. A similar interlock occurs on high level in the Feed tank. The actions that occur here are that the transfer valve from the Mix tank is closed and the Mix tank recycle valve is opened. The final filter system interlock occurs if the Mix tank pump exhibits high discharge pressure. This interlock is in place to prevent dead heading the pump, and the action is to stop the pump.

\subsection{Pilot Plant II AutoSpec, Simulator Verification, and DCS Programming}

An automation specification (AUTOSPEC) was written for Pilot Plant II to facilitate the distributed control system (DCS) programming. The use of AUTOSPEC was chosen as the most effective means of documenting the complex process operation logic. The AUTOSPEC is an effective communication tool because it breaks down a complex process into logically organized groupings of process equipment and instrumentation. It provides a road map for the control systems programming. It also provides a very effective means for managing change.

Pilot Plant II was divided into four separate AUTOSPEC units based on how the process equipment interacted. The four AUTOSPEC units were the Filter unit, the Mix tank unit, the Hydrogen unit, and the Reactor unit (which includes the Sylthermo temperature controller).

An AUTOSPEC was written for each of the four units. Each AUTOSPEC contains a general unit description, a movement diagram, a movement table, a reset table, an operation description, an operation step table, a permissive table, an alarm table, and a instrumentation list.

The purpose of the general unit description is to describe the process equipment and instrumentation as well as provide a brief overview of how the unit operates. The movement diagram shows in block diagram form the operations of the unit. For example, the operations for the Filter are: Suspend, Idle, Filtration, Drain, Blowdown, and Rinse. It also shows interactions with other units. The movement diagram works in conjunction with the movement table. The movement table outlines in tabular form how a unit proceeds from one operation to another. Its purpose is to insure that unit operations proceed in a logical process. 
The purpose of the reset table is to provide a means for the control system to identify what operations are "pickable". Only those operations that are reset are "pickable". The general unit description, movement diagram, movement table, and reset table provide the information on how the unit will operate.

The operation description and operation step table describe the specific actions that are taken during an operation. The operation description is a step by step verbal explanation of the actions that occur during that operation. The operation step table compliments the operation description by providing the same information in tabular form.

The permissive table lists the conditions that must be met to enter an operation and/or to remain in that operation. Permissives are also known as "watch dogs" because they are used to monitor the operation to prevent or stop inappropriate actions from occurring.

Another important means of monitoring the process during an operation is through the use of alarms. The alarm table lists critical process alarms and identifies when these alarms should be active or inactive. The alarm table is an effective way of insuring intelligent process alarming and reducing nuisance alarms. The final document in the AUTOSPEC is the instrument list. Its purpose is simply to list the instruments in a particular unit.

Verification of the control system took place during the control configuration phase utilizing a process simulator. The process was extensively simulated using a process simulator computer package. Using this package, a rudimentary model of major process vessels and lines was created, along with appropriate user graphics. This simulation was then connected to an off-line version of the proposed control scheme. The simulation is capable of behaving very much like the real process and can be used to quickly test ESS/ESD functions and Process Interlocks. It can also be used to rapidly test the proper operation of control sequences to assure that all steps are executed exactly as prescribed in the Automation Specification. Use of the package greatly decreased configuration time, undoubtedly reduced the number of Process Change Requests (PCRs), and allowed for the safe startup of Pilot Plant II.

Distributive control system programming was completed for Pilot Plant II. The process is built in one compound running in a single Control Processor hosted by an Application Processor.

Graphical user interfacing is handled by any of three Workstation Processors - two single display units or a dual-display unit with windowing capability to display up to five. All the Workstation Processor's are hosted by another Application Processor.

Field Bus Modules are used to communicate with field instruments and devices. Each analog module is capable of passing up to eight inputs and/or outputs, while discrete modules can handle $16 \mathrm{I} / \mathrm{O}$ 's.

Residing within the Control Processor are control blocks, sequence blocks, timer blocks, and Process Logic Blocks (PLBs). These blocks are all interconnected in the control scheme. Using these blocks, the Control Processor evaluates data received as inputs from the Field Bus Modules and decides on appropriate control action which is then executed through the Field Bus Modules. 


\section{BARRY FULL-SCALE DESIGN}

In January, 1997, design issues were resolved to establish annual throughput and on line time. It was decided that the reactor would be designed to the quantitative risk assessment (QRA) high integrity vessel standard, with piping likely utilizing high integrity flange closures. Several meetings were held in Barry, Wales to review preliminary design information and safety issues. An external safety consultant was contacted to study the preliminary Barry design and make recommendations regarding process safety.

A capital cost estimate for the full scale plant began development in February. Preliminary economics indicated a very favorable net present value.

Process Flow Diagrams and Cost Estimates for the plant were further revised in March. A fruitful cost-reduction alternatives brainstorming session was conducted.

Several engineering and design reviews were held in April to highlight the need for finalized flow diagrams as soon as possible, to allow early procurement activities to proceed. Design rates were set. An engineering and construction review of the Pilot Plant II project was held to capture learning that can be transferred to the next scaled up process. A preliminary computer simulation modeling the full-scale process was started. Optimization of the design was underway. A preliminary request for quotation was submitted for the reactor.

First-revision process flow diagrams were finalized in May. Preliminary discussions with vendors began. Reactor design calculations and heat transfer calculations were a focus in May.

In June, the computer simulation and model of the full-scale process was made functional. Piping and instrumentation diagrams, filter system design, hot oil system design, and siting considerations were a focus in June. The preliminary request for quotation for the reactor returned in mid-June. The delay in Pilot Plant II start-up freed some start-up team members to contribute to the full scale design work at a $50 \%$ effort.

Technology Package development progressed in July 1997. Several budget quotes on equipment were obtained. A second draft of P\&IDs was completed by the process engineering team so that the capital engineering could take responsibility for them. Preliminary control strategy for the Design Package was prepared. A Budget quote from a second vendor for the reactor was received at about $50 \%$ of the first vendor's quote. Physical size estimates for the equipment were made and provided to Capital engineering so that preliminary layout work could be started.

In August, the Technology Package Development was completed [51, 52]. The design-basis of the full scale unit was revised to reduce the size of the reactor. A filter technology was selected based on its utilization at other Dow Corming sites. Safety design, process maintenance, DPR inventory, design basis, and area classification were reviewed. Increasingly, design basis details are being finalized.

Dow Coming's Facilities Engineering department took control of the design effort in September. A capital authorization request was submitted for about $40 \%$ of total funds. It was approved by all required Barry site people and was scheduled for review by the Board of Directors. Updated process economics showed a favorable NPV compared to quench and landfill of DPR. Design plans for the DPR filter and DPR storage tanks were finalized. Communications with an outside firm were underway to define the QRA safety study. Siting plans were reviewed with the site manager. Estimates for an altemate location showed that the additional equipment required significant capital if the reactor was not adjacent to the DPR column. A preliminary ESD/interlock table was developed. Discussions were underway to consider how the plant would 
comply with IEC-1508 standards. Additional flammability testing by a third-party laboratory was arranged for hydrogenolysis materials, to support the Barry safety studies.

In October, discipline leads from Dow Corning's Facilities Engineering (FE) department came "up to speed" on their various portions of the project - mechanical, electrical, instrumentation, etc.

Emphasis was on civil/architectural, relief valve sizing, materials of construction, manual valves, and electrical area classification. The preliminary results for the Quantitative Risk Analysis were reviewed with DNV Technica. The reactor risk was determined to be $0.1 \%$ of site risk and that it would not significantly contribute to off-site hazards. Domino effects were included in the analysis. Based on this, the reactor siting remained in the fluid bed reactor area. Reviews were also held this month with the site Safety, Health and Environmental team and Safety Audit Team. Firm plans were made for a Hazards and Operability study in January 1998 with participation from FE and Pilot Plant II engineers.

Emphasis in November was on heat transfer and hydrogen usage. In addition, reactor sizing, manual valve selection, piping and vessel flange closure selection, and economic analyses were investigated.

In December, emphasis was on reactor mechanical design finalization and hydrogen usage.

The HAZOP study was conducted in January, 1998. The filter, reactor and hot oil reviews were completed. Reactor bids were received from two vendors; two more were in process.

Quotations from all four reactor vendors had been received by the end of February.

Design efforts for the Barry unit in May were focused on completing the Front End Package and finalizing the Capital Cost Estimate. 


\section{ENERGY AND WASTE BENEFITS}

\subsection{Current vs. Proposed Technology $q$ fajulation}

DPR is currently quenched with a lime slurry that yields a siloxane gel type product and lime salts. No chloride ion is recovered by this process. The proposed technology when fully implemented will recover better than $80 \%$ of the DPR as usable chlorosilanes. These chlorosilanes will then be further processed and the chloride ion recycled. Upon commercialization, the proposed technology will reduce landfill waste by better than $80 \%$ and reduce the amount of metallurgical grade silicon and chloride ion needed to produce a specified amount of methyl silicones.

\subsection{Market Penetration}

Dow Corning conservatively estimates that the methyl silicone market will expand $7 \%$ per year through the year 2010. The global growth rate from 1978 to 1992 was $9 \%$ per year, and SRI International puts the annual growth rate at $7 \%$ per year from 1991 through 1994-95 [59]. The current global production of dimethyldichlorosilane is approximately 2.7 billion pounds per year. From the above $7 \%$ expansion, the projected dimethyldichlorosilane production will be 6.1 billion pounds per year in 2010. Silicon makes up 21.7 weight percent of dimethyldichlorosilane. Therefore the current silicone industry demand for silicon is 586 million pounds plus the inefficiencies cased from the byproduct formation of DPR.

DPR constitutes about five weight percent of the Direct Process output, about 135 million pounds per year in today's market (305 million pounds per year in 2010). DPR averages about two silicon atoms per molecule, and has an average molecular weight of 220 . Recovering eighty percent of the DPR as useful chlorosilanes saves about 27.5 million pounds of silicon per year. By the year 2010, this savings would grow to 62.1 million pounds per year.

Without implementation of this technology, the current landfill usage will grow at the same rate, as will the demand for make-up chloride ion. Dow Corning is willing to license this technology to other methyl silicone manufacturers.

\subsection{Energy and Waste Savings}

The Direct Process is not $100 \%$ efficient. As much as $5 \%$ more silicon is required due to these inefficiencies. Silicon is smeited from quartz in silicon fumaces that use large amounts of evergy: $109,322 \mathrm{Btu} / \mathrm{b} \mathrm{Si}$. The proposed process for recovering valuable chlorosilanes from the waste uses very little energy: 7,857 Btu/fb Si. Hence, when compared to silicon furnaces, the energy savings is large and silicon efficiency gets closer to unity. In today's market, global implementation of this technology would save $2.8(10)^{12} \mathrm{Btu} / \mathrm{yr}$. 
Table 19. Energy Savings

\begin{tabular}{|l|l|l|l|l|r|}
\hline A & B & C & D = B - C & E & F = D x E \\
\hline Description & $\begin{array}{l}\text { Current } \\
\text { Technology } \\
\text { (Btus/lb Si) }\end{array}$ & $\begin{array}{l}\text { Proposed } \\
\text { Technology } \\
\text { (Btus/lb Si) }\end{array}$ & $\begin{array}{l}\text { Energy savings } \\
\text { per unit, } \\
\text { current less } \\
\text { proposed } \\
\text { (Btu/lb Si) }\end{array}$ & $\begin{array}{l}\text { Pounds of Si } \\
\text { Saved per } \\
\text { year in 2010 }\end{array}$ & $\begin{array}{l}\text { Energy savings in } \\
\text { Year 2010 (1012 } \\
\text { Btus/yr) }\end{array}$ \\
\hline SiO2 & 179 & & 179 & $62,100,000$ & 0.011 \\
\hline Coke & 3,792 & & 3,792 & $62,100,000$ & 0.235 \\
\hline Coal & 13,741 & & 13,741 & $62,100,000$ & 0.853 \\
\hline $\begin{array}{l}\text { Electricity (@ } \\
\text { B,500 }\end{array}$ & 69,300 & 7,857 & 61,443 & $62,100,000$ & 3.816 \\
\hline Drus/kWh) & & & 13,031 & $62,100,000$ & 0.809 \\
\hline Electrode & 13,031 & & 9,280 & $62,100,000$ & 0.576 \\
\hline Total & 9,280 & & 101,466 & $62,100,000$ & 6.301 \\
\hline
\end{tabular}

\subsection{Waste Reduction}

The DPR is currently quenched with a lime slurry and landfilled as silica-like product. The hydrolyzed DPR has a molecular weight average of about 160 . Approximately 1.5 pounds of calcium chloride salt is produced per pound of DPR hydrolyzed. The proposed technology would reduce the landfilled amount by the efficiency of the process, which is expected to be about eighty percent.

Table 20. Waste Reduction

\begin{tabular}{|l|l|l|l|l|l|}
\hline A & B & C & D = B - C & E & F = D x E \\
\hline Description & $\begin{array}{l}\text { Current } \\
\text { Technology } \\
\text { (Tons/ton } \\
\text { DPR) }\end{array}$ & $\begin{array}{l}\text { Proposed } \\
\text { Technology } \\
\text { (Tons/ton } \\
\text { DPR) }\end{array}$ & $\begin{array}{l}\text { Waste } \\
\text { Reduction } \\
\text { per unit, } \\
\text { current less } \\
\text { proposed } \\
\text { (Tons/ton } \\
\text { DPR) }\end{array}$ & $\begin{array}{l}\text { DPR } \\
\text { Recycled in } \\
\text { 2010 }(106 \\
\text { Tons) }\end{array}$ & $\begin{array}{l}\text { Waste } \\
\text { Reduction in } \\
\text { Year 2010 } \\
\text { (106 } \\
\text { tons/year) }\end{array}$ \\
\hline $\begin{array}{l}\text { Quenched } \\
\text { DPR to } \\
\text { landfill }\end{array}$ & 0.73 & 0.20 & 0.53 & 0.15 & 0.081 \\
\hline CaC12 & 1.50 & 0.22 & 1.28 & 0.15 & 0.195 \\
\hline Total & 2.23 & 0.42 & 1.81 & 0.15 & 0.276 \\
\hline
\end{tabular}




\section{BUSINESS}

\section{I Economic Attractiveness}

Cost analysis of an existing Direct Process train shows that metallurgical grade silicon contributes the greatest share toward the variable cost of basic chlorosilane intermediates. High energy costs associated with the production of silicon metal is the major manufacturing cost. Another significant contributor to variable cost is the loss of chloride due to process inefficiencies, i.e., chloride loss as salt in the lime quench of DPR. There is also the cost of landfilling the solids from the quench. The current costs for each of these to Dow Coming is a closely held business fact. Dow Coming believes that implementation of this technology has a positive cash impact.

Table 21. Industrial Participation

\begin{tabular}{|l|c|l|c|}
\hline Partner & Cost Sharing, FAR & Cost Sharing, Non-FAR & Total \\
\hline DOE & $\$ 1,716,701$ & & $\$ 1,716,701$ \\
\hline Dow Corning & $\$ 25,056,420$ & & $\$ 25,056,420$ \\
\hline Total & $\$ 26,773,121$ & & $\$ 26,773,121$ \\
\hline
\end{tabular}

\subsection{Industrial Competitiveness}

All domestic and international silicon producers have the same problems associated with the DPR. Each producer's environmental costs will continue to escalate with further need for landfill space and potential environmental regulation. Without the novel waste conversion technology supported by this agreement, producers will be at a cost disadvantage in manufacturing methyl silicones.

\subsection{Employment Impact}

The construction and production of a commercial plant utilizing this novel waste conversion technology will have beneficial employment effects. There are four domestic producers of chlorosilane intermediates. There would be capital spending of approximately $\$ 20$ million for each commercial process. Upon completion of the process, each commercial unit would require a staff of approximately seven permanent positions.

\subsection{Commercialization plans}

Dow Corning expects the successful completion of the proposed technology will be readily adopted by the industry under a licensing agreement with Dow Corning. Basic chlorosilanes are manufactured at four sites in the United States. Dow Corning expects all of these U.S. producers to license this technology.

\subsection{Foreign Trade}

About forty percent of all silicones are manufactured in the United States. Implementing this technology by U.S. manufacturers will give them a lower manufacturing cost compared to foreign producers. The foreign producers will continue to shoulder the continued costs of chloride ion 
loss and silicon inefficiency. The lower cost position of U.S. manufacturers may allow them to increase their market share of the silicone market. 


\section{PROJECT MANAGMENT}

\subsection{Research Plan}

Planned Activity FY 1998

- Full-Scale plant detailed design

- Full-Scale plant procurement

- Full-Scale plant construction

- Project management and reporting

Planned Activity FY 1999

- Full-Scale plant construction

- Full-Scale Start-up

- Data analysis

- Project management and reporting

Planned Activity FY 2000

- Full-Scale plant Start-up

- Data Analysis

- Investigate reaction conditions

- Investigate feed preparations and compositions

- Conduct capacity test

- Commission plant for use completely by manufacturing unit

- Project management and reporting 
Table 22. Milestones

\begin{tabular}{|c|c|c|c|}
\hline Milestone & Planned & Actual & Date of Estimate \\
\hline \multicolumn{4}{|l|}{ Pilot Plant: } \\
\hline Detailed desian & $10 / 17 / 94$ & $12 / 3104$ & 0241104 \\
\hline Procurement and Construction & $08 / 31 / 94$ & $12 / 31 / 94$ & 0211104 \\
\hline Start-un & $12 / 30 / 94$ & $05 / 31 / 95$ & $02 / 11 / 194$ \\
\hline Operation & $07 / 31 / 95$ & $03 / 31 / 96$ & $02 / 1194$ \\
\hline Data Analysis & $11 / 30 / 95$ & $06 / 30 / 96$ & $02 / 11 / 94$ \\
\hline $\mathrm{G}_{0}-\mathrm{N}_{0} \mathrm{G}_{0}$ & $11 / 30 / 95$ & $12 / 31 / 95$ & $02 / 1104$ \\
\hline \multicolumn{4}{|l|}{ Pilot Plant II } \\
\hline Technology package & $03 / 11 / 96$ & $03 / 31 / 96$ & 052109 \\
\hline Project package & $02 / 15 / 96$ & $03 / 31 / 96$ & $0521 / 98$ \\
\hline Detailed enga: Desian/orocure & $02 / 28 / 98$ & $01 / 31 / 97$ & $05 / 21 / 98$ \\
\hline Construction & $04 / 30 / 98$ & $03 / 31 / 98$ & $05 / 21 / 98$ \\
\hline Safety training: pre-start-up & $03 / 31 / 97$ & $03 / 31 / 97$ & $0,2 / 21 / 98$ \\
\hline Process start-up & $04 / 30 / 98$ & $02 / 28 / 98$ & $05 / 21 / 98$ \\
\hline Process ontimization & $04 / 30 / 98$ & & $0521 / 98$ \\
\hline Econ analysis and commercial olan & $04 / 30 / 98$ & $01 / 31 / 98$ & $0521 / 98$ \\
\hline Project management and reporting & $0400 / 98$ & & $05 / 2108$ \\
\hline End of Phase lila & $04 / 30 / 98$ & & 0521198 \\
\hline \multicolumn{4}{|l|}{ Full scale } \\
\hline Preliminary engineering & $01 / 31 / 98$ & $01 / 31 / 98$ & $0501 / 98$. \\
\hline Cost estimate & $01 / 31 / 98$ & $08 / 31 / 98$ & 052108 \\
\hline Rermitting & $04 / 30 / 98$ & $03 / 31 / 98$ & $05 / 2108$ \\
\hline Detailed design & $09 / 30 / 98$ & & $0521 / 98$ \\
\hline Construction/procurement. & $09 / 30 / 99$ & & $05 / 2108$ \\
\hline Start-up & $01 / 31 / 00$ & & $0501 / 98$ \\
\hline Data analysis and performance update & $01 / 31 / 00$ & & 050108 \\
\hline Project management and reporting & $01 / 31 / 00$ & & $05 / 2108$ \\
\hline End of Phase IIIB & $01 / 31 / 00$ & & 0521198 \\
\hline Full scale - demonstrate reaction conditions & $12 / 31 / 99$ & & 052108 \\
\hline Feed orenaration requirements & $0228 / 00$ & & 052108 \\
\hline Feed composition & $04 / 30 / 00$ & & $05 / 2108$ \\
\hline Canacity testing & $06 / 30 / 00$ & & 052108 \\
\hline Data analusis and verformance undate & $07 / 31 / 00$ & & 052108 \\
\hline Commissioning test: hand off to manufasturing & $07 / 31 / 00$ & & 050108 \\
\hline Project management and reporting & $09 / 30 / 00$ & & $05 / 21 / 98$ \\
\hline End of Phase IV & $09 / 30 / 00$ & & 052108 \\
\hline
\end{tabular}


Table 23. Budget ( $\$$ in thousands)

\begin{tabular}{|c|c|c|c|c|c|c|c|c|c|}
\hline Row OIT\# & $99566 \mathrm{FY}$ & 93 & 94 & 95 & 96 & 97 & 98 & 99 & 00 \\
\hline A & DOE & so & so & $\$ 663.5$ & $\$ 59.0$ & $\$ 127.2$ & $\$ 254.0$ & $\$ 139.1$ & $\$ 473.9$ \\
\hline B & $\begin{array}{l}\text { Capital } \\
\text { Equipment }\end{array}$ & so & so & so & so & so & so & so & so \\
\hline $\begin{array}{l}C=A+B \\
+ \text { Prev yrs }\end{array}$ & $\begin{array}{l}\text { Cumulative } \\
\text { DOE }\end{array}$ & \$o & so & $\$ 663.5$ & $\$ 722.5$ & 5849.7 & $\$ 1.103 .7$ & $\$ 1.242 .8$ & $\$ 1,716.7$ \\
\hline D & Industry & so & $\$ 18.1$ & $\$ 1,525.4$ & $\$ 1.708 .6$ & $\$ 3.426 .0$ & $\$ 7.019 .1$ & $\$ 10.411 .0$ & $\$ 948.2$ \\
\hline $\begin{array}{l}E=D+ \\
\text { Prev yrs }\end{array}$ & $\begin{array}{l}\text { Cumulative } \\
\text { Industry }\end{array}$ & so & S18.1 & $\$ 1.543 .5$ & $\$ 3.479 .7$ & $\$ 6,678.1$ & $\$ 13.697 .2$ & $\$ 24.108 .2$ & $\$ 25.056 .4$ \\
\hline $\begin{array}{l}F=A+B \\
+D\end{array}$ & Project & so & $\$ 18.1$ & S2.188.9 & $\$ 1,767.6$ & $\$ 3,553.2$ & $\$ 7,273.1$ & $\$ 10,550.1$ & $\$ 1.422 .1$ \\
\hline \multirow[t]{2}{*}{$G=C+E$} & $\begin{array}{l}\text { Cumulative } \\
\text { Project }\end{array}$ & so & $\$ 18.1$ & $\$ 2,207.0$ & 54.202 .2 & $\$ 7,527.8$ & $\$ 13.800 .9$ & $\$ 24,351.0$ & $\$ 26,773.1$ \\
\hline & $\begin{array}{l}\text { Date of } \\
\text { Estimate }\end{array}$ & $7 / 94$ & $10 / 98$ & $10 / 98$ & $10 / 98$ & $10 / 98$ & $10 / 98$ & $5 / 98$ & $5 / 98$ \\
\hline
\end{tabular}

\subsection{Policy/Regulatory}

Future chlorine emissions, even in the form of inorganic salts, seem likely to be regulated more severely than they are now. Landfill of even non-hazardous waste (quenched DPR is a nonhazardous waste) is also likely to become regulated in the near future.

\subsection{Impact on the U.S.}

About forty percent of all silicones are manufactured in the United States. Implementation of this technology by U.S. manufacturers will give them a lower manufacturing cost compared to foreign producers. The foreign producers will continue to should the continued costs of chloride ion loss and silicon inefficiency. The lower cost position of U.S. manufacturers may allow them to increase their market share of the silicone market. 


\section{SUMMARY}

The Pilot Plant reactor demonstrated DPR conversion $>85 \%$. During its operation, significant problems were experienced with aluminum chloride desublimation and plugging, and materials failures due to chloride stress corrosion cracking. Problems due to aluminum chloride plugging were resolved in the Pilot Plant by changing the product recovery system to a liquid contacting condenser. Alternative materials of construction were identified by corrosion coupon testing. Hastelloy and Inconel were determined to perform best.

The Pilot Plant II hydrogenolysis reactor has demonstrated filtered DPR conversion $>85 \%$; $\mathrm{Me}_{2} \mathrm{SiCl}_{2}$ production and $\mathrm{MeHSiCl}_{2}$ production have been greater than expected. Significant obstacles were overcome during its operation through May 1998, such as valve malfunction, heater failure, and reactor plugging. Significant improvements compared to Pilot Plant operation were made in the areas of product value and overall reliability.

Design efforts for the Full-Scale unit in Barry, Wales are well underway, with start-up targeted for the turn of the century. 


\section{EXPERIMENTAL}

\subsection{Analytical Methods Used for Feed and Product Samples}

\subsubsection{Laboratory gas chromatograph}

The determination of compositions for the various streams in the Pilot Plant was achieved using gas chromatography. Several samples from early 1995 experimentation were analyzed in the lab in SMI using the same GC as was used in most of the earlier lab experiments. These analyses did incorporate an octane internal standard which was added to each sample analyzed. In general, results were very similar to those obtained from the lab runs in terms of the amount of nonelutable species which were found to exist as indicated by the internal standard. It was common for 10 to $15 \%$ non-elutable species to be found present in feed samples, which were, in turn, assumed to be high boilers. Product samples were most often $95-100 \%$ elutable.

Based on the predictability of non-elutable fractions in the feed and product samples and the greater need to have timely identification of low boilers in product samples, it was decided that a dedicated GC at the Pilot Plant was preferred for sample analysis. Such an analyzer could be readily used by Pilot Plant engineers.

\subsubsection{Pilot plant gas chromatograph}

The Pilot Plant GC was equipped with a column and helium carrier gas.

The capability for on-line, automatic sampling of feed and product streams existed. Early 1995 runs utilized this capability, but later problems which developed with the system forced manual injection to be used exclusively in 1996. A method for automatic calculation of stream compositions was programmed into the Pilot Plant analyzer PC. Most often, however, correction of the data for misplaced peaks was necessary. This was done using a spreadsheet into which peak areas for different components were entered. Compositions were then calculated from peak areas and known weighting factors within the spreadsheet. All samples analyzed on the Pilot Plant GC were analyzed without an internal standard.

The Pilot Plant GC was calibrated periodically throughout the operation of the unit. In particular, it was calibrated on a monthly basis from late 1995 until shutdown of the unit in mid 1996 in accordance with quality procedures written to comply with ISO 9001 standards. Calibrations were performed by injecting a sample from a refrigerated vial containing a previously prepared standard solution of methyl chlorosilanes. The standard vials were prepared for calibration of the lab GC in SMI prior to the startup of the Pilot Plant. The results of each calibration run were compared to weight percent ranges for three key components as determined from historical data for the standard (from the lab GC and original setup of the Pilot Plant GC).

In addition, the GC results for important samples were periodically checked using a research lab $\mathrm{GC}$ both with and without octane internal standards. During the course of the operation of the Pilot Plant, the original lab GC was replaced with a different instrument. Also, efforts to improve analytical techniques for DPR and similar analysis were constantly being made within the research analytical group [12].

\subsection{Other Analytical Methods}

Other testing was performed by research analytical (\%Al, \%O), Carroliton plant QA (\% solids, $\% 02$ in reactor head space), Midland analytical (CHN analysis, solids NMR), or outside personnel (various safety tests) as needed, according to standard methods. The use of data from these 
various tests was much more limited within this report to specific sections and discussion of specific topics related to Pilot Plant operation. 


\section{FUTURE WORK}

Future work for Pilot Plant II will initially concentrate on providing critical design information for the full scale design. First, this will involve determining a minimum hydrogen feed rate. This is critical for sizing the hydrogen recovery system and determining the source of hydrogen. The major capital cost items for hydrogen recovery are the compressor and membrane. The purchase price for these two units is very dependent on the ratio of hydrogen to chlorosilanes fed and. therefore, large capital cost savings could be realized if hydrogen is minimized. Other factors which impact the size of the compressor and membrane are energy recovery unit (ERU) capacity and purity of recovered hydrogen.

The effects of total DPR recycle will be investigated. For the Pilot Plant II system this means only feeding the adjoining FBR's DPR to Pilot Plant Il, and never pumping the adjoining FBR's DPR to any other destination. The intent is to complete an aluminum chloride and high boiler mass balance, and determine the effect on filter element life and reactor conversion. The results of this trial will determine whether the full scale process requires a flash still after the reactor to purge the high boilers to a By-Product Chlorosilane Hydrolysis process.

Corrosion testing will continue in the Pilot Plant II reactor. The corrosion coupons inside the Pilot Plant II reactor will be analyzed. This will involve removal of the reactor head. The corrosion coupons in the reactor will help verify the choice of materials for the Barry unit. NDT testing of the Pilot Plant II reactor and piping will also be performed.

Evaluating alternative ball valves to replace the existing valves at Pilot Plant II will continue. At least four different valves have been installed for testing. Final vendor selection will be determined by degree of shut-off, cost, delivery time, operability, stem leaks and body leaks.

The unit is intended to be released to the total control of manufacturing personnel by end of calendar year 1998. 


\section{REFERENCES}

1. US Patent 2,606,811; August 12, 1952.

2. US Patent 3,639,105; February 1, 1972.

3. US Patent 4,059,608; November 22, 1977.

4. US Patent 4,079,071; March 14, 1978.

5. US Patent $4,393,229 ;$ July $12,1983$.

6. Internal technical information services (TIS) Report; August 16, 1991.

7. Internal TIS Report August 24, 1993.

8. US Patent 5,292,909; March 8, 1994.

9. US Patent 5,292,912; March 8, 1994.

10. US Patent 5,321,147; June 14, 1994.

11. US Patent 5,326,896; July 5, 1994.

12. Internal TIS Report; August 22, 1996.

13. Internal TIS Report, September 30, 1996.

14. Internal TIS Report; November 27, 1996.

15. Internal TIS Report; February 14, 1997.

16. "Syltherm® 800 Heat Transfer Fluid", Dow Chemical Company Product Technical Data booklet, Form No. 176-01435-593AMS, April 1993.

17. Internal TIS Memo, July 30, 1998.

18. Internal TIS Report; June 7,1994.

19. Internal Monthly Report, June 24, 1994.

20. Internal TIS Report; June 7, 1994.

21. Gavroy, D.; Joly-Vuillemin, C.; Cordier, G.; Delmas, H.; "Gas Hold-up, Liquid Circulation, and Gas-Liquid Mass Transfer in Slurry Bubble Columns", Chemical Engineering Research and Design; August, 1995; p. 637-642.

22. Wilkinson, Peter M.; Spek, Arie P.; van Dierdonck, Laurent L.; "Design Parameters Estimation for Scale-up of High-Pressure Bubble Columns", AIChE Journal; April 1992, p. 544-554.

23. Concordia, Joseph J.; "Batch Catalytic Gas/Liquid Reactors: Types and Performance Characteristics", Chemical Engineering Progress; March 1990, p. 50-54.

24. Thomas, C.A.; Anhydrous Aluminum Chloride in Organic Chemistry; 1941.

25. Internal TIS report on methylation Pilot Plant.

26. Internal TIS Report; January 5, 1987.

27. Internal memo dated May 18, 1993. (This memo includes copies of an article by Krasnova in 1985, an article by Devyatykh in 1984, a memo by Frye in 1966, and a memo by Weigle in 1993.)

28. Letter from metallurgist., July $28,1995$.

29. "Determination of Cracking Mode in Stainless Steel Fitting", report by metallurgist, July 29, 1995.

30. "Destructive Examinations of a Whitey Valve and a Reducing Union", report by metallurgist, November 7, 1995.

31. Telephone conversation with materials expert.

32. Report from metallurgical inspector. April 24, 1996.

33. "Steels for Hydrogen Service at Elevated Temperatures and Pressures in Petroleum Refineries and Petrochemical Plants", API Publication Number 941, American Petroleum Institute, April 1990.

34. Murakami, Y.; Nomura, T.; Watanabe, J.; "Heavy Section 2 1/4 Cr-1 Mo Steel for Hydrogenation Reactors"; American Society for Testing and Materials, Special Technical . Publication Number 755, 1982, pp. 383-417. 
35. Ishiguro, T.; Murakami, Y.; Ohnishi, K.; Watanabe, J.; "A 2 1/4 Cr-1 Mo Pressure Vessel Steel with Improved Creep Rupture Strength", American Society for Testing and Materials, Special Technical Publication Number 755, 1982, pp. 129-147.

36. Gibala, R. And Hehemann, R.F.; Hydrogen Embrittlement and Stress Corrosion Cracking; American Society for Metals, Metals Park, OH; 1984.

37. Mui, Jeffrey Y. P.; "Corrosion Mechanism of Metals and Alloys in the Silicon-HydrogenChlorosilane System at 500 C"; NACE Journal, February 1985, pp. 63-69.

38. Telephone conversation, March 11, 1997.

39. Telephone conversation, March 17, 1997.

40. Telephone conversation, March 17, 1997.

41. Internal TIS Report; February 9, 1994.

42. "Hydrogenolysis Project- Chemistry Summary"; September 10, 1992.

43. Atwell, W.H.; Weyenberg, D.R.; "Silylene Chemistry II. A Kinetic Study of the Thermolysis of sym-Dimethoxytetramethyldisilane"; Journal of Organometallic Chemistry; Volume 18; 1969; pp. 69-75.

44. Baird, R.B.; Sefcik, M.D.; Ring, M.A.; "The Thermal Decomposition of Methyldisilane and 1,2-Dimethyldisilane"; Inorganic Chemistry, Vol. 10, No. 5, 1971; pp. 883-886.

45. Atwell, W.H.; Weyenberg, D.R.; "Silylene Chemistry"; Intra-Science Chemistry Reports, Volume 7, 1973, pp. 139-145.

46. Jenkins, R.L.; Vanderwielen, A.J.; Ruis, S.P.; Gird, S.R.; Ring, M.A.; "Pyrolysis of halodisilanes and the Formation and Insertion Reactions of Chlorosilylene and Fluorosilylene"; Inorganic Chemistry, Volume 12, No. 12, 1973; pp. 2968-2972.

47. Davidson, Iain M.T.; Delf, Michael E.; "Formation of Silylenes in the Thermolysis of Methylchlorodisilanes"; Journal of the Chemical Society; Volume 1; 1976; pp. 1912-1918.

48. Moedritzer, Kurt; "Redistribution reactions of organometallic compounds of silicon, germanium, tin and lead"; Organometallic Chemistry Reviews, 1966, pp. 179-213.

49. Moedritzer, Kurt; "Redistribution equilibria of organometallic compounds"; Advanced Organometallic Chemistry, 1968, pp. 171-233.

50. Internal presentation to Staff, April 24, 1998.

51. Internal TIS Report, September 5, 1997.

52. Internal TIS Report, September 5, 1997.

53. Herzog, U.; Roewer, G.; Paetzold, U.; "Catalytic hydrogenation of chlorine containing disilanes with tributylstannane"; Journal of Organometallic Chemistry; 1995; p. 494.

54. Hengge, E.; Grogger, C.; Uhlig, F.; Roewer, G.; Herzog, U.; Paetzold, U.; "Hydration of silicon halogen-containing compounds with trialkylstannyl chloride/sodium hydride"; Monatsh. Chem.; 1995; pp. 549-555.

55. Herzog, U.; Richter, R.; Brendler, E.; Roewer, G.; "Methylchloroooligosilanes as products of the base catalyszed disproportionation of various methylchlorodisilanes"; Journal of Organometallic Chemistry; 1996; p. 221-228.

56. US Patent 5,606,090; May 98, 1997.

57. US Patent 5,627,298; July 01, 1997.

58. US Patent 5,629,438; July 17, 1997.

59. Smart, Marilynne; "Silicones", Chemical Economics Handbook Marketing Research Report August, 1996. 